\title{
Re-engineering of Yohimbine's Biological Activity through Ring Distortion: Identification and Structure-Activity Relationships of a New Class of Antiplasmodial Agents
}

Nicholas G. Paciaroni†, David J. Perry ${ }^{\ddagger}$, Verrill M. Norwood IV†, Claribel Murillo-Solano $\ddagger$, Jennifer Collins ${ }^{\ddagger}$, Srinivasarao Tenneti ${ }^{\dagger}$, Debopam Chakrabarti $\ddagger^{*}$, Robert W. Huigens $\mathrm{III}^{{ }^{*}}$

tDepartment of Medicinal Chemistry and Center for Natural Product Drug Discovery \& Development (CNPD3), College of Pharmacy, University of Florida, Gainesville, FL; ‡Division of Molecular Microbiology, Burnett School of Biomedical Sciences, University of Central Florida, Orlando, FL.

\footnotetext{
*Corresponding authors e-mail addresses: rhuigens@cop.ufl.edu, dchak@ucf.edu
}

\section{Supporting Information}




\section{Table of Contents}

1. General Information.

2. Chemical Synthesis \& Characterization. (Y1 series, then $\mathrm{Y7}$ series) $\mathbf{S 4}$

3. Supporting Figure 1. Dose-dependent antiplasmodial activity for selected yohimbine analogues in chloroquine-resistant (Dd2) cells.

4. Supporting Figure 2. Dose-dependent antiplasmodial activity for selected yohimbine analogues in chloroquine-sentitive (3D7) cells.

5. Supporting Table 1.

6. Kill Kinetics for Y1f, DHA and Atovaquone.

7. Stage Specific Activity for Y1f.

8. NMR Spectra. 


\section{General Information.}

All synthetic reactions were carried out under an inert atmosphere of argon unless otherwise specified. All reagents for chemical synthesis were purchased from commercial sources and used without further purification. Reagents were purchased at $\geq 95 \%$ purity and commercially available controls were used in our biological investigations without further purification. Analytical thin layer chromatography (TLC) was performed using $250 \mu \mathrm{m}$ Silica Gel 60 F254 pre-coated plates (EMD Chemicals Inc.). Flash column chromatography was performed using 230-400 Mesh 60^ Silica Gel from Sorbent Technologies. All melting points were obtained, uncorrected, using a Mel-Temp capillary melting point apparatus from Laboratory Services, Inc.

NMR experiments were recorded using broadband probes on Varian Mercury-Plus $400 \mathrm{MHz}$ spectrometer (400 MHz for ${ }^{1} \mathrm{H}$ NMR; $100 \mathrm{MHz}$ for ${ }^{13} \mathrm{C}$ NMR), Bruker Avance II $500 \mathrm{MHz}$ spectrometer (500 MHz for ${ }^{1} \mathrm{H}$ NMR; $125 \mathrm{MHz}$ for ${ }^{13} \mathrm{C} \mathrm{NMR}$ ), or Bruker Avance II $600 \mathrm{MHz}$ spectrometer $(600 \mathrm{MHz}$ for ${ }^{1} \mathrm{H}$ NMR; $150 \mathrm{MHz}$ for ${ }^{13} \mathrm{C}$ NMR). All spectra are presented using MestReNova 11.0 (Mnova) software and are displayed without the use of the signal suppression function. Spectra were obtained in deuterated chloroform or DMSO (reference peaks also included for ${ }^{1} \mathrm{H}$ and $\left.{ }^{13} \mathrm{C} \mathrm{NMRs}\right): \mathrm{CDCl}_{3}\left({ }^{1} \mathrm{H}\right.$ NMR: 7.26 ppm; ${ }^{13} \mathrm{C}$ NMR: 77.23 ppm), $d_{6}$-DMSO ( ${ }^{1} \mathrm{H}$ NMR: 2.50 ppm; ${ }^{13} \mathrm{C}$ NMR: 39.52 ppm). NMR samples where the respective solvent peaks were buried in the sample signals referenced TMS at 0.00 ppm for ${ }^{1} \mathrm{H}$ NMR experiments. NMR experiments were performed at room temperature unless otherwise indicated. Chemical shift values $(\delta)$ are reported in parts per million $(\mathrm{ppm})$ for all ${ }^{1} \mathrm{H}$ NMR and ${ }^{13} \mathrm{C}$ NMR spectra. ${ }^{1} \mathrm{H}$ NMR multiplicities are reported as: $\mathrm{s}=$ singlet, $\mathrm{d}=$ doublet, $\mathrm{t}=$ triplet, $\mathrm{q}=$ quartet, $\mathrm{p}=$ pentet, $\mathrm{m}=$ multiplet, $\mathrm{br}=$ broad. Melting points were obtained on a Mel-Temp II capillary melting point apparatus and were uncorrected. High-resolution mass spectra were obtained from the Mass Spectrometry Facility in the Chemistry Department at the University of Florida.

All biological experiments, including: antiplasmodial screen \& dose-response assays (with Dd2 and 3D7 strains), stage-specific activity assays, kill kinetics and mammalian cytotoxicity assays (with HepG2 cells) were performed using experimental protocols described in Roberts, B. F.; Zheng, Y.; Cleaveleand, J.; Lee, S.; Lee, E.; Ayong, L.; Yuan, Y.; Chakrabarti, D. Int. J. Parasitol. Drugs Drug Resist. 2017, 7, 120 - 129. 


\section{Chemical Synthesis \& Characterization.}
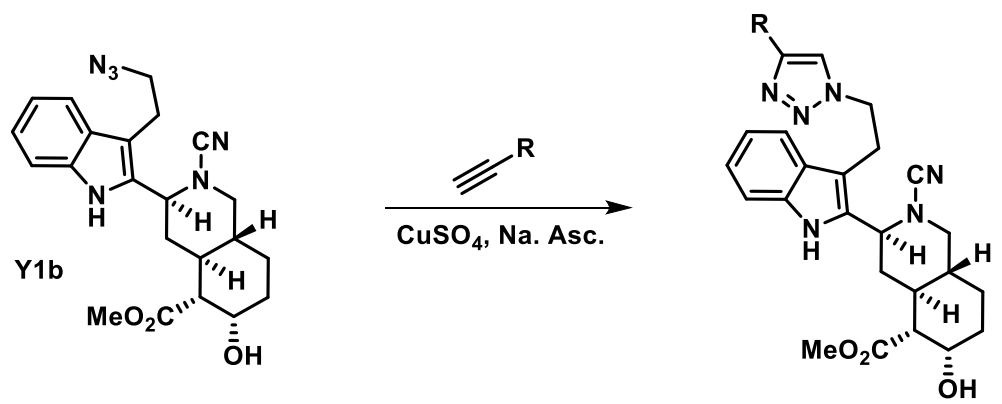

General procedure for the synthesis of indole-triazoles $\mathrm{Y} 1 \mathrm{i}$ and $\mathrm{Y1j}$. Anhydrous copper sulfate (6.9 $\mathrm{mg}, 0.04 \mathrm{mmol})$ and sodium ascorbate $(26.9 \mathrm{mg}, 0.14 \mathrm{mmol})$ were added to a reaction vial and dissolved in a 1:2 tert-butanol:water solution $(2.4 \mathrm{~mL})$. The resulting mixture was added to a roundbottom flask containing Y1b $(39.0 \mathrm{mg}, 0.09 \mathrm{mmol})$. Then, propargyl alcohol $(16.1 \mu \mathrm{L}, 0.28 \mathrm{mmol}, 3.0$ equiv) was added to the reaction followed by dichloromethane $(0.8 \mathrm{~mL})$. The reaction was vigorously stirred at room temperature for 2 hours. Upon completion, the biphasic mixture was then quenched with brine and the crude product was extracted with dichloromethane using a separatory funnel. The organic layers were collected, dried with sodium sulfate, filtered and concentrated. The crude product was then purified via column chromatography using 99:1 ethyl acetate:triethylamine to ethyl acetate:methanol:triethylamine $97.5: 1.5: 1$ to afford $\mathbf{Y 1 i}(21.5 \mathrm{mg}, 49 \%)$ as a colorless foam.

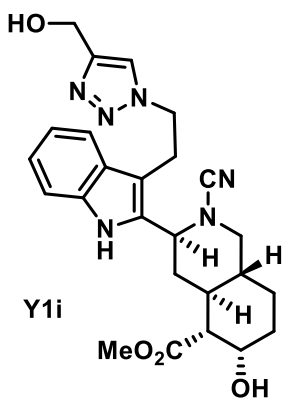

Yield: 49\%; $21.5 \mathrm{mg}$ of $\mathrm{Y1i}$ isolated as a colorless foam.

${ }^{1}$ H NMR: $\left(400 \mathrm{MHz}, \mathrm{CDCl}_{3}\right) \delta 7.97(\mathrm{~d}, J=8.1 \mathrm{~Hz}, 1 \mathrm{H}), 7.48(\mathrm{~d}, J=7.8 \mathrm{~Hz}, 1 \mathrm{H}), 7.31$ $(\mathrm{t}, J=7.7 \mathrm{~Hz}, 1 \mathrm{H}), 7.24(\mathrm{t}, J=8.1 \mathrm{~Hz}, 1 \mathrm{H}), 7.11(\mathrm{~s}, 1 \mathrm{H}), 4.73-4.55(\mathrm{~m}, 4 \mathrm{H}), 4.20(\mathrm{~m}$, $1 \mathrm{H}), 4.14(\mathrm{dd}, J=11.9,3.6 \mathrm{~Hz}, 1 \mathrm{H}), 3.84(\mathrm{~s}, 3 \mathrm{H}), 3.84(\mathrm{~m}, 1 \mathrm{H}$, buried under singlet), $3.52(\mathrm{br} \mathrm{m}, 1 \mathrm{H}), 3.29-3.21(\mathrm{~m}, 2 \mathrm{H}), 2.75(\mathrm{dd}, J=13.4,11.2 \mathrm{~Hz}, 1 \mathrm{H}), 2.20(\mathrm{~d}, J=$ $11.6 \mathrm{~Hz}, 1 \mathrm{H}), 2.06(\mathrm{q}, J=12.0 \mathrm{~Hz}, 1 \mathrm{H}), 1.97(\mathrm{~m}, 1 \mathrm{H}), 1.79(\mathrm{dt}, J=12.6,3.4 \mathrm{~Hz}, 1 \mathrm{H})$, $1.65-1.40(\mathrm{~m}, 3 \mathrm{H}), 1.25(\mathrm{~m}, 1 \mathrm{H}), 0.87(\mathrm{q}, J=12.0 \mathrm{~Hz}, 1 \mathrm{H})$.

'H NMR: $\left(500 \mathrm{MHz}, d_{6}\right.$-DMSO) $\delta 8.11(\mathrm{~d}, J=7.6 \mathrm{~Hz}, 1 \mathrm{H}), 7.76(\mathrm{~s}, 1 \mathrm{H}), 7.65(\mathrm{~d}, J=8.0 \mathrm{~Hz}, 1 \mathrm{H}), 7.26$ (t, $J=6.7 \mathrm{~Hz}, 1 \mathrm{H}), 7.21(\mathrm{t}, J=7.6 \mathrm{~Hz}, 1 \mathrm{H}), 5.09(\mathrm{~m}, 1 \mathrm{H}), 4.72(\mathrm{~d}, J=4.2 \mathrm{~Hz}, 1 \mathrm{H}), 4.63-4.57(\mathrm{~m}, 2 \mathrm{H})$, $4.50-4.43(\mathrm{~m}, 3 \mathrm{H}), 4.11(\mathrm{~m}, 1 \mathrm{H}), 4.05(\mathrm{dd}, J=14.1,3.5 \mathrm{~Hz}, 1 \mathrm{H}), 3.67(\mathrm{~s}, 3 \mathrm{H}), 3.25-3.18(\mathrm{~m}, 2 \mathrm{H})$, $2.76(\mathrm{dd}, J=14.0,12.1 \mathrm{~Hz}, 1 \mathrm{H}), 2.20(\mathrm{dd}, J=11.5,2.7 \mathrm{~Hz}, 1 \mathrm{H}), 2.14(\mathrm{dt}, J=12.3,3.3 \mathrm{~Hz}, 1 \mathrm{H}$ ), 2.00 (qd, $J=11.3,2.8 \mathrm{~Hz}, 1 \mathrm{H}), 1.76(\mathrm{~m}, 1 \mathrm{H}), 1.53(\mathrm{tt}, J=12.5,2.1 \mathrm{~Hz}, 1 \mathrm{H}), 1.44(\mathrm{qd}, J=12.5,2.4 \mathrm{~Hz}, 1 \mathrm{H})$, $1.32(\mathrm{~m}, 1 \mathrm{H}), 1.25(\mathrm{~m}, 1 \mathrm{H}), 1.17(\mathrm{~m}, 1 \mathrm{H}), 0.78(\mathrm{q}, J=11.9 \mathrm{~Hz}, 1 \mathrm{H})$.

${ }^{13} \mathrm{C}$ NMR: $\left(125 \mathrm{MHz}, d_{6}\right.$-DMSO) $\delta$ 172.4, 148.7, 147.8, 137.9, 132.0, 129.9, 122.7, 122.3, 121.3, 119.0, 112.0, 104.0, 66.4, 54.9, 59.2, 54.3, 51.7, 51.2, 49.2, 45.4, 34.9, 34.0, 32.0, 25.2, 22.2.

HRMS (ESI): calc. for $\mathrm{C}_{25} \mathrm{H}_{31} \mathrm{~N}_{6} \mathrm{O}_{4}[\mathrm{M}+\mathrm{H}]^{+}: 479.2401$, found: 479.2411 .

MP: $179-181^{\circ} \mathrm{C}$. 


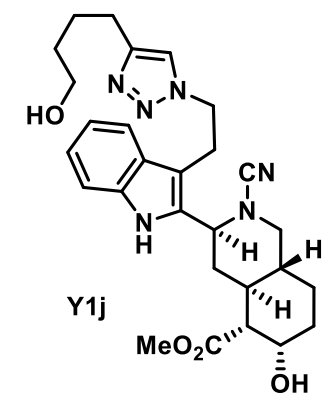

Yield: $69 \%$; $32.3 \mathrm{mg}$ of $\mathbf{Y 1 j}$ isolated as a colorless foam.

1H NMR: $\left(600 \mathrm{MHz}, \mathrm{CDCl}_{3}\right) \delta 7.99(\mathrm{~d}, J=8.2 \mathrm{~Hz}, 1 \mathrm{H}), 7.49(\mathrm{dt}, J=7.9,0.9 \mathrm{~Hz}, 1 \mathrm{H})$, 7.32 (ddd, $J=8.3,7.2,1.2 \mathrm{~Hz}, 1 \mathrm{H}), 7.25(\mathrm{~m}, 1 \mathrm{H}), 6.71(\mathrm{~s}, 1 \mathrm{H}), 4.64(\mathrm{dt}, J=13.6,6.0$ $\mathrm{Hz}, 1 \mathrm{H}$ ), 4.52 (ddd, $J=13.8,7.7,6.4 \mathrm{~Hz}, 1 \mathrm{H}), 4.21(\mathrm{q}, J=2.5 \mathrm{~Hz}, 1 \mathrm{H}), 4.05$ (dd, $J=$ 11.7, 3.7 Hz, $1 \mathrm{H}), 3.90(\mathrm{dd}, J=13.6,4.5 \mathrm{~Hz}, 1 \mathrm{H}), 3.82(\mathrm{~s}, 3 \mathrm{H}), 3.58-3.54(\mathrm{~m}, 2 \mathrm{H})$, $3.28-3.23(\mathrm{~m}, 2 \mathrm{H}), 3.13(\mathrm{br} \mathrm{s}, 1 \mathrm{H}), 2.77(\mathrm{dd}, J=13.6,11.3 \mathrm{~Hz}, 1 \mathrm{H}), 2.65-2.54$ $(\mathrm{m}, 2 \mathrm{H}), 2.19(\mathrm{dd}, J=11.6,2.1 \mathrm{~Hz}, 1 \mathrm{H}), 2.09(\mathrm{qd}, J=11.5,3.0 \mathrm{~Hz}, 1 \mathrm{H}), 2.07-1.94$ $(\mathrm{m}, 2 \mathrm{H}), 1.65-1.38(\mathrm{~m}, 8 \mathrm{H}), 1.23(\mathrm{~m}, 1 \mathrm{H}), 0.85(\mathrm{q}, J=12.0 \mathrm{~Hz}, 1 \mathrm{H})$.

${ }^{13} \mathrm{C}$ NMR: $\left(150 \mathrm{MHz}, \mathrm{CDCl}_{3}\right) \delta 175.1,150.7,147.8,137.8,132.1,130.7,123.6,122.3,121.9,118.7$, $112.4,104.6,66.8,62.4,54.8,52.4,52.3,49.9,46.1,40.0,35.2,35.1,32.3,31.2,26.1,25.9,25.3$, 22.8 .

HRMS (ESI): calc. for $\mathrm{C}_{28} \mathrm{H}_{37} \mathrm{~N}_{6} \mathrm{O}_{4}[\mathrm{M}+\mathrm{H}]^{+}: 521.2870$, found: 521.2873 .

MP: $94-96^{\circ} \mathrm{C}$.
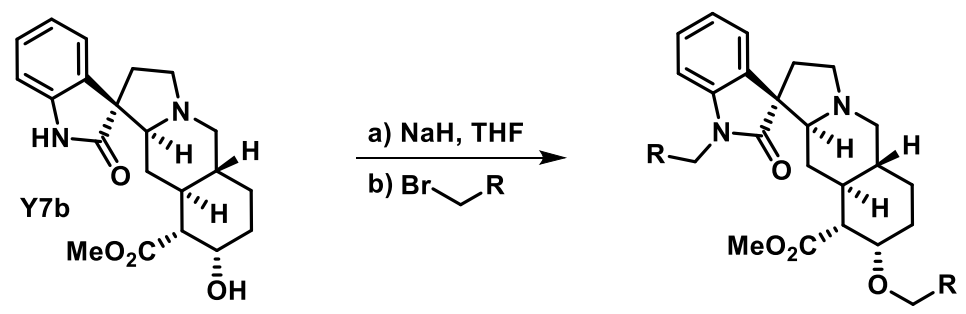

General procedure for the synthesis of di-alkylated products $\mathrm{Y7m}-\mathrm{Y7} \mathbf{\mathrm { v }}$. Tetrahydrofuran $(2 \mathrm{~mL})$ was added to a round-bottom flask followed by sodium hydride $(29.8 \mathrm{mg}, 0.74 \mathrm{mmol}, 60 \%$ dispersion in mineral oil) and cooled to $0{ }^{\circ} \mathrm{C}$. Next, a solution of $\mathrm{Y} 7 \mathrm{~b}(67.3 \mathrm{mg}, 0.18 \mathrm{mmol})$ in $0.5 \mathrm{~mL}$ of tetrahydrofuran was added to the reaction mixture, which was allowed to stir for 10 minutes. Then, a solution of 4-methoxybenzyl bromide $(76.7 \mathrm{mg}, 0.38 \mathrm{mmol})$ dissolved in $0.5 \mathrm{~mL}$ of tetrahydrofuran was added to the reaction mixture, which was slowly warmed to room temperature over 13 hours. Upon completion, the reaction was quenched via brine and extracted with ethyl acetate using a separatory funnel. The organic layers were collected, dried with sodium sulfate, filtered and concentrated. The crude mixture was then purified via column chromatography using hexanes:ethyl acetate:triethylamine 66:33:1 to $49.5: 49.5: 1$ to elute $\mathrm{Y7m}$ (23.5 mg, 21\%) as a pale-yellow film.

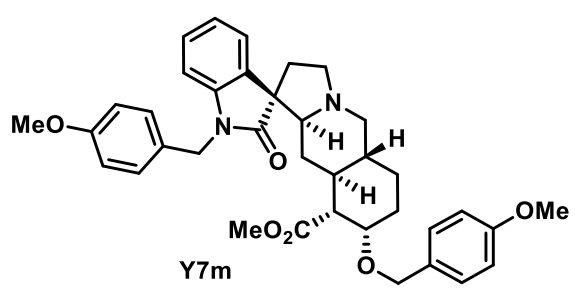

Yield: $21 \%$; $23.5 \mathrm{mg}$ of $\mathbf{Y 7 m}$ isolated as a pale-yellow film.

${ }^{1} \mathrm{H}$ NMR: $\left(400 \mathrm{MHz}, \mathrm{CDCl}_{3}\right) \delta 7.36(\mathrm{~d}, J=7.4 \mathrm{~Hz}, 1 \mathrm{H}), 7.22-7.14(\mathrm{~m}$, $4 \mathrm{H}), 7.11(\mathrm{t}, J=7.8 \mathrm{~Hz}, 1 \mathrm{H}), 6.97(\mathrm{t}, J=7.4 \mathrm{~Hz}, 1 \mathrm{H}), 6.89-6.81(\mathrm{~m}$, 4H), $6.67(\mathrm{~d}, J=7.7 \mathrm{~Hz}, 1 \mathrm{H}), 5.05(\mathrm{~d}, J=15.4 \mathrm{~Hz}, 1 \mathrm{H}), 4.60(\mathrm{~d}, J=$ $15.4 \mathrm{~Hz}, 1 \mathrm{H}), 4.47(\mathrm{~d}, J=11.8 \mathrm{~Hz}, 1 \mathrm{H}), 4.22(\mathrm{~d}, J=11.8 \mathrm{~Hz}, 1 \mathrm{H}), 3.88$ $(\mathrm{m}, 1 \mathrm{H}), 3.79(\mathrm{~s}, 3 \mathrm{H}), 3.76(\mathrm{~s}, 3 \mathrm{H}), 3.47(\mathrm{~s}, 3 \mathrm{H}), 3.28(\mathrm{t}, J=8.5 \mathrm{~Hz}, 1 \mathrm{H}), 3.10(\mathrm{dd}, J=10.8,3.4 \mathrm{~Hz}, 1 \mathrm{H})$, $2.66(\mathrm{~d}, J=11.0 \mathrm{~Hz}, 1 \mathrm{H}), 2.53(\mathrm{q}, J=8.7 \mathrm{~Hz}, 1 \mathrm{H}), 2.41(\mathrm{~m}, 1 \mathrm{H}), 2.13-1.91(\mathrm{~m}, 4 \mathrm{H}), 1.80(\mathrm{qd}, J=11.0$, $3.2 \mathrm{~Hz}, 1 \mathrm{H}), 1.66-1.16(\mathrm{~m}, 5 \mathrm{H}), 0.42(\mathrm{q}, J=11.6 \mathrm{~Hz}, 1 \mathrm{H})$. 
${ }^{13} \mathrm{C}$ NMR: $\left(125 \mathrm{MHz}, \mathrm{CDCl}_{3}\right) \delta 179.4,172.6,159.2,159.1,142.5,133.9,130.9,129.2,128.7,128.4$, $127.5,124.9,122.3,114.4,113.8,108.9,74.6,72.2,70.2,59.1,56.4,55.5,55.4,53.9,52.7,51.3,43.5$, $40.5,36.1,35.3,31.1,28.1,23.8$.

HRMS (ESI): calc. for $\mathrm{C}_{37} \mathrm{H}_{43} \mathrm{~N}_{2} \mathrm{O}_{6}[\mathrm{M}+\mathrm{H}]^{+}:$611.3116, found: 611.3132 .

MP: $53-55^{\circ} \mathrm{C}$.

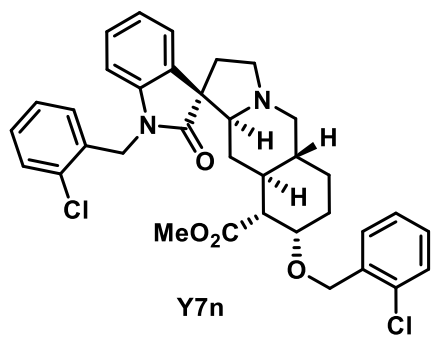

Yield: 89\%; $61.5 \mathrm{mg}$ of $\mathbf{Y 7 n}$ isolated as a colorless foam.

1H NMR: $\left(400 \mathrm{MHz}, \mathrm{CDCl}_{3}\right) \delta 7.46(\mathrm{~d}, J=7.6 \mathrm{~Hz}, 1 \mathrm{H}), 7.42(\mathrm{~d}, J=7.4 \mathrm{~Hz}$, $1 \mathrm{H}), 7.38(\mathrm{dd}, J=7.6,1.6 \mathrm{~Hz}, 1 \mathrm{H}), 7.32-7.25(\mathrm{~m}, 2 \mathrm{H}), 7.24-7.16(\mathrm{~m}, 3 \mathrm{H})$, $7.14(\mathrm{td}, J=7.8,1.3 \mathrm{~Hz}, 1 \mathrm{H}), 7.06-6.99(\mathrm{~m}, 2 \mathrm{H}), 6.64(\mathrm{~d}, J=7.7 \mathrm{~Hz}, 1 \mathrm{H})$, $5.18(\mathrm{~d}, J=16.6 \mathrm{~Hz}, 1 \mathrm{H}), 4.89(\mathrm{~d}, J=16.6 \mathrm{~Hz}, 1 \mathrm{H}), 4.64(\mathrm{~d}, J=13.2 \mathrm{~Hz}, 1 \mathrm{H})$, $4.34(\mathrm{~d}, J=13.2 \mathrm{~Hz}, 1 \mathrm{H}), 4.00(\mathrm{~m}, 1 \mathrm{H}), 3.51(\mathrm{~s}, 3 \mathrm{H}), 3.32$ (t, $J=7.9 \mathrm{~Hz}, 1 \mathrm{H})$, $3.13(\mathrm{dd}, J=10.8,3.5 \mathrm{~Hz}, 1 \mathrm{H}), 2.71(\mathrm{~d}, J=11.3 \mathrm{~Hz}, 1 \mathrm{H}), 2.56(\mathrm{q}, J=8.7 \mathrm{~Hz}, 1 \mathrm{H}), 2.44(\mathrm{~m}, 1 \mathrm{H}), 2.20$ (dt, $J=10.7,3.1 \mathrm{~Hz}, 1 \mathrm{H}), 2.16-2.03(\mathrm{~m}, 2 \mathrm{H}), 1.98(\mathrm{t}, J=10.7 \mathrm{~Hz}, 1 \mathrm{H}), 1.88(\mathrm{qd}, J=11.3,3.2 \mathrm{~Hz}, 1 \mathrm{H})$, $1.57(\mathrm{dt}, J=12.0,3.0 \mathrm{~Hz}, 1 \mathrm{H}), 1.51-1.35(\mathrm{~m}, 3 \mathrm{H}), 1.29(\mathrm{~m}, 1 \mathrm{H}), 0.53(\mathrm{q}, J=11.5 \mathrm{~Hz}, 1 \mathrm{H})$.

${ }^{13} \mathrm{C}$ NMR: $\left(100 \mathrm{MHz}, \mathrm{CDCl}_{3}\right) \delta$ 179.7, $172.6,142.2,136.5,133.7,133.4,133.0,132.3,129.7,129.0$, $128.9,128.8,128.5,128.1,127.7,127.6,127.0,124.9,122.7,108.7,75.9,72.1,67.5,59.1,56.5,53.9$, $52.7,51.4,41.3,40.5,36.2,35.5,31.2,28.1,23.8$.

HRMS (ESI): calc. for $\mathrm{C}_{35} \mathrm{H}_{37} \mathrm{Cl}_{2} \mathrm{~N}_{2} \mathrm{O}_{4}[\mathrm{M}+\mathrm{H}]^{+}: 619.2124$, found: 619.2151 .

MP: $78-80^{\circ} \mathrm{C}$.

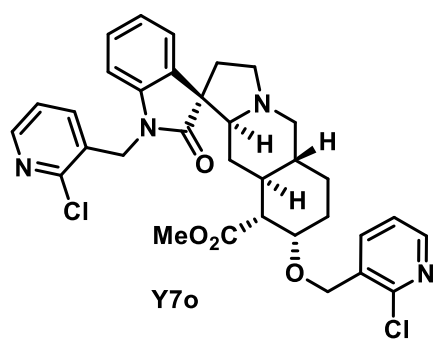

Yield: 37\%; $31.4 \mathrm{mg}$ of Y7o isolated as a colorless foam.

'H NMR: $\left(400 \mathrm{MHz}, \mathrm{CDCl}_{3}\right) \delta 8.34-8.25(\mathrm{~m}, 2 \mathrm{H}), 7.81(\mathrm{~d}, J=7.6 \mathrm{~Hz}, 1 \mathrm{H})$, $7.42(\mathrm{~d}, J=7.3 \mathrm{~Hz}, 1 \mathrm{H}), 7.36(\mathrm{~d}, J=7.7 \mathrm{~Hz}, 1 \mathrm{H}), 7.31-7.20(\mathrm{~m}, 2 \mathrm{H}), 7.17$ $(\mathrm{t}, J=7.7 \mathrm{~Hz}, 1 \mathrm{H}), 7.05(\mathrm{t}, J=7.5 \mathrm{~Hz}, 1 \mathrm{H}), 6.66(\mathrm{~d}, J=7.7 \mathrm{~Hz}, 1 \mathrm{H}), 5.18(\mathrm{~d}$, $J=16.9 \mathrm{~Hz}, 1 \mathrm{H}), 4.85(\mathrm{~d}, J=16.9 \mathrm{~Hz}, 1 \mathrm{H}), 4.62(\mathrm{~d}, J=13.9 \mathrm{~Hz}, 1 \mathrm{H}), 4.27(\mathrm{~d}$, $J=13.9 \mathrm{~Hz}, 1 \mathrm{H}), 4.05(\mathrm{~m}, 1 \mathrm{H}), 3.51(\mathrm{~s}, 3 \mathrm{H}), 3.31(\mathrm{t}, J=9.0 \mathrm{~Hz}, 1 \mathrm{H}), 3.14(\mathrm{~d}$, $J=10.6 \mathrm{~Hz}, 1 \mathrm{H}), 2.68(\mathrm{~d}, J=10.6 \mathrm{~Hz}, 1 \mathrm{H}), 2.54(\mathrm{q}, J=8.7 \mathrm{~Hz}, 1 \mathrm{H}), 2.43(\mathrm{dd}, J=12.9,10.6 \mathrm{~Hz}, 1 \mathrm{H})$, $2.27-2.03(\mathrm{~m}, 3 \mathrm{H}), 1.96(\mathrm{t}, J=10.4 \mathrm{~Hz}, 1 \mathrm{H}), 1.84(\mathrm{q}, J=10.7 \mathrm{~Hz}, 1 \mathrm{H}), 1.53(\mathrm{dt}, J=12.1,2.8 \mathrm{~Hz}, 1 \mathrm{H})$, $1.50-1.22(\mathrm{~m}, 4 \mathrm{H}), 0.51(\mathrm{q}, J=11.5 \mathrm{~Hz}, 1 \mathrm{H})$.

${ }^{13} \mathrm{C}$ NMR: $\left(100 \mathrm{MHz}, \mathrm{CDCl}_{3}\right) \delta$ 179.9, 172.5, 150.0, 148.8, 148.7, 148.2, 141.7, 137.2, 137.0, 133.6, $133.5,130.4,127.9,125.1,123.4,123.1,123.0,108.5,76.5,72.3,66.6,59.1,56.6,54.0,52.4,51.5$, $40.8,40.3,36.2,35.4,31.2,28.0,23.8$.

HRMS (ESI): calc. for $\mathrm{C}_{33} \mathrm{H}_{35} \mathrm{Cl}_{2} \mathrm{~N}_{4} \mathrm{O}_{4}[\mathrm{M}+\mathrm{H}]^{+}: 621.2030$, found: 621.2020 .

MP: $79-81^{\circ} \mathrm{C}$. 


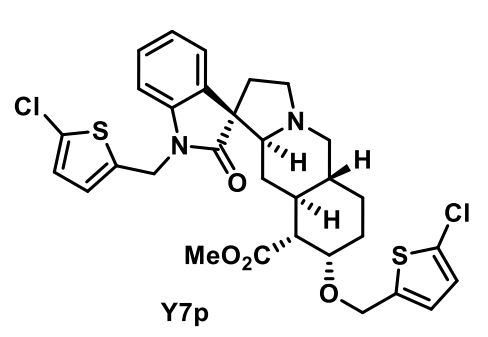

Yield: 34\%; $29.2 \mathrm{mg}$ of Y7p isolated as a pale-yellow foam.

'H NMR: $\left(600 \mathrm{MHz}, \mathrm{CDCl}_{3}\right) \delta 7.37(\mathrm{~d}, J=7.4 \mathrm{~Hz}, 1 \mathrm{H}), 7.19$ (t, $J=7.6 \mathrm{~Hz}$, $1 \mathrm{H}), 7.01(\mathrm{t}, J=7.5 \mathrm{~Hz}, 1 \mathrm{H}), 6.83-6.77(\mathrm{~m}, 2 \mathrm{H}), 6.75-6.71(\mathrm{~m}, 2 \mathrm{H}), 6.66$ $(\mathrm{d}, J=3.7 \mathrm{~Hz}, 1 \mathrm{H}), 5.11(\mathrm{~d}, J=15.7 \mathrm{~Hz}, 1 \mathrm{H}), 4.76(\mathrm{~d}, J=15.9 \mathrm{~Hz}, 1 \mathrm{H}), 4.56$ (d, $J=12.9 \mathrm{~Hz}, 1 \mathrm{H}), 4.34(\mathrm{~d}, J=12.8 \mathrm{~Hz}, 1 \mathrm{H}), 3.93(\mathrm{~s}, 1 \mathrm{H}), 3.54(\mathrm{~s}, 3 \mathrm{H})$, 3.26 (t, $J=8.4 \mathrm{~Hz}, 1 \mathrm{H}), 3.09(\mathrm{~d}, J=10.7 \mathrm{~Hz}, 1 \mathrm{H}), 2.62(\mathrm{~d}, J=11.0 \mathrm{~Hz}, 1 \mathrm{H})$, $2.51(\mathrm{q}, J=8.8 \mathrm{~Hz}, 1 \mathrm{H}), 2.37(\mathrm{dd}, J=14.4,11.4 \mathrm{~Hz}, 1 \mathrm{H}), 2.08-1.89(\mathrm{~m}, 4 \mathrm{H}), 1.74(\mathrm{q}, J=11.3 \mathrm{~Hz}$, $1 \mathrm{H}), 1.45-1.18(\mathrm{~m}, 5 \mathrm{H}), 0.42(\mathrm{q}, J=11.6 \mathrm{~Hz}, 1 \mathrm{H})$

${ }^{13}$ C NMR: $\left(150 \mathrm{MHz}, \mathrm{CDCl}_{3}\right) \delta 179.0,172.5,141.7,140.5,137.8,133.8,130.2,129.6,127.6,126.1$, $125.8,125.7,125.3,125.1,122.7,108.4,75.0,72.0,65.5,59.0,56.3,53.8,52.8,51.6,40.5,39.2,36.0$, $35.4,31.1,28.2,23.8$.

HRMS (ESI): calc. for $\mathrm{C}_{31} \mathrm{H}_{33} \mathrm{Cl}_{2} \mathrm{~N}_{2} \mathrm{O}_{4} \mathrm{~S}_{2}[\mathrm{M}+\mathrm{H}]^{+}:$631.1253, found: 631.1240 .

MP: $54-56^{\circ} \mathrm{C}$.

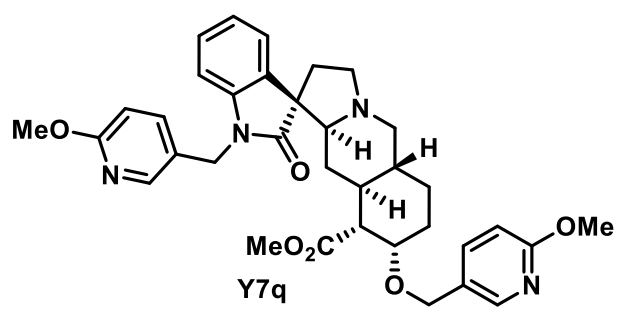

Yield: $39 \%$; $32.6 \mathrm{mg}$ of $\mathbf{Y 7 q}$ isolated as a colorless, amorphous solid.

${ }^{1} \mathrm{H}$ NMR: $\left(400 \mathrm{MHz}, \mathrm{CDCl}_{3}\right) \delta 8.11(\mathrm{~d}, J=2.4 \mathrm{~Hz}, 1 \mathrm{H}), 7.98(\mathrm{~d}, J=$ $2.4 \mathrm{~Hz}, 1 \mathrm{H}), 7.48(\mathrm{~d}, J=2.1 \mathrm{~Hz}, 1 \mathrm{H}), 7.46(\mathrm{~d}, J=2.1 \mathrm{~Hz}, 1 \mathrm{H}), 7.35$ $(\mathrm{d}, J=7.3 \mathrm{~Hz}, 1 \mathrm{H}), 7.12$ (td, $J=7.7,1.3 \mathrm{~Hz}, 1 \mathrm{H}), 6.97$ (t, $J=7.5$ $\mathrm{Hz}, 1 \mathrm{H}), 6.76-6.67(\mathrm{~m}, 3 \mathrm{H}), 5.03(\mathrm{~d}, J=15.4 \mathrm{~Hz}, 1 \mathrm{H}), 4.57(\mathrm{~d}, J=15.4 \mathrm{~Hz}, 1 \mathrm{H}), 4.45(\mathrm{~d}, J=11.9 \mathrm{~Hz}$, $1 \mathrm{H}), 4.18(\mathrm{~d}, J=11.9 \mathrm{~Hz}, 1 \mathrm{H}), 3.90(\mathrm{~s}, 3 \mathrm{H}), 3.87(\mathrm{~m}, 1 \mathrm{H}$; signal partially buried), $3.87(\mathrm{~s}, 3 \mathrm{H}), 3.47(\mathrm{~s}$, $3 \mathrm{H}$ ), 3.27 (td, $J=8.5,2.3 \mathrm{~Hz}, 1 \mathrm{H}$ ), 3.09 (dd, $J=10.7,3.5 \mathrm{~Hz}, 1 \mathrm{H}$ ), 2.62 (dd, $J=11.2,2.5 \mathrm{~Hz}, 1 \mathrm{H}$ ), 2.51 (q, $J=8.8 \mathrm{~Hz}, 1 \mathrm{H}), 2.38(\mathrm{ddd}, J=12.0,9.4,2.2 \mathrm{~Hz}, 1 \mathrm{H}), 2.10-1.96(\mathrm{~m}, 3 \mathrm{H}), 1.93(\mathrm{t}, J=10.5 \mathrm{~Hz}, 1 \mathrm{H})$, $1.74(\mathrm{qd}, J=11.3,3.1 \mathrm{~Hz}, 1 \mathrm{H}), 1.46-1.30(\mathrm{~m}, 4 \mathrm{H}), 1.22(\mathrm{~m}, 1 \mathrm{H}), 0.37(\mathrm{q}, J=11.6 \mathrm{~Hz}, 1 \mathrm{H})$.

${ }^{13} \mathrm{C}$ NMR: $\left(100 \mathrm{MHz}, \mathrm{CDCl}_{3}\right) \delta 179.5,172.5,164.0,163.9,146.1,145.7,141.9,139.0,138.4,133.7$, 127.6, 126.8, 124.9, 124.8, 122.6, 111.9, 110.9, 108.5, 74.8, 72.2, 67.8, 59.0, 56.4, 53.8, 53.6, 53.6, $52.5,51.4,40.9,40.3,36.0,35.2,31.0,28.1,23.8$.

HRMS (ESI): calc. for $\mathrm{C}_{35} \mathrm{H}_{41} \mathrm{~N}_{4} \mathrm{O}_{6}[\mathrm{M}+\mathrm{H}]^{+}:$: 613.3021, found: 613.3006 .

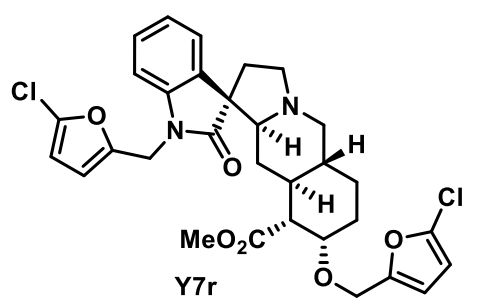

Yield: 32\%; $29.9 \mathrm{mg}$ of $\mathbf{Y 7 r}$ isolated as a colorless foam.

'H NMR: $\left(500 \mathrm{MHz}, \mathrm{CDCl}_{3}\right) \delta 7.37(\mathrm{~d}, J=7.3 \mathrm{~Hz}, 1 \mathrm{H}), 7.21(\mathrm{t}, J=7.7 \mathrm{~Hz}$, $1 \mathrm{H}), 7.02(\mathrm{t}, J=7.5 \mathrm{~Hz}, 1 \mathrm{H}), 6.88(\mathrm{~d}, J=7.8 \mathrm{~Hz}, 1 \mathrm{H}), 6.21(\mathrm{~d}, J=3.3 \mathrm{~Hz}$, $1 \mathrm{H}), 6.19(\mathrm{~d}, J=3.3 \mathrm{~Hz}, 1 \mathrm{H}), 6.07(\mathrm{~d}, J=3.3 \mathrm{~Hz}, 1 \mathrm{H}), 6.05(\mathrm{~d}, J=3.3 \mathrm{~Hz}$, $1 \mathrm{H}), 4.87(\mathrm{~d}, J=16.2 \mathrm{~Hz}, 1 \mathrm{H}), 4.75(\mathrm{~d}, J=16.2 \mathrm{~Hz}, 1 \mathrm{H}), 4.37(\mathrm{~d}, J=13.5$ $\mathrm{Hz}, 1 \mathrm{H}), 4.18(\mathrm{~d}, J=13.5 \mathrm{~Hz}, 1 \mathrm{H}), 3.91(\mathrm{~m}, 1 \mathrm{H}), 3.49(\mathrm{~s}, 3 \mathrm{H}), 3.25(\mathrm{t}, J=8.5 \mathrm{~Hz}, 1 \mathrm{H}), 3.08(\mathrm{dd}, J=$ 10.8, 3.4 Hz, 1H), 2.58 (d, $J=11.2 \mathrm{~Hz}, 1 \mathrm{H}$ ), 2.50 (q, $J=8.8 \mathrm{~Hz}, 1 \mathrm{H}$ ), 2.35 (ddd, $J=12.0,9.3,2.2 \mathrm{~Hz}$, 
1H), $2.06-1.96(\mathrm{~m}, 3 \mathrm{H}), 1.93(\mathrm{t}, J=10.7 \mathrm{~Hz}, 1 \mathrm{H}), 1.70(\mathrm{qd}, J=11.4,3.1 \mathrm{~Hz}, 1 \mathrm{H}), 1.43-1.28(\mathrm{~m}, 4 \mathrm{H})$, $1.21(\mathrm{~m}, 1 \mathrm{H}), 0.41(\mathrm{q}, J=11.6 \mathrm{~Hz}, 1 \mathrm{H})$.

${ }^{13} \mathrm{C}$ NMR: $\left(125 \mathrm{MHz}, \mathrm{CDCl}_{3}\right) \delta 179.0,172.5,151.9,149.5,142.0,136.5,135.8,133.6,127.7,125.0$, 122.6, 111.5, 110.5, 108.6, 107.4, 107.0, 74.9, 72.0, 62.5, 59.0, 56.3, 53.8, 52.6, 51.5, 40.4, 37.1, 36.0, $35.4,31.1,28.0,23.8$.

HRMS (ESI): calc. for $\mathrm{C}_{31} \mathrm{H}_{33} \mathrm{Cl}_{2} \mathrm{~N}_{2} \mathrm{O}_{6}[\mathrm{M}+\mathrm{H}]^{+}:$599.1710, found: 599.1701 .

MP: $49-51^{\circ} \mathrm{C}$.

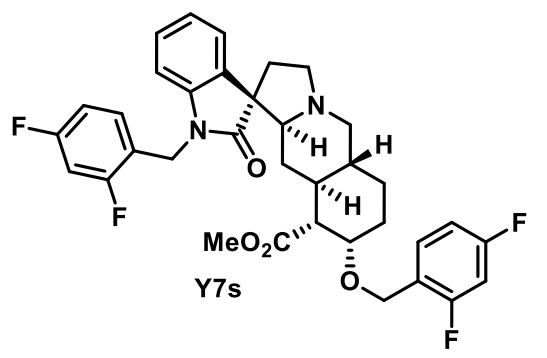

Yield: $51 \% ; 50.2 \mathrm{mg}$ of $\mathbf{Y 7 s}$ isolated as a colorless foam.

1H NMR: $\left(500 \mathrm{MHz}, \mathrm{CDCl}_{3}\right) \delta 7.37(\mathrm{~d}, J=7.4 \mathrm{~Hz}, 1 \mathrm{H}), 7.32$ (q, $J=8.0$ $\mathrm{Hz}, 1 \mathrm{H}), 7.20$ (q, $J=7.7 \mathrm{~Hz}, 1 \mathrm{H}), 7.15(\mathrm{t}, J=7.9 \mathrm{~Hz}, 1 \mathrm{H}), 7.00(\mathrm{t}, J=7.5$ $\mathrm{Hz}, 1 \mathrm{H}), 6.92-6.83(\mathrm{~m}, 2 \mathrm{H}), 6.80(\mathrm{~m}, 1 \mathrm{H}), 6.77-6.70(\mathrm{~m}, 2 \mathrm{H}), 5.08(\mathrm{~d}$, $J=15.8 \mathrm{~Hz}, 1 \mathrm{H}), 4.72(\mathrm{~d}, J=15.8 \mathrm{~Hz}, 1 \mathrm{H}), 4.54(\mathrm{~d}, J=12.3 \mathrm{~Hz}, 1 \mathrm{H})$, $4.28(\mathrm{~d}, J=12.3 \mathrm{~Hz}, 1 \mathrm{H}), 3.92(\mathrm{~m}, 1 \mathrm{H}), 3.46(\mathrm{~s}, 3 \mathrm{H}), 3.29(\mathrm{t}, J=8.6 \mathrm{~Hz}$, $1 \mathrm{H}), 3.10(\mathrm{dd}, J=11.0,3.5 \mathrm{~Hz}, 1 \mathrm{H}), 2.65(\mathrm{~d}, J=11.3 \mathrm{~Hz}, 1 \mathrm{H}), 2.52(\mathrm{q}, J=8.8 \mathrm{~Hz}, 1 \mathrm{H}), 2.40(\mathrm{~m}, 1 \mathrm{H})$, $2.12(\mathrm{dt}, J=11.1,3.2 \mathrm{~Hz}, 1 \mathrm{H}), 2.06-1.98(\mathrm{~m}, 2 \mathrm{H}), 1.94(\mathrm{t}, J=10.7 \mathrm{~Hz}, 1 \mathrm{H}), 1.77$ (qd, $J=11.3,3.2 \mathrm{~Hz}$, $1 \mathrm{H}), 1.44-1.32(\mathrm{~m}, 4 \mathrm{H}), 1.24(\mathrm{~m}, 1 \mathrm{H}), 0.39(\mathrm{q}, J=11.5 \mathrm{~Hz}, 1 \mathrm{H})$.

${ }^{13}$ C NMR: $\left(125 \mathrm{MHz}, \mathrm{CDCl}_{3}\right) \delta$ 179.6, 172.3, 162.7 (dd, $\left.J=248,12.2 \mathrm{~Hz}\right), 162.5$ (dd, $J=248,12.2 \mathrm{~Hz}$ ), 159.7, 159.6, 141.9, 133.7, 131.0 (dd, $J=9.8,5.9 \mathrm{~Hz}$ ), 130.7 (dd, $J=9.9,5.1 \mathrm{~Hz}), 127.7,125.0,122.7$, $121.7(\mathrm{~d}, J=14.1 \mathrm{~Hz}), 119.3(\mathrm{~d}, J=13.1 \mathrm{~Hz}), 112.4$ (dd, $J=21.3,3.5 \mathrm{~Hz}), 111.4(\mathrm{dd}, J=20.8,3.5 \mathrm{~Hz}$ ), 108.3, 103.9 (t, $J=25.5 \mathrm{~Hz}), 103.6$ (t, $J=25.5 \mathrm{~Hz}), 75.4,72.3,63.6,59.0,56.4,53.8,52.4,51.3,40.4$, $36.5,36.0,35.2,31.0,27.9,23.7$.

HRMS (ESI): calc. for $\mathrm{C}_{35} \mathrm{H}_{35} \mathrm{~F}_{4} \mathrm{~N}_{2} \mathrm{O}_{4}[\mathrm{M}+\mathrm{H}]^{+}:$: 623.2527, found: 623.2546 .

MP: $61-63^{\circ} \mathrm{C}$.

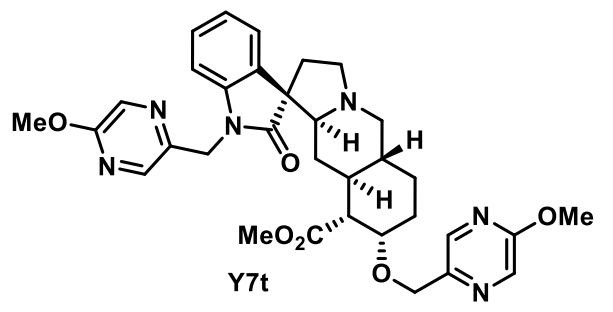

Yield: 46\%; $49.5 \mathrm{mg}$ of Y7t isolated as a colorless, amorphous solid.

'1H NMR: $\left(500 \mathrm{MHz}, \mathrm{CDCl}_{3}\right) \delta 8.15(\mathrm{~s}, 1 \mathrm{H}), 8.11(\mathrm{~s}, 1 \mathrm{H}), 8.09(\mathrm{~s}, 1 \mathrm{H})$, $7.97(\mathrm{~s}, 1 \mathrm{H}), 7.37(\mathrm{~d}, J=7.4 \mathrm{~Hz}, 1 \mathrm{H}), 7.14(\mathrm{t}, J=7.7 \mathrm{~Hz}, 1 \mathrm{H}), 6.99$ (t, $J=7.5 \mathrm{~Hz}, 1 \mathrm{H}), 6.79(\mathrm{~d}, J=7.8 \mathrm{~Hz}, 1 \mathrm{H}), 5.10(\mathrm{~d}, J=15.8 \mathrm{~Hz}, 1 \mathrm{H})$, $4.85(\mathrm{~d}, J=15.8 \mathrm{~Hz}, 1 \mathrm{H}), 4.60(\mathrm{~d}, J=12.7 \mathrm{~Hz}, 1 \mathrm{H}), 4.34(\mathrm{~d}, J=12.7$ $\mathrm{Hz}, 1 \mathrm{H}), 3.98(\mathrm{~m}, 1 \mathrm{H}), 3.94(\mathrm{~s}, 3 \mathrm{H}), 3.89(\mathrm{~s}, 3 \mathrm{H}), 3.56(\mathrm{~s}, 3 \mathrm{H}), 3.27(\mathrm{t}, J=8.2 \mathrm{~Hz}, 1 \mathrm{H}), 3.09$ (dd, $J=$ 10.9, $3.5 \mathrm{~Hz}, 1 \mathrm{H}$ ), $2.63(\mathrm{~d}, J=11.2 \mathrm{~Hz}, 1 \mathrm{H}$ ), 2.51 (q, $J=8.8 \mathrm{~Hz}, 1 \mathrm{H}$ ), 2.39 (ddd, $J=12.1,9.2,2.3 \mathrm{~Hz}$, $1 \mathrm{H}), 2.12(\mathrm{dt}, J=10.6,3.1 \mathrm{~Hz}, 1 \mathrm{H}), 2.07(\mathrm{dd}, J=11.7,2.9 \mathrm{~Hz}, 1 \mathrm{H}), 2.04-1.88(\mathrm{~m}, 2 \mathrm{H}), 1.79$ (qd, $J=$ 11.4, 3.2 Hz, 1H), $1.45-1.32(\mathrm{~m}, 4 \mathrm{H}), 1.24(\mathrm{~m}, 1 \mathrm{H}), 0.45(\mathrm{q}, J=11.5 \mathrm{~Hz}, 1 \mathrm{H})$. 
${ }^{13} \mathrm{C}$ NMR: $\left(125 \mathrm{MHz}, \mathrm{CDCl}_{3}\right) \delta 179.3,172.7,160.0,159.9,145.3,143.0,142.2,139.6,139.3,135.0$, $134.2,133.7,127.6,125.0,122.6,108.8,76.2,72.0,69.6,59.0,56.4,53.8,53.8,53.8,52.8,51.5,43.1$, $40.4,36.1,35.4,31.1,28.3,23.8$.

HRMS (ESI): calc. for $\mathrm{C}_{33} \mathrm{H}_{39} \mathrm{~N}_{6} \mathrm{O}_{6}[\mathrm{M}+\mathrm{H}]^{+}:$615.2956, found: 615.2955 .

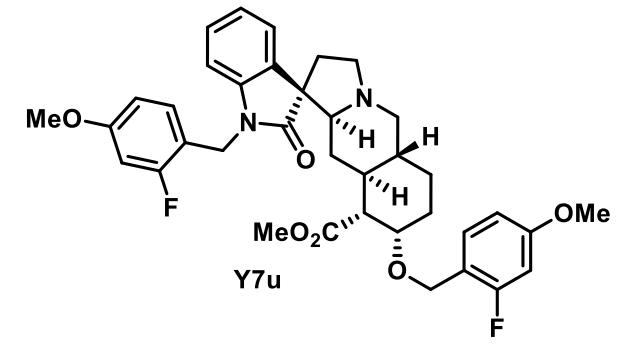

Yield: 55\%; $32.4 \mathrm{mg}$ of $\mathbf{Y 7 u}$ isolated as a colorless foam.

'H NMR: $\left(500 \mathrm{MHz}, \mathrm{CDCl}_{3}\right) \delta 7.36(\mathrm{~d}, J=7.3 \mathrm{~Hz}, 1 \mathrm{H}), 7.21(\mathrm{t}, J=$ $8.5 \mathrm{~Hz}, 1 \mathrm{H}), 7.14(\mathrm{t}, J=8.0 \mathrm{~Hz}, 1 \mathrm{H}), 7.11(\mathrm{t}, J=8.5 \mathrm{~Hz}, 1 \mathrm{H}), 6.98(\mathrm{t}$, $J=7.5 \mathrm{~Hz}, 1 \mathrm{H}), 6.75(\mathrm{~d}, J=7.8 \mathrm{~Hz}, 1 \mathrm{H}), 6.70-6.64(\mathrm{~m}, 2 \mathrm{H}), 6.61$ $-6.53(\mathrm{~m}, 2 \mathrm{H}), 5.02(\mathrm{~d}, J=15.6 \mathrm{~Hz}, 1 \mathrm{H}), 4.73(\mathrm{~d}, J=15.6 \mathrm{~Hz}, 1 \mathrm{H})$, $4.49(\mathrm{~d}, J=12.0 \mathrm{~Hz}, 1 \mathrm{H}), 4.27(\mathrm{~d}, J=12.0 \mathrm{~Hz}, 1 \mathrm{H}), 3.89(\mathrm{~m}, 1 \mathrm{H})$, $3.78(\mathrm{~s}, 3 \mathrm{H}), 3.74(\mathrm{~s}, 3 \mathrm{H}), 3.45(\mathrm{~s}, 3 \mathrm{H}), 3.27(\mathrm{t}, J=8.1 \mathrm{~Hz}, 1 \mathrm{H}), 3.09(\mathrm{dd}, J=10.7,3.5 \mathrm{~Hz}, 1 \mathrm{H}), 2.64(\mathrm{~d}$, $J=10.9 \mathrm{~Hz}, 1 \mathrm{H}), 2.52(\mathrm{q}, J=8.8 \mathrm{~Hz}, 1 \mathrm{H}), 2.39(\mathrm{ddd}, J=11.9,9.3,2.2 \mathrm{~Hz}, 1 \mathrm{H}), 2.11(\mathrm{dd}, J=13.7,3.1$ $\mathrm{Hz}, 1 \mathrm{H}), 2.05-1.98(\mathrm{~m}, 2 \mathrm{H}), 1.94(\mathrm{t}, J=10.9 \mathrm{~Hz}, 1 \mathrm{H}), 1.77(\mathrm{qd}, J=11.3,3.2 \mathrm{~Hz}, 1 \mathrm{H}), 1.47-1.37(\mathrm{~m}$, $2 \mathrm{H}), 1.37-1.28(\mathrm{~m}, 2 \mathrm{H}), 1.24(\mathrm{~m}, 1 \mathrm{H}), 0.40(\mathrm{q}, J=11.5 \mathrm{~Hz}, 1 \mathrm{H})$.

${ }^{13} \mathrm{C}$ NMR: $(125 \mathrm{MHz}, \mathrm{CDCl} 3) \delta$ 179.6, $172.5,161.4(\mathrm{~d}, J=246 \mathrm{~Hz}), 161.2(\mathrm{~d}, J=245 \mathrm{~Hz}), 160.6(\mathrm{~d}, J=$ $10.8 \mathrm{~Hz}), 160.5(\mathrm{~d}, J=10.9 \mathrm{~Hz}), 142.2,133.7,131.1(\mathrm{~d}, J=6.2 \mathrm{~Hz}), 130.3(\mathrm{~d}, J=5.8 \mathrm{~Hz}), 127.6,124.8$, 122.5, $117.6(\mathrm{~d}, J=15.7 \mathrm{~Hz}), 115.2(\mathrm{~d}, J=15.0 \mathrm{~Hz}), 111.0(\mathrm{~d}, J=2.2 \mathrm{~Hz}), 109.9$ (d, $J=2.6 \mathrm{~Hz}), 108.5$, $101.6(\mathrm{~d}, J=5.0 \mathrm{~Hz}), 101.4(\mathrm{~d}, J=4.9 \mathrm{~Hz}), 74.9,72.1,63.7,59.1,56.4,55.7,55.7,53.9,52.7,51.3$, $40.5,36.6,36.1,35.4,31.1,28.0,23.8$.

HRMS (ESI): calc. for $\mathrm{C}_{37} \mathrm{H}_{41} \mathrm{~F}_{2} \mathrm{~N}_{2} \mathrm{O}_{6}[\mathrm{M}+\mathrm{H}]^{+}:$647.2927, found: 647.2932 .

MP: $61-63^{\circ} \mathrm{C}$.

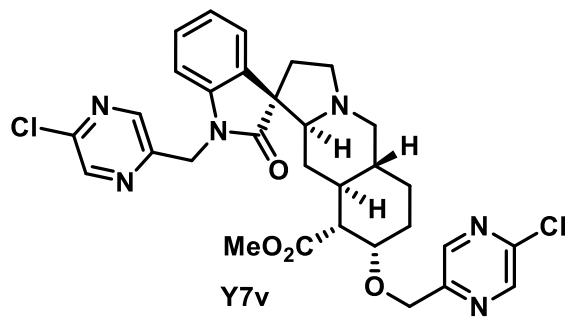

Yield: $60 \% ; 75.0 \mathrm{mg}$ of $\mathbf{Y 7 v}$ isolated as a colorless film.

'H NMR: $\left(500 \mathrm{MHz}, \mathrm{CDCl}_{3}\right) \delta 8.64(\mathrm{~s}, 0.6 \mathrm{H}$, major rotamer), 8.55 (s, $1 \mathrm{H}), 8.46(\mathrm{~s}, 0.4 \mathrm{H}$, minor rotamer), $8.42(\mathrm{~m}, 1 \mathrm{H}), 8.29(\mathrm{~m}, 1 \mathrm{H}), 7.39$ $(\mathrm{d}, J=7.3 \mathrm{~Hz}, 1 \mathrm{H}$ ), 7.16 (t, $J=7.7 \mathrm{~Hz}, 1 \mathrm{H}), 7.02$ (t, $J=7.5 \mathrm{~Hz}, 1 \mathrm{H}$ ), $6.73(\mathrm{dd}, J=7.8,4.0 \mathrm{~Hz}, 1 \mathrm{H}), 5.18(\mathrm{dd}, J=16.1,11.4 \mathrm{~Hz}, 1 \mathrm{H}), 4.89$ $(\mathrm{t}, J=16.1 \mathrm{~Hz}, 1 \mathrm{H}), 4.67(\mathrm{t}, J=14.0 \mathrm{~Hz}, 1 \mathrm{H}), 4.40(\mathrm{t}, J=13.8 \mathrm{~Hz}, 1 \mathrm{H})$, $4.01(\mathrm{~s}, 1 \mathrm{H}), 3.59(\mathrm{~m}, 3 \mathrm{H}$, due to rotameric mixture), $3.29(\mathrm{~m}, 1 \mathrm{H}), 3.11(\mathrm{dd}, J=10.8,3.4 \mathrm{~Hz}, 1 \mathrm{H}), 2.64$ $(\mathrm{m}, 1 \mathrm{H}), 2.53(\mathrm{q}, J=8.8 \mathrm{~Hz}, 1 \mathrm{H}), 2.41(\mathrm{~m}, 1 \mathrm{H}), 2.19-2.07(\mathrm{~m}, 2 \mathrm{H}), 2.07-1.88(\mathrm{~m}, 2 \mathrm{H}), 1.81(\mathrm{~m}, 1 \mathrm{H})$, $1.52-1.20(\mathrm{~m}, 5 \mathrm{H}), 0.44(\mathrm{q}, J=11.6 \mathrm{~Hz}, 1 \mathrm{H})$. Note: We believe several ${ }^{1} \mathrm{H}$ NMR signals in this spectrum are complicated by rotamers and have added some elevated temperature NMRs in $d_{6}$-DMSO in the spectra section of this supporting information document (NMR tabulation not present for these additional spectra).

${ }^{13} \mathrm{C}$ NMR: $\left(125 \mathrm{MHz}, \mathrm{CDCl}_{3}\right) \delta 179.4,172.5,152.6,152.3,150.2,149.9,148.6,148.2,147.2,146.1$, 144.3, 143.8, 143.6, 143.3, 142.9, 142.8, 141.7, 141.7, 140.0, 139.5, 133.6, 127.7, 125.1, 122.9, 108.4, $76.8,72.0,69.4,58.8,56.4,53.7,52.6,51.7,51.7,42.8,40.3,36.0,35.3,31.0,28.1,23.7$. Note: This 
spectrum shows a mixture of rotational isomers (ten additional carbon signals correspond to eight additional aromatic carbons for the pyrazine fragments and two additional aliphatic carbons for the benzylic methylene carbons).

HRMS (ESI): calc. for $\mathrm{C}_{31} \mathrm{H}_{33} \mathrm{Cl}_{2} \mathrm{~N}_{6} \mathrm{O}_{4}[\mathrm{M}+\mathrm{H}]^{+}: 623.1935$, found: 623.1925 .

MP: $68-70^{\circ} \mathrm{C}$.
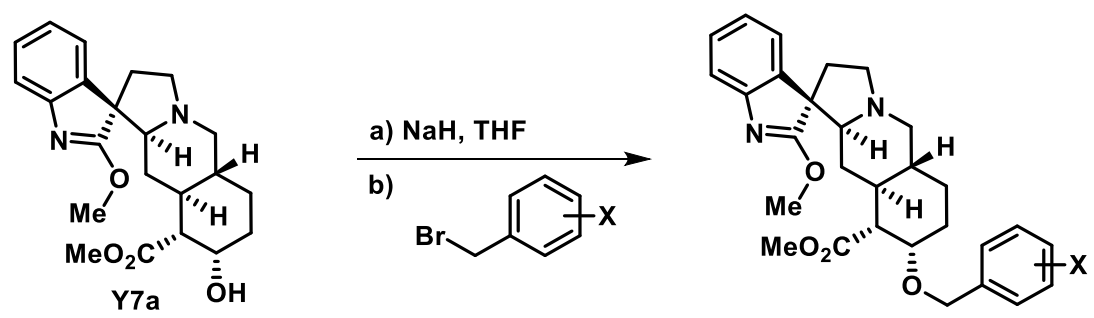

General procedure for the synthesis of 0 -alkylated imino methyl ether products $Y 7 \mathbf{w}-\mathrm{Y7z}$. Tetrahydrofuran $(1 \mathrm{~mL})$ was added to a round-bottom flask followed by sodium hydride (22.8 $\mathrm{mg}, 0.57$ $\mathrm{mmol}, 60 \%$ dispersion in mineral oil). The mixture was cooled to $0{ }^{\circ} \mathrm{C}$ and then a solution of $\mathrm{Y7a}(104.2$ $\mathrm{mg}, 0.27 \mathrm{mmol}$ ) in $1.0 \mathrm{~mL}$ of tetrahydrofuran was added and allowed to stir for 10 minutes. Then, 4fluoro-2-(trifluoromethyl)benzyl bromide $(46.0 \mu \mathrm{L}, 0.30 \mathrm{mmol}$ ) was added and the reaction mixture was slowly warmed to room temperature over 14 hours. Upon completion, the reaction was quenched via brine and extracted with ethyl acetate using a separatory funnel. The organic layers were then collected, dried with sodium sulfate, filtered and concentrated. The crude mixture was purified via column chromatography using hexanes:ethyl acetate:triethylamine 66:33:1 to 49.5:49.5:1 to afford Y7w (115.4 $\mathrm{mg}, 76 \%)$ as a colorless film.

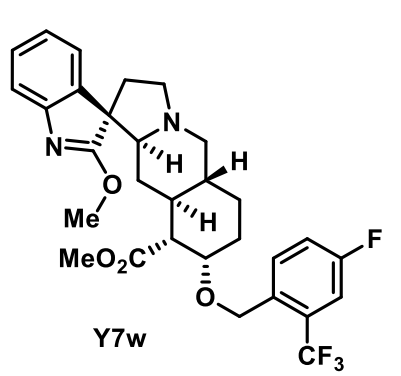

Yield: $76 \% ; 115.4 \mathrm{mg}$ of $\mathbf{Y 7} \mathbf{w}$ isolated as a colorless residue.

'H NMR: $\left(500 \mathrm{MHz}, \mathrm{CDCl}_{3}\right) \delta 7.60(\mathrm{dd}, J=8.6,5.6 \mathrm{~Hz}, 1 \mathrm{H}), 7.35(\mathrm{~d}, J=7.3 \mathrm{~Hz}$, $1 \mathrm{H}), 7.31-7.27(\mathrm{~m}, 2 \mathrm{H}), 7.24-7.18(\mathrm{~m}, 2 \mathrm{H}), 7.02(\mathrm{t}, J=7.4 \mathrm{~Hz}, 1 \mathrm{H}), 4.65(\mathrm{~d}$, $J=13.0 \mathrm{~Hz}, 1 \mathrm{H}), 4.35(\mathrm{~d}, J=13.0 \mathrm{~Hz}, 1 \mathrm{H}), 4.05(\mathrm{~s}, 3 \mathrm{H}), 3.95(\mathrm{~m}, 1 \mathrm{H}), 3.50(\mathrm{~s}$, $3 \mathrm{H}$ ), 3.27 (td, $J=8.6,2.3 \mathrm{~Hz}, 1 \mathrm{H}$ ), 3.11 (dd, $J=10.7,3.4 \mathrm{~Hz}, 1 \mathrm{H}), 2.55$ (dd, $J=$ 11.2, $2.6 \mathrm{~Hz}, 1 \mathrm{H}), 2.41(\mathrm{q}, J=8.8 \mathrm{~Hz}, 1 \mathrm{H}), 2.26(\mathrm{ddd}, J=11.9,9.2,2.3 \mathrm{~Hz}, 1 \mathrm{H})$, $2.14(\mathrm{~m}, 1 \mathrm{H}), 2.11(\mathrm{dd}, J=11.3,2.4 \mathrm{~Hz}, 1 \mathrm{H}), 2.00(\mathrm{~m}, 1 \mathrm{H}), 1.90(\mathrm{t}, J=10.6 \mathrm{~Hz}, 1 \mathrm{H}), 1.75(\mathrm{qd}, J=11.3$, $3.2 \mathrm{~Hz}, 1 \mathrm{H}), 1.45-1.17(\mathrm{~m}, 5 \mathrm{H}), 0.48(\mathrm{q}, J=11.6 \mathrm{~Hz}, 1 \mathrm{H})$.

${ }^{13} \mathrm{C}$ NMR: $\left(125 \mathrm{MHz}, \mathrm{CDCl}_{3}\right) \delta 182.3,172.5,161.4(\mathrm{~d}, \mathrm{~J}=248 \mathrm{~Hz}), 152.6,141.0,133.3(\mathrm{q}, \mathrm{J}=2.0 \mathrm{~Hz})$, $131.3(\mathrm{~d}, J=7.8 \mathrm{~Hz}), 128.9$ (qd, $J=31.8,7.7 \mathrm{~Hz}$ ), 127.7, 123.6, 123.6 (qd, $J=274,2.8 \mathrm{~Hz}), 123.3$, 118.9 (dd, $J=20.5,0.8 \mathrm{~Hz}$ ), 118.2, $113.2(\mathrm{dq}, J=25.2,5.8 \mathrm{~Hz}), 76.3,69.8,66.0$ (q, $J=2.8 \mathrm{~Hz}$ ), 59.8, 59.1, 56.6, 53.6, 52.4, 51.4, 40.4, 36.3, 33.1, 30.7, 28.1, 23.7.

HRMS (ESI): calc. for $\mathrm{C}_{30} \mathrm{H}_{33} \mathrm{~F}_{4} \mathrm{~N}_{2} \mathrm{O}_{4}[\mathrm{M}+\mathrm{H}]^{+}: 561.2371$, found: 561.2384 .

MP: $117-119^{\circ} \mathrm{C}$. 


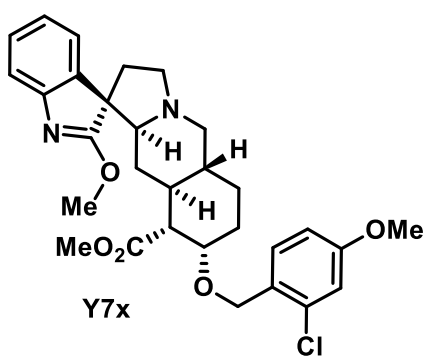

Yield: 73\%; $102.1 \mathrm{mg}$ of $\mathbf{Y 7 x}$ isolated as a colorless film.

'H NMR: $\left(400 \mathrm{MHz}, \mathrm{CDCl}_{3}\right) \delta 7.35(\mathrm{~d}, J=7.2 \mathrm{~Hz}, 1 \mathrm{H}), 7.32-7.24(\mathrm{~m}, 2 \mathrm{H})$, $7.21(\mathrm{td}, J=7.6,1.3 \mathrm{~Hz}, 1 \mathrm{H}), 7.03(\mathrm{td}, J=7.4,1.2 \mathrm{~Hz}, 1 \mathrm{H}), 6.86(\mathrm{~d}, J=2.6$ $\mathrm{Hz}, 1 \mathrm{H}), 6.78(\mathrm{dd}, J=8.5,2.6 \mathrm{~Hz}, 1 \mathrm{H}), 4.55(\mathrm{~d}, J=12.3 \mathrm{~Hz}, 1 \mathrm{H}), 4.28(\mathrm{~d}, J=$ $12.3 \mathrm{~Hz}, 1 \mathrm{H}), 4.05(\mathrm{~s}, 3 \mathrm{H}), 3.92(\mathrm{~m}, 1 \mathrm{H}), 3.77(\mathrm{~s}, 3 \mathrm{H}), 3.48(\mathrm{~s}, 3 \mathrm{H}), 3.27(\mathrm{t}, J$ $=8.2 \mathrm{~Hz}, 1 \mathrm{H}), 3.11(\mathrm{dd}, J=10.8,3.4 \mathrm{~Hz}, 1 \mathrm{H}), 2.55(\mathrm{~d}, J=11.3 \mathrm{~Hz}, 1 \mathrm{H}), 2.41$ (q, $J=8.8 \mathrm{~Hz}, 1 \mathrm{H}$ ), 2.26 (ddd, $J=11.8,9.1,2.3 \mathrm{~Hz}, 1 \mathrm{H}$ ), 2.17 (dt, $J=11.2,2.8 \mathrm{~Hz}, 1 \mathrm{H}$ ), 2.07 (dd, $J=$ 11.6, 3.0 Hz, $1 \mathrm{H}), 2.00(\mathrm{~m}, 1 \mathrm{H}), 1.90(\mathrm{t}, J=10.6 \mathrm{~Hz}, 1 \mathrm{H}), 1.74(\mathrm{qd}, J=11.4,3.2 \mathrm{~Hz}, 1 \mathrm{H}), 1.51-1.21$ $(\mathrm{m}, 5 \mathrm{H}), 0.47(\mathrm{q}, J=11.6 \mathrm{~Hz}, 1 \mathrm{H})$. Note: This spectrum referenced TMS at $0.00 \mathrm{ppm}$.

${ }^{13} \mathrm{C}$ NMR: $\left(100 \mathrm{MHz}, \mathrm{CDCl}_{3}\right) \delta 182.4,172.5,159.6,152.5,141.0,133.7,130.5,128.3,127.6,123.6$, $123.3,118.1,114.6,113.0,75.2,69.9,67.2,59.7,59.2,56.6,55.7,53.7,52.4,51.5,40.4,36.2$, 33.2, $30.7,28.0,23.8$.

HRMS (ESI): calc. for $\mathrm{C}_{30} \mathrm{H}_{36} \mathrm{CIN}_{2} \mathrm{O}_{5}[\mathrm{M}+\mathrm{H}]^{+}: 539.2307$, found: 539.2323 .

MP: $170-172^{\circ} \mathrm{C}$.

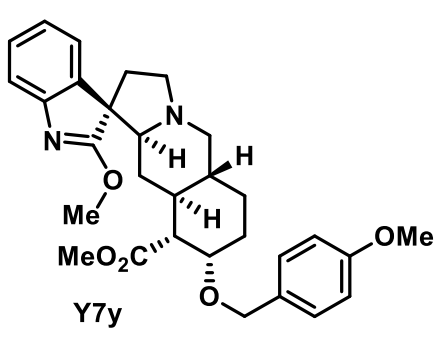

Yield: 55\%; $50.2 \mathrm{mg}$ of Y7y isolated as a colorless, amorphous solid. Note: Y7y was purified via column chromatography using alumina neutral act I with hexanes:ethyl acetate.

1H NMR: $\left(500 \mathrm{MHz}, \mathrm{CDCl}_{3}\right) \delta 7.34(\mathrm{~d}, J=7.1 \mathrm{~Hz}, 1 \mathrm{H}), 7.29(\mathrm{~d}, J=7.7 \mathrm{~Hz}$, $1 \mathrm{H}), 7.20(\mathrm{td}, J=7.6,1.3 \mathrm{~Hz}, 1 \mathrm{H}), 7.14(\mathrm{~d}, J=8.6 \mathrm{~Hz}, 2 \mathrm{H}), 7.03(\mathrm{t}, J=7.4$ $\mathrm{Hz}, 1 \mathrm{H}), 6.83(\mathrm{~d}, J=8.6 \mathrm{~Hz}, 2 \mathrm{H}), 4.46(\mathrm{~d}, J=11.8 \mathrm{~Hz}, 1 \mathrm{H}), 4.19(\mathrm{~d}, J=11.8$ $\mathrm{Hz}, 1 \mathrm{H}), 4.04(\mathrm{~s}, 3 \mathrm{H}), 3.87(\mathrm{~m}, 1 \mathrm{H}), 3.77(\mathrm{~s}, 3 \mathrm{H}), 3.45(\mathrm{~s}, 3 \mathrm{H}), 3.26(\mathrm{t}, J=8.8 \mathrm{~Hz}, 1 \mathrm{H}), 3.10(\mathrm{~d}, J=9.5$ $\mathrm{Hz}, 1 \mathrm{H}$ ), $2.54(\mathrm{~d}, J=11.0 \mathrm{~Hz}, 1 \mathrm{H}$ ), 2.40 (q, $J=9.4 \mathrm{~Hz}, 1 \mathrm{H}$ ), 2.25 (ddd, $J=11.8,9.2,2.2 \mathrm{~Hz}, 1 \mathrm{H}$ ), 2.11 $-1.94(\mathrm{~m}, 3 \mathrm{H}), 1.90(\mathrm{t}, J=10.0 \mathrm{~Hz}, 1 \mathrm{H}), 1.72(\mathrm{q}, J=10.8 \mathrm{~Hz}, 1 \mathrm{H}), 1.49-1.21(\mathrm{~m}, 5 \mathrm{H}), 0.45(\mathrm{q}, J=$ $11.4 \mathrm{~Hz}, 1 \mathrm{H})$.

${ }^{13} \mathrm{C}$ NMR: $\left(125 \mathrm{MHz}, \mathrm{CDCl}_{3}\right) \delta 182.4,172.5,159.2,152.5,141.0,130.7,129.3,127.6,123.6,123.3$, $118.1,113.8,74.4,70.1,69.9,59.7,59.2,56.6,55.4,53.7,52.4,51.4,40.4,36.1,33.1,30.6,28.0$, 23.8 .

HRMS (ESI): calc. for $\mathrm{C}_{30} \mathrm{H}_{37} \mathrm{~N}_{2} \mathrm{O}_{5}[\mathrm{M}+\mathrm{H}]^{+}:$505.2697, found: 505.2696.

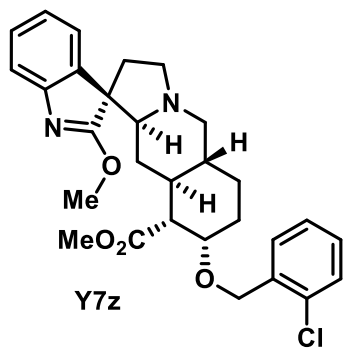

Yield: $79 \%$; $56.1 \mathrm{mg}$ of $\mathbf{Y 7 z}$ isolated as a colorless foam.

'H NMR: $\left(600 \mathrm{MHz}, \mathrm{CDCl}_{3}\right) \delta 7.41(\mathrm{~d}, J=7.6 \mathrm{~Hz}, 1 \mathrm{H}), 7.36(\mathrm{~d}, J=7.5 \mathrm{~Hz}, 1 \mathrm{H})$, $7.31-7.27(\mathrm{~m}, 2 \mathrm{H}), 7.25-7.19(\mathrm{~m}, 2 \mathrm{H}), 7.18(\mathrm{td}, J=7.7,1.8 \mathrm{~Hz}, 1 \mathrm{H}), 7.04(\mathrm{t}, J$ $=7.4 \mathrm{~Hz}, 1 \mathrm{H}), 4.62(\mathrm{~d}, J=13.0 \mathrm{~Hz}, 1 \mathrm{H}), 4.33(\mathrm{~d}, J=13.0 \mathrm{~Hz}, 1 \mathrm{H}), 4.05(\mathrm{~s}, 3 \mathrm{H})$, $3.96(\mathrm{~m}, 1 \mathrm{H}), 3.48(\mathrm{~s}, 3 \mathrm{H}), 3.27(\mathrm{t}, J=7.5 \mathrm{~Hz}, 1 \mathrm{H}), 3.12(\mathrm{~d}, J=9.3 \mathrm{~Hz}, 1 \mathrm{H}), 2.56$ $(\mathrm{d}, J=9.6 \mathrm{~Hz}, 1 \mathrm{H}), 2.42(\mathrm{q}, J=8.8 \mathrm{~Hz}, 1 \mathrm{H}), 2.26(\mathrm{~m}, 1 \mathrm{H}), 2.18(\mathrm{dt}, J=10.6,2.9$ 
$\mathrm{Hz}, 1 \mathrm{H}), 2.10(\mathrm{dd}, J=11.7,3.0 \mathrm{~Hz}, 1 \mathrm{H}), 2.01(\mathrm{~m}, 1 \mathrm{H}), 1.92(\mathrm{t}, J=10.8 \mathrm{~Hz}, 1 \mathrm{H}), 1.77$ (qd, $J=11.3,1.8$ $\mathrm{Hz}, 1 \mathrm{H}), 1.46-1.33(\mathrm{~m}, 4 \mathrm{H}), 1.29(\mathrm{~m}, 1 \mathrm{H}), 0.48(\mathrm{q}, J=12.0 \mathrm{~Hz}, 1 \mathrm{H})$.

${ }^{13} \mathrm{C}$ NMR: $\left(150 \mathrm{MHz}, \mathrm{CDCl}_{3}\right) \delta 182.4,172.5,152.6,141.0,136.4,132.7,129.2,129.2,128.6,127.7$, 127.0, 123.7, 123.3, 118.2, 75.8, 69.9, 67.5, 59.8, 59.1, 56.7, 53.6, 52.5, 51.5, 40.5, 36.3, 33.2, 30.7, $28.1,23.8$.

HRMS (ESI): calc. for $\mathrm{C}_{29} \mathrm{H}_{34} \mathrm{CIN}_{2} \mathrm{O}_{4}[\mathrm{M}+\mathrm{H}]^{+}:$509.2202, found: 509.2193 .

MP: $131-133^{\circ} \mathrm{C}$.
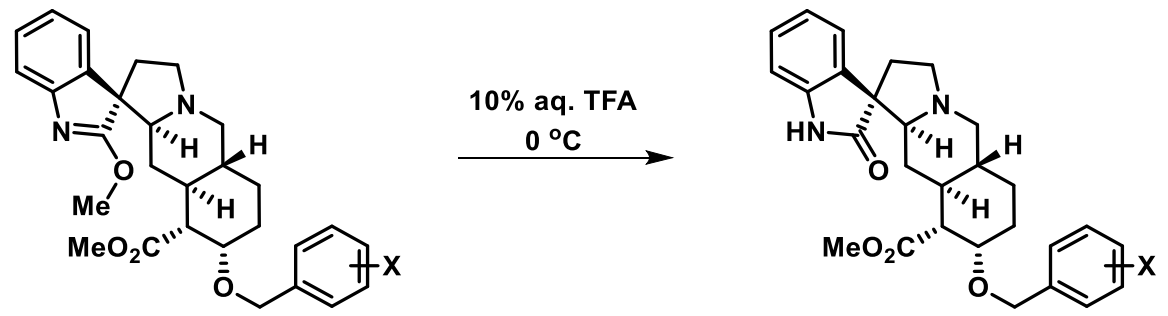

General procedure for the synthesis of free amides Y7aa - Y7ad. Y7w (110.0 mg, $0.20 \mathrm{mmol})$ was first added to a round-bottom flask followed by the addition of solution of $10 \%$ aqueous trifluoroacetic acid $(4.0 \mathrm{~mL}, 0.05 \mathrm{M})$ at $0{ }^{\circ} \mathrm{C}$. The reaction was allowed to stir at $0{ }^{\circ} \mathrm{C}$ for 3.25 hours before being quenched with a $3 \mathrm{M}$ ammonium hydroxide solution. The crude product was then extracted with ethyl acetate in a separatory funnel. The organic layers were then washed with brine, dried with sodium sulfate, filtered and concentrated. The crude mixture was purified via column chromatography using hexanes:ethyl acetate:triethylamine 66:33:1 to 49.5:49.5:1 to afford Y7aa (89.4 mg, 83\%) as a colorless film.

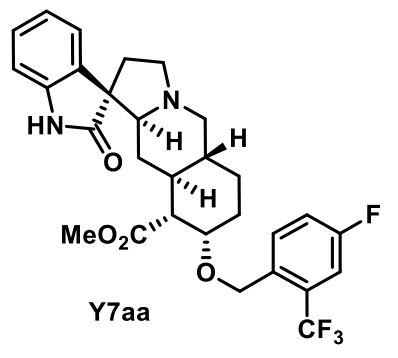

Yield: 83\%; $89.4 \mathrm{mg}$ of Y7aa isolated as a colorless film.

1'H NMR: $\left(500 \mathrm{MHz}, \mathrm{CDCl}_{3}\right) \delta 9.01(\mathrm{~s}, 1 \mathrm{H}), 7.64(\mathrm{t}, J=6.6 \mathrm{~Hz}, 1 \mathrm{H}), 7.36(\mathrm{~d}, J=$ $7.4 \mathrm{~Hz}, 1 \mathrm{H}), 7.28(\mathrm{~m}, 1 \mathrm{H}), 7.22(\mathrm{t}, J=8.1 \mathrm{~Hz}, 1 \mathrm{H}), 7.17(\mathrm{t}, J=7.8 \mathrm{~Hz}, 1 \mathrm{H}), 6.99$ $(\mathrm{t}, J=7.6 \mathrm{~Hz}, 1 \mathrm{H}), 6.91(\mathrm{~d}, J=7.7 \mathrm{~Hz}, 1 \mathrm{H}), 4.67(\mathrm{~d}, J=13.1 \mathrm{~Hz}, 1 \mathrm{H}), 4.35(\mathrm{~d}, J$ $=13.1 \mathrm{~Hz}, 1 \mathrm{H}), 3.98(\mathrm{~m}, 1 \mathrm{H}), 3.50(\mathrm{~s}, 3 \mathrm{H}), 3.27(\mathrm{t}, J=8.6 \mathrm{~Hz}, 1 \mathrm{H}), 3.11(\mathrm{~d}, J=$ $10.6 \mathrm{~Hz}, 1 \mathrm{H}), 2.61(\mathrm{~d}, J=11.1 \mathrm{~Hz}, 1 \mathrm{H}), 2.50(\mathrm{q}, J=8.9 \mathrm{~Hz}, 1 \mathrm{H}), 2.38$ (t, $J=11.2$ $\mathrm{Hz}, 1 \mathrm{H}), 2.18-2.09(\mathrm{~m}, 2 \mathrm{H}), 2.01(\mathrm{q}, J=10.5 \mathrm{~Hz}, 1 \mathrm{H}), 1.94(\mathrm{t}, J=10.5 \mathrm{~Hz}, 1 \mathrm{H}), 1.84(\mathrm{q}, J=10.5 \mathrm{~Hz}$, $1 \mathrm{H}), 1.51(\mathrm{~d}, J=12.1 \mathrm{~Hz}, 1 \mathrm{H}), 1.46-1.35(\mathrm{~m}, 3 \mathrm{H}), 1.29(\mathrm{~m}, 1 \mathrm{H}), 0.55(\mathrm{q}, J=11.7 \mathrm{~Hz}, 1 \mathrm{H})$.

${ }^{13} \mathrm{C}$ NMR: $\left(125 \mathrm{MHz}, \mathrm{CDCl}_{3}\right) \delta$ 182.2, $172.7,161.3(\mathrm{~d}, J=247 \mathrm{~Hz}), 140.7,134.2,133.4,131.1(\mathrm{~d}, J=$ $7.7 \mathrm{~Hz}$ ), 128.6 (qd, $J=31.7,7.7 \mathrm{~Hz}), 127.6,125.0,123.6(\mathrm{qd}, J=274,2.8 \mathrm{~Hz}), 122.3,118.9(\mathrm{~d}, J=$ $20.5 \mathrm{~Hz}$ ), 113.1 (dq, $J=25.2,5.9 \mathrm{~Hz}$ ), 109.9, 76.5, 71.7, 65.9 (q, $J=2.9 \mathrm{~Hz}$ ), 59.0, 56.9, 53.8, 52.7, 51.4, 40.4, 36.2, 35.6, 31.0, 28.2, 23.8.

HRMS (ESI): calc. for $\mathrm{C}_{29} \mathrm{H}_{31} \mathrm{~F}_{4} \mathrm{~N}_{2} \mathrm{O}_{4}[\mathrm{M}+\mathrm{H}]^{+}: 547.2214$, found: 547.2204 .

MP: $73-75^{\circ} \mathrm{C}$. 
Yield: 98\%; $93.0 \mathrm{mg}$ of Y7ab isolated as a colorless film.

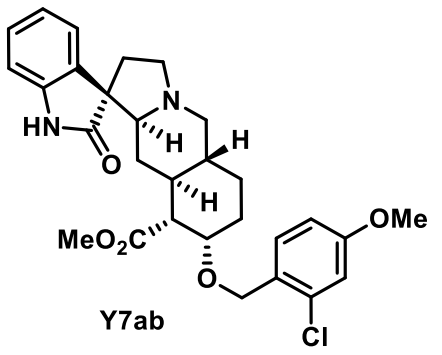

${ }^{1} \mathrm{H}$ NMR: $\left(500 \mathrm{MHz}, \mathrm{CDCl}_{3}\right) \delta 8.88(\mathrm{~s}, 1 \mathrm{H}), 7.36(\mathrm{~d}, J=7.3 \mathrm{~Hz}, 1 \mathrm{H}), 7.29$ (d, $J=8.6 \mathrm{~Hz}, 1 \mathrm{H}), 7.16(\mathrm{t}, J=7.8 \mathrm{~Hz}, 1 \mathrm{H}), 6.98(\mathrm{t}, J=7.6 \mathrm{~Hz}, 1 \mathrm{H}), 6.89(\mathrm{~d}, J=$ $7.8 \mathrm{~Hz}, 1 \mathrm{H}), 6.85(\mathrm{~s}, 1 \mathrm{H}), 6.78(\mathrm{~d}, J=8.7 \mathrm{~Hz}, 1 \mathrm{H}), 4.55(\mathrm{~d}, J=12.3 \mathrm{~Hz}, 1 \mathrm{H})$, $4.27(\mathrm{~d}, J=12.3 \mathrm{~Hz}, 1 \mathrm{H}), 3.94(\mathrm{~m}, 1 \mathrm{H}), 3.75(\mathrm{~s}, 3 \mathrm{H}), 3.49(\mathrm{~s}, 3 \mathrm{H}), 3.26(\mathrm{t}, J=$ $8.7 \mathrm{~Hz}, 1 \mathrm{H}), 3.10(\mathrm{~d}, J=10.7 \mathrm{~Hz}, 1 \mathrm{H}), 2.60(\mathrm{~d}, J=10.9 \mathrm{~Hz}, 1 \mathrm{H}), 2.49(\mathrm{q}, J=$ $8.9 \mathrm{~Hz}, 1 \mathrm{H}), 2.37(\mathrm{t}, J=11.4 \mathrm{~Hz}, 1 \mathrm{H}), 2.15(\mathrm{~d}, J=11.0 \mathrm{~Hz}, 1 \mathrm{H}), 2.09(\mathrm{~d}, J=11.0 \mathrm{~Hz}, 1 \mathrm{H}), 2.00(\mathrm{q}, J=$ $11.0 \mathrm{~Hz}, 1 \mathrm{H}), 1.94(\mathrm{t}, J=10.9 \mathrm{~Hz}, 1 \mathrm{H}), 1.81(\mathrm{q}, J=11.0 \mathrm{~Hz}, 1 \mathrm{H}), 1.50(\mathrm{~d}, J=12.3 \mathrm{~Hz}, 1 \mathrm{H}), 1.46-1.32$ $(\mathrm{m}, 3 \mathrm{H}), 1.27(\mathrm{~m}, 1 \mathrm{H}), 0.52(\mathrm{q}, J=11.7 \mathrm{~Hz}, 1 \mathrm{H})$.

${ }^{13} \mathrm{C}$ NMR: $\left(125 \mathrm{MHz}, \mathrm{CDCl}_{3}\right) \delta 182.0,172.7,159.5,140.7,134.1,133.4,130.2,128.4,127.6,125.0$, 122.2, 114.6, 112.9, 109.8, 75.5, 71.7, 67.2, 59.0, 56.9, 55.6, 53.7, 52.8, 51.4, 40.4, 36.1, 35.6, 31.0, 28.1, 23.8.

HRMS (ESI): calc. for $\mathrm{C}_{29} \mathrm{H}_{34} \mathrm{CIN}_{2} \mathrm{O}_{5}[\mathrm{M}+\mathrm{H}]^{+}: 525.2150$, found: 525.2149 .

MP: $83-85^{\circ} \mathrm{C}$.

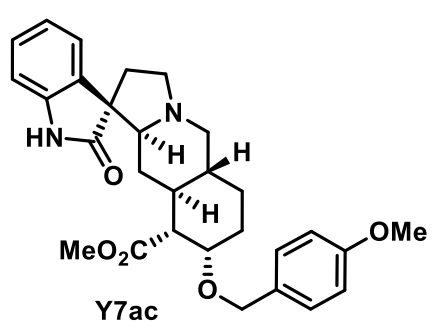

Yield: 54\%; $12.2 \mathrm{mg}$ of Y7ac isolated as a pale-yellow film.

'H NMR: $\left(400 \mathrm{MHz}, \mathrm{CDCl}_{3}\right) \delta 7.89(\mathrm{~s}, 1 \mathrm{H}), 7.35(\mathrm{~d}, J=7.5 \mathrm{~Hz}, 1 \mathrm{H}), 7.21-$ $7.12(\mathrm{~m}, 3 \mathrm{H}), 6.99(\mathrm{t}, J=7.4 \mathrm{~Hz}, 1 \mathrm{H}), 6.88-6.79(\mathrm{~m}, 3 \mathrm{H}), 4.46(\mathrm{~d}, J=11.8$ $\mathrm{Hz}, 1 \mathrm{H}), 4.21(\mathrm{~d}, J=11.8 \mathrm{~Hz}, 1 \mathrm{H}), 3.89(\mathrm{~m}, 1 \mathrm{H}), 3.78(\mathrm{~s}, 3 \mathrm{H}), 3.47(\mathrm{~s}, 3 \mathrm{H})$, 3.25 (t, $J=8.4 \mathrm{~Hz}, 1 \mathrm{H}), 3.08(\mathrm{~d}, J=9.8 \mathrm{~Hz}, 1 \mathrm{H}), 2.57(\mathrm{~d}, J=10.7 \mathrm{~Hz}, 1 \mathrm{H})$, $2.47(\mathrm{q}, J=8.7 \mathrm{~Hz}, 1 \mathrm{H}), 2.37(\mathrm{t}, J=11.1 \mathrm{~Hz}, 1 \mathrm{H}), 2.13-1.87(\mathrm{~m}, 4 \mathrm{H}), 1.79$ (q, $J=11.3 \mathrm{~Hz}, 1 \mathrm{H}), 1.50-1.18(\mathrm{~m}, 5 \mathrm{H}), 0.48(\mathrm{q}, J=11.6 \mathrm{~Hz}, 1 \mathrm{H})$.

${ }^{13} \mathrm{C}$ NMR: $\left(100 \mathrm{MHz}, \mathrm{CDCl}_{3}\right) \delta 181.4,172.8,159.2,140.4,134.2,130.8,129.2,127.6,125.2,122.4$, $113.8,109.5,74.6,71.9,70.2,59.0,56.8,55.5,53.8,52.8,51.5,40.5,36.0,35.6,31.1$, 28.2, 23.8.

HRMS (ESI): calc. for $\mathrm{C}_{29} \mathrm{H}_{35} \mathrm{~N}_{2} \mathrm{O}_{5}[\mathrm{M}+\mathrm{H}]^{+}: 491.2540$, found: 491.2536 .

MP: $87-89^{\circ} \mathrm{C}$.

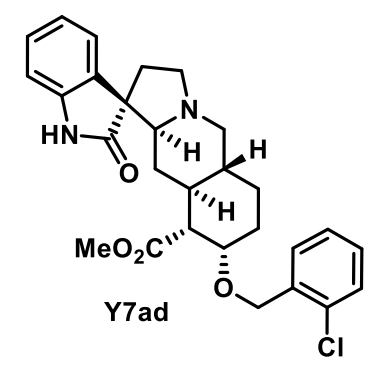

Yield: 53\%; $16.8 \mathrm{mg}$ of Y7ad isolated as a colorless film.

'H NMR: $\left(400 \mathrm{MHz}, \mathrm{CDCl}_{3}\right) \delta 8.10(\mathrm{~s}, 1 \mathrm{H}), 7.44(\mathrm{~d}, J=7.6 \mathrm{~Hz}, 1 \mathrm{H}), 7.37(\mathrm{~d}, J=$ $7.4 \mathrm{~Hz}, 1 \mathrm{H}), 7.32-7.22(\mathrm{~m}, 2 \mathrm{H}), 7.22-7.15(\mathrm{~m}, 2 \mathrm{H}), 7.01(\mathrm{t}, J=7.5 \mathrm{~Hz}, 1 \mathrm{H})$, $6.87(\mathrm{~d}, J=7.7 \mathrm{~Hz}, 1 \mathrm{H}), 4.63(\mathrm{~d}, J=13.2 \mathrm{~Hz}, 1 \mathrm{H}), 4.33(\mathrm{~d}, J=13.2 \mathrm{~Hz}, 1 \mathrm{H}), 3.99$ $(\mathrm{m}, 1 \mathrm{H}), 3.50(\mathrm{~s}, 3 \mathrm{H}), 3.27(\mathrm{t}, J=8.5 \mathrm{~Hz}, 1 \mathrm{H}), 3.11(\mathrm{dd}, J=11.0,3.5 \mathrm{~Hz}, 1 \mathrm{H}), 2.60$ $(\mathrm{d}, J=10.9 \mathrm{~Hz}, 1 \mathrm{H}), 2.50(\mathrm{q}, J=8.7 \mathrm{~Hz}, 1 \mathrm{H}), 2.38$ (ddd, $J=11.6,9.2,2.1 \mathrm{~Hz}, 1 \mathrm{H}$ ), $2.19(\mathrm{~m}, 1 \mathrm{H}), 2.12(\mathrm{dd}, J=11.7,2.8 \mathrm{~Hz}, 1 \mathrm{H}), 2.02(\mathrm{~m}, 1 \mathrm{H}), 1.95(\mathrm{t}, J=10.6 \mathrm{~Hz}, 1 \mathrm{H}), 1.85(\mathrm{qd}, J=11.2$, $1.9 \mathrm{~Hz}, 1 \mathrm{H}), 1.51(\mathrm{dt}, J=12.2,2.9 \mathrm{~Hz}, 1 \mathrm{H}), 1.47-1.34(\mathrm{~m}, 3 \mathrm{H}), 1.27(\mathrm{~m}, 1 \mathrm{H}), 0.52(\mathrm{q}, J=11.6 \mathrm{~Hz}$, $1 \mathrm{H})$. Note: This spectrum referenced TMS at $0.00 \mathrm{ppm}$. 
${ }^{13} \mathrm{C}$ NMR: $\left(100 \mathrm{MHz}, \mathrm{CDCl}_{3}\right) \delta 181.6,172.8,140.5,136.5,134.2,132.3,129.0,128.9,128.5,127.7$, 127.0, 125.2, 122.4, 109.6, 76.0, 71.9, 67.5, 59.0, 56.8, 53.8, 52.8, 51.5, 40.5, 36.2, 35.6, 31.1, 28.2, 23.8 .

HRMS (ESI): calc. for $\mathrm{C}_{28} \mathrm{H}_{32} \mathrm{CIN}_{2} \mathrm{O}_{4}[\mathrm{M}+\mathrm{H}]^{+}:$495.2045, found: 495.2044 .

MP: $97-99^{\circ} \mathrm{C}$.
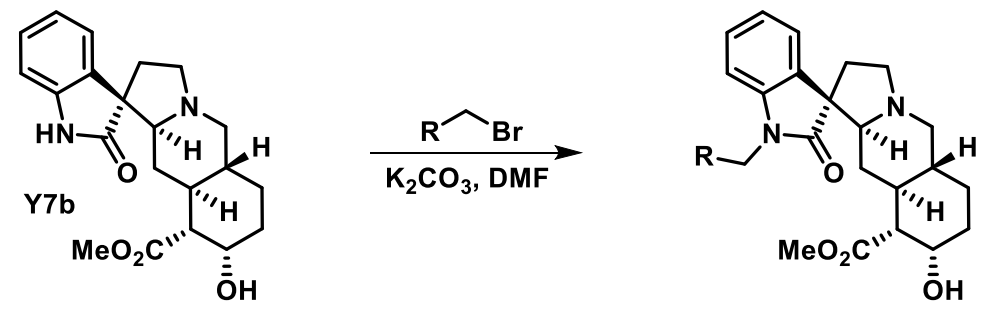

General procedure for the synthesis of $\mathbf{N}$-alkylated products $\mathrm{Y7ae}-\mathrm{Y} 7 \mathrm{ai}$. Y7b $(45.7 \mathrm{mg}, 0.12$ $\mathrm{mmol}$ ) and potassium carbonate $(42.6 \mathrm{mg}, 0.31 \mathrm{mmol})$ were added to a round bottom flask, then dissolved with $\mathrm{N}, \mathrm{N}$-dimethylformamide $(3 \mathrm{~mL}, 0.04 \mathrm{M}$ ). 3-Fluorobenzyl bromide (16.6 $\mu \mathrm{L}, 0.14 \mathrm{mmol})$ was added and the reaction mixture, which was then allowed to stir at room temperature for 24 hours. Upon completion, the reaction was quenched via brine, extracted with ethyl acetate and washed with additional brine $(4 x)$ in a separatory funnel. The organic layers were then collected, dried with sodium sulfate, filtered and concentrated. The crude product was then purified via column chromatography using hexanes:ethyl acetate:triethylamine $66: 33: 1$ to $49.5: 49.5: 1$ to afford Y7ae (46.6 mg, 79\%) as a colorless foam.

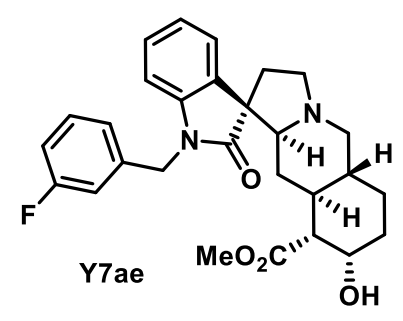

Yield: $79 \%$; $46.6 \mathrm{mg}$ of Y7ae isolated as a colorless foam.

1H NMR: $\left(400 \mathrm{MHz}, \mathrm{CDCl}_{3}\right) \delta 7.42(\mathrm{~d}, J=7.4 \mathrm{~Hz}, 1 \mathrm{H}), 7.27(\mathrm{q}, J=7.7,1 \mathrm{H})$, $7.14(\mathrm{t}, J=7.7 \mathrm{~Hz}, 1 \mathrm{H}), 7.06-6.98(\mathrm{~m}, 2 \mathrm{H}), 6.96-6.86(\mathrm{~m}, 2 \mathrm{H}), 6.65(\mathrm{~d}, J=$ $7.7 \mathrm{~Hz}, 1 \mathrm{H}), 5.06(\mathrm{~d}, J=15.9 \mathrm{~Hz}, 1 \mathrm{H}), 4.70(\mathrm{~d}, J=15.9 \mathrm{~Hz}, 1 \mathrm{H}), 4.08(\mathrm{~m}, 1 \mathrm{H})$, $3.52(\mathrm{~s}, 3 \mathrm{H}), 3.28(\mathrm{td}, J=8.8,2.5 \mathrm{~Hz}, 1 \mathrm{H}), 3.10(\mathrm{dd}, J=10.9,3.6 \mathrm{~Hz}, 1 \mathrm{H}), 3.03$ (br. s, $1 \mathrm{H}$ ), 2.60 (d, $J=11.6 \mathrm{~Hz}, 1 \mathrm{H}$ ), 2.53 (q, $J=8.8 \mathrm{~Hz}, 1 \mathrm{H}$ ), 2.40 (ddd, $J=12.3,9.3,2.5 \mathrm{~Hz}, 1 \mathrm{H}$ ), $2.09(\mathrm{dd}, J=11.6,1.0 \mathrm{~Hz}, 1 \mathrm{H}), 2.06-1.87(\mathrm{~m}, 3 \mathrm{H}), 1.73(\mathrm{qd}, J=11.5,3.4 \mathrm{~Hz}, 1 \mathrm{H}), 1.54(\mathrm{~m}, 1 \mathrm{H}), 1.48$ - $1.34(\mathrm{~m}, 2 \mathrm{H}), 1.27(\mathrm{~m}, 1 \mathrm{H}), 1.01(\mathrm{dt}, J=12.2,3.1 \mathrm{~Hz}, 1 \mathrm{H}), 0.66(\mathrm{q}, J=11.7 \mathrm{~Hz}, 1 \mathrm{H})$.

${ }^{13} \mathrm{C}$ NMR: $\left(100 \mathrm{MHz}, \mathrm{CDCl}_{3}\right) \delta 179.4,175.4,163.1(\mathrm{~d}, J=247 \mathrm{~Hz}), 142.0,138.9(\mathrm{~d}, J=7.0 \mathrm{~Hz}), 133.5$, $130.6(\mathrm{~d}, J=8.3 \mathrm{~Hz}), 127.7,125.1,122.9(\mathrm{~d}, J=2.9 \mathrm{~Hz}), 122.8,114.7(\mathrm{~d}, J=21 \mathrm{~Hz}), 114.2(\mathrm{~d}, J=22$ $\mathrm{Hz}), 108.7,71.6,66.9,58.9,56.4,53.5,52.6,51.7(\mathrm{~d}, J=1.9 \mathrm{~Hz}), 43.6(\mathrm{~d}, J=1.7 \mathrm{~Hz}), 40.5,36.2,35.7$, 31.6, 30.7, 23.5 .

HRMS (ESI): calc. for $\mathrm{C}_{28} \mathrm{H}_{32} \mathrm{FN}_{2} \mathrm{O}_{4}[\mathrm{M}+\mathrm{H}]^{+}: 479.2341$, found: 479.2332 .

MP: $111-113^{\circ} \mathrm{C}$. 


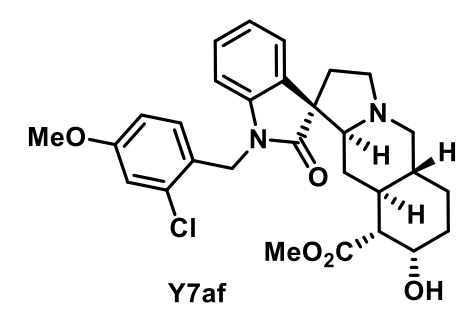

Yield: $80 \% ; 62.3 \mathrm{mg}$ of Y7af isolated as a colorless film.

'H NMR: $\left(400 \mathrm{MHz}, \mathrm{CDCl}_{3}\right) \delta 7.43(\mathrm{~d}, J=5.4 \mathrm{~Hz}, 1 \mathrm{H}), 7.15(\mathrm{td}, J=7.7,1.3$ $\mathrm{Hz}, 1 \mathrm{H}), 7.03(\mathrm{t}, J=7.5 \mathrm{~Hz}, 1 \mathrm{H}), 6.97(\mathrm{~d}, J=8.7 \mathrm{~Hz}, 1 \mathrm{H}), 6.92(\mathrm{~d}, J=2.6 \mathrm{~Hz}$, $1 \mathrm{H}), 6.74(\mathrm{dd}, J=8.6,2.6 \mathrm{~Hz}, 1 \mathrm{H}), 6.70(\mathrm{~d}, J=7.8 \mathrm{~Hz}, 1 \mathrm{H}), 5.07(\mathrm{~d}, J=16.1$ $\mathrm{Hz}, 1 \mathrm{H}), 4.84(\mathrm{~d}, J=16.1 \mathrm{~Hz}, 1 \mathrm{H}), 4.09(\mathrm{~m}, 1 \mathrm{H}), 3.76(\mathrm{~s}, 3 \mathrm{H}), 3.54(\mathrm{~s}, 3 \mathrm{H})$, $3.31(\mathrm{t}, J=8.0 \mathrm{~Hz}, 1 \mathrm{H}), 3.13(\mathrm{~d}, J=8.9 \mathrm{~Hz}, 1 \mathrm{H}), 2.91(\mathrm{~s}, 1 \mathrm{H}), 2.63(\mathrm{~d}, J=11.3 \mathrm{~Hz}, 1 \mathrm{H}), 2.55(\mathrm{q}, J=9.4$ $\mathrm{Hz}, 1 \mathrm{H}$ ), 2.41 (ddd, $J=12.0,9.3,2.4 \mathrm{~Hz}, 1 \mathrm{H}), 2.11(\mathrm{dd}, J=11.7,2.0 \mathrm{~Hz}, 1 \mathrm{H}), 2.08-1.89(\mathrm{~m}, 3 \mathrm{H}), 1.75$ (qd, $J=11.5,2.5 \mathrm{~Hz}, 1 \mathrm{H}), 1.61-1.21(\mathrm{~m}, 4 \mathrm{H}), 1.04(\mathrm{dt}, J=12.2,3.0 \mathrm{~Hz}, 1 \mathrm{H}), 0.68(\mathrm{~d}, J=12.3 \mathrm{~Hz}$, $1 \mathrm{H})$.

${ }^{13} \mathrm{C}$ NMR: $\left(125 \mathrm{MHz}, \mathrm{CDCl}_{3}\right) \delta 179.6,175.2,159.6,142.2,133.6,133.4,129.2,127.7,125.4,124.9$, $122.7,115.0,113.6,108.8,71.8,66.9,59.0,56.5,55.6,53.7,52.7,51.7,40.9,40.5,36.2$, 35.5, 31.6, $30.7,23.5$.

HRMS (ESI): calc. for $\mathrm{C}_{29} \mathrm{H}_{34} \mathrm{CIN}_{2} \mathrm{O}_{5}[\mathrm{M}+\mathrm{H}]^{+}: 525.2150$, found, 525.2155 .

MP: $63-65^{\circ} \mathrm{C}$.

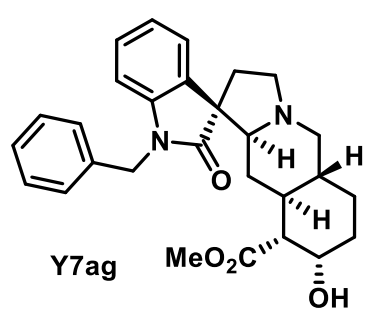

Yield: 93\%; $46.8 \mathrm{mg}$ of Y7ag isolated as a colorless foam.

${ }^{1} \mathrm{H}$ NMR: $\left(500 \mathrm{MHz}, \mathrm{CDCl}_{3}\right) \delta 7.40(\mathrm{~d}, J=7.3 \mathrm{~Hz}, 1 \mathrm{H}), 7.33-7.27(\mathrm{~m}, 2 \mathrm{H}), 7.25$ $-7.21(\mathrm{~m}, 3 \mathrm{H}), 7.13(\mathrm{t}, J=7.7 \mathrm{~Hz}, 1 \mathrm{H}), 7.01(\mathrm{t}, J=7.5 \mathrm{~Hz}, 1 \mathrm{H}), 6.69(\mathrm{~d}, J=7.8$ $\mathrm{Hz}, 1 \mathrm{H}), 5.09(\mathrm{~d}, J=15.6 \mathrm{~Hz}, 1 \mathrm{H}), 4.70(\mathrm{~d}, J=15.6 \mathrm{~Hz}, 1 \mathrm{H}), 4.08(\mathrm{~m}, 1 \mathrm{H}), 3.50$ (s, 3H), 3.29 (td, $J=8.7,2.4 \mathrm{~Hz}, 1 \mathrm{H}$ ), 3.11 (dd, $J=10.8,3.6 \mathrm{~Hz}, 1 \mathrm{H}$ ), 3.00 (br. s, 1H), 2.61 (dd, $J=11.3,2.5 \mathrm{~Hz}, 1 \mathrm{H}$ ), $2.54(\mathrm{q}, J=8.8 \mathrm{~Hz}, 1 \mathrm{H}$ ), 2.41 (ddd, $J=12.3,9.4,2.5 \mathrm{~Hz}, 1 \mathrm{H}$ ), 2.08 $(\mathrm{dd}, J=11.7,2.0 \mathrm{~Hz}, 1 \mathrm{H}), 2.02(\mathrm{dt}, J=12.9,8.4 \mathrm{~Hz}, 1 \mathrm{H}), 1.97-1.89(\mathrm{~m}, 2 \mathrm{H}), 1.74(\mathrm{qd}, J=11.5,3.4$ $\mathrm{Hz}, 1 \mathrm{H}), 1.55(\mathrm{~m}, 1 \mathrm{H}), 1.44(\mathrm{dt}, J=13.5,3.0 \mathrm{~Hz}, 1 \mathrm{H}), 1.38(\mathrm{~m}, 1 \mathrm{H}), 1.29(\mathrm{~m}, 1 \mathrm{H}), 1.00(\mathrm{dt}, J=12.3,3.1$ $\mathrm{Hz}, 1 \mathrm{H}), 0.64(\mathrm{q}, J=11.7 \mathrm{~Hz}, 1 \mathrm{H})$.

${ }^{13} \mathrm{C}$ NMR: $\left(125 \mathrm{MHz}, \mathrm{CDCl}_{3}\right) \delta 179.5,175.4,142.4,136.4,133.6,128.9,127.7,127.6,127.4,124.9$, 122.6, 108.8, 71.8, 66.9, 59.0, 56.5, 53.7, 52.7, 51.7, 44.0, 40.6, 36.3, 35.4, 31.5, 30.7, 23.6.

HRMS (ESI): calc. for $\mathrm{C}_{28} \mathrm{H}_{33} \mathrm{~N}_{2} \mathrm{O}_{4}[\mathrm{M}+\mathrm{H}]^{+}: 461.2434$, found: 461.2456 .

MP: $155-157^{\circ} \mathrm{C}$.

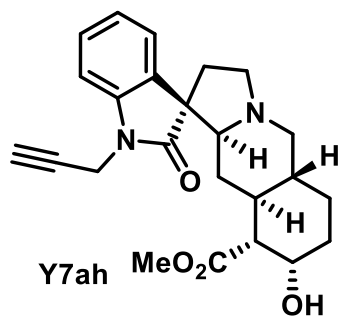

Yield: 82\%; $72.5 \mathrm{mg}$ of Y7ah isolated as a tan foam.

1H NMR: $\left(500 \mathrm{MHz}, \mathrm{CDCl}_{3}\right) \delta 7.39(\mathrm{~d}, J=7.4 \mathrm{~Hz}, 1 \mathrm{H}), 7.27(\mathrm{~m}, 1 \mathrm{H}), 7.07(\mathrm{t}, J=$ $7.5 \mathrm{~Hz}, 1 \mathrm{H}), 7.00(\mathrm{~d}, J=7.8 \mathrm{~Hz}, 1 \mathrm{H}), 4.55(\mathrm{dd}, J=17.7,2.5 \mathrm{~Hz}, 1 \mathrm{H}), 4.40(\mathrm{dd}, J=$ 17.7, $2.5 \mathrm{~Hz}, 1 \mathrm{H}), 4.06(\mathrm{~m}, 1 \mathrm{H}), 3.52(\mathrm{~s}, 3 \mathrm{H}), 3.26(\mathrm{t}, J=9.0 \mathrm{~Hz}, 1 \mathrm{H}), 3.12(\mathrm{~s}, 1 \mathrm{H})$, 3.08 (dd, $J=11.3,3.5 \mathrm{~Hz}, 1 \mathrm{H}$ ), $2.54-2.43(\mathrm{~m}, 2 \mathrm{H}$ ), 2.34 (ddd, $J=12.4,9.4,2.5$ $\mathrm{Hz}, 1 \mathrm{H}), 2.17$ (t, $J=2.5 \mathrm{~Hz}, 1 \mathrm{H}), 2.06(\mathrm{dd}, J=11.5,2.0 \mathrm{~Hz}, 1 \mathrm{H}), 1.97(\mathrm{dt}, J=13.2$, 
$8.5 \mathrm{~Hz}, 1 \mathrm{H}), 1.93-1.85(\mathrm{~m}, 2 \mathrm{H}), 1.68(\mathrm{qd}, J=11.4,3.3 \mathrm{~Hz}, 1 \mathrm{H}), 1.52(\mathrm{~m}, 1 \mathrm{H}), 1.41(\mathrm{~d}, J=14.2 \mathrm{~Hz}$, $1 \mathrm{H}), 1.36(\mathrm{~m}, 1 \mathrm{H}), 1.25(\mathrm{q}, J=10.8 \mathrm{~Hz}, 1 \mathrm{H}), 0.94(\mathrm{dt}, J=12.5,3.0 \mathrm{~Hz}, 1 \mathrm{H}), 0.59(\mathrm{q}, J=11.7 \mathrm{~Hz}, 1 \mathrm{H})$.

${ }^{13} \mathrm{C}$ NMR: $\left(125 \mathrm{MHz}, \mathrm{CDCl}_{3}\right) \delta 178.4,175.7,141.3,133.3,127.7,124.9,123.0,108.8,77.4,72.1,71.8$, $66.7,58.9,56.4,53.5,52.5,51.6,40.6,36.3,35.1,31.4,30.5,29.5,23.5$.

HRMS (ESI): calc. for $\mathrm{C}_{24} \mathrm{H}_{29} \mathrm{~N}_{2} \mathrm{O}_{4}[\mathrm{M}+\mathrm{H}]^{+}: 409.2122$, found: 409.2112 .

MP: $56-58^{\circ} \mathrm{C}$.

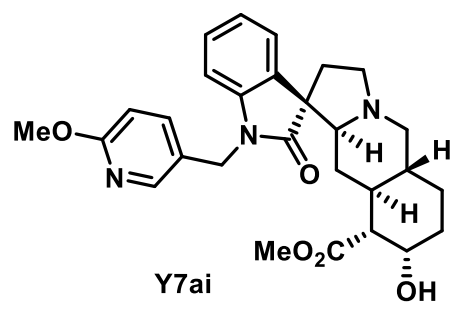

Yield: $47 \%$; $40.1 \mathrm{mg}$ of Y7ai isolated as a colorless film.

$3 \mathrm{H}$ ), 3.28 (t, $J=8.3 \mathrm{~Hz}, 1 \mathrm{H}$ ), $3.10(\mathrm{dd}, J=10.9,3.6 \mathrm{~Hz}, 1 \mathrm{H}), 3.00(\mathrm{br} \mathrm{s}, 1 \mathrm{H}), 2.57(\mathrm{~d}, J=11.2 \mathrm{~Hz}, 1 \mathrm{H}$ ), 2.52 (q, $J=8.8 \mathrm{~Hz}, 1 \mathrm{H}$ ), 2.38 (ddd, $J=12.4,9.4,2.5 \mathrm{~Hz}, 1 \mathrm{H}$ ), 2.06 (dd, $J=11.6,2.1 \mathrm{~Hz}, 1 \mathrm{H}), 2.00$ (m, $1 \mathrm{H}), 1.96-1.87(\mathrm{~m}, 2 \mathrm{H}), 1.71(\mathrm{qd}, J=11.5,3.5 \mathrm{~Hz}, 1 \mathrm{H}), 1.52(\mathrm{qd}, J=12.3,2.8 \mathrm{~Hz}, 1 \mathrm{H}), 1.43(\mathrm{dt}, J=$ 13.6, 3.0 Hz, 1H), $1.36(\mathrm{~m}, 1 \mathrm{H}), 1.25(\mathrm{~m}, 1 \mathrm{H}), 0.93(\mathrm{dt}, J=12.2,3.1 \mathrm{~Hz}, 1 \mathrm{H}), 0.59(\mathrm{q}, J=11.7 \mathrm{~Hz}, 1 \mathrm{H})$.

${ }^{13} \mathrm{C}$ NMR: $\left(125 \mathrm{MHz}, \mathrm{CDCl}_{3}\right) \delta 179.4,175.4,163.9,145.7,141.9,138.3,133.6,127.7,125.1,124.7$, 122.8, 111.6, 108.6, 71.8, 66.9, 59.0, 56.4, 53.6, 53.6, 52.6, 51.7, 41.0, 40.5, 36.3, 35.3, 31.5, 30.6, 23.6.

HRMS (ESI): calc. for $\mathrm{C}_{28} \mathrm{H}_{34} \mathrm{~N}_{3} \mathrm{O}_{5}[\mathrm{M}+\mathrm{H}]^{+}:$492.2493, found: 492.2486 .

MP: $49-51{ }^{\circ} \mathrm{C}$.
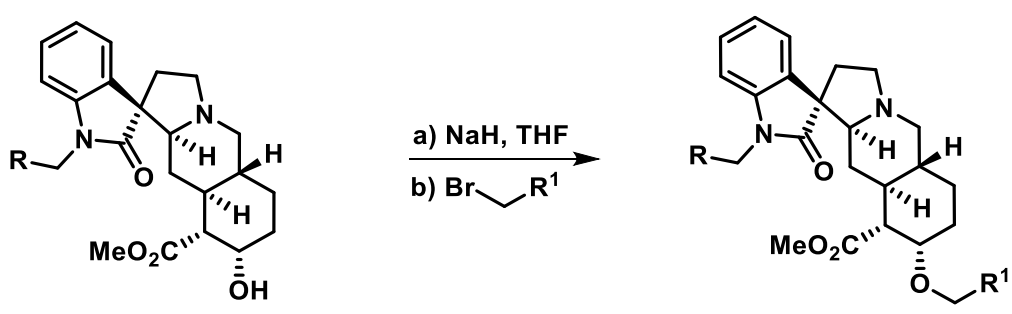

General procedure for the synthesis of mixed functionalized products Y7aj - Y7am. Tetrahydrofuran $(1.7 \mathrm{~mL})$ was added to a round-bottom flask followed by sodium hydride $(8.4 \mathrm{mg}, 0.21$ $\mathrm{mmol}, 60 \%$ dispersion in mineral oil). The mixture was cooled to $0{ }^{\circ} \mathrm{C}$ and then Y7ag $(64.3 \mathrm{mg}, 0.14$ $\mathrm{mmol}$ ) dissolved in $0.3 \mathrm{~mL}$ of tetrahydrofuran was added and allowed to stir for 10 minutes. Then, 2chloro-4-methoxybenzyl bromide $(36.2 \mathrm{mg}, 0.15 \mathrm{mmol})$ was added to the reaction mixture, which was allowed to stir while warming to room temperature over 7 hours. Upon completion, the reaction was quenched via brine and extracted with ethyl acetate. The organic layers were then collected, dried with sodium sulfate, filtered and concentrated. The crude product was purified via column chromatography using hexanes:ethyl acetate:triethylamine $66: 33: 1$ to $49.5: 49.5: 1$ to afford Y7aj (62.0 $\mathrm{mg}, 72 \%$ ) as a colorless foam. 


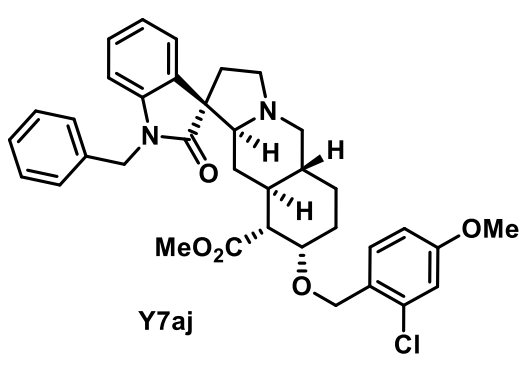

Yield: $72 \% ; 62.0 \mathrm{mg}$ of Y7aj isolated as a colorless film.

${ }^{1} \mathrm{H}$ NMR: $\left(500 \mathrm{MHz}, \mathrm{CDCl}_{3}\right) \delta 7.39(\mathrm{~d}, J=7.2 \mathrm{~Hz}, 1 \mathrm{H}), 7.35-7.28(\mathrm{~m}$, $3 \mathrm{H}), 7.25-7.19(\mathrm{~m}, 3 \mathrm{H}), 7.11(\mathrm{t}, J=7.8 \mathrm{~Hz}, 1 \mathrm{H}), 6.99(\mathrm{t}, J=7.6 \mathrm{~Hz}$, $1 \mathrm{H}), 6.87(\mathrm{~s}, 1 \mathrm{H}), 6.82(\mathrm{~d}, J=8.4 \mathrm{~Hz}, 1 \mathrm{H}), 6.65(\mathrm{~d}, J=7.8 \mathrm{~Hz}, 1 \mathrm{H}), 5.13$ $(\mathrm{d}, J=15.6 \mathrm{~Hz}, 1 \mathrm{H}), 4.67(\mathrm{~d}, J=15.6 \mathrm{~Hz}, 1 \mathrm{H}), 4.57(\mathrm{~d}, J=12.4 \mathrm{~Hz}, 1 \mathrm{H})$, $4.29(\mathrm{~d}, J=12.4 \mathrm{~Hz}, 1 \mathrm{H}), 3.96(\mathrm{~m}, 1 \mathrm{H}), 3.78(\mathrm{~s}, 3 \mathrm{H}), 3.50(\mathrm{~s}, 3 \mathrm{H}), 3.29$ (t, $J=7.2 \mathrm{~Hz}, 1 \mathrm{H}), 3.12(\mathrm{~d}, J=10.6 \mathrm{~Hz}, 1 \mathrm{H}), 2.69(\mathrm{~d}, J=10.9 \mathrm{~Hz}, 1 \mathrm{H}), 2.55(\mathrm{q}, J=8.9 \mathrm{~Hz}, 1 \mathrm{H}), 2.43$ (t, $J=11.2 \mathrm{~Hz}, 1 \mathrm{H}), 2.16(\mathrm{~d}, J=12.7 \mathrm{~Hz}, 1 \mathrm{H}), 2.11-2.01(\mathrm{~m}, 2 \mathrm{H}), 1.97(\mathrm{t}, J=11.3 \mathrm{~Hz}, 1 \mathrm{H}), 1.84(\mathrm{q}, J$ $=11.6 \mathrm{~Hz}, 1 \mathrm{H}), 1.50(\mathrm{~d}, J=12.4 \mathrm{~Hz}, 1 \mathrm{H}), 1.47-1.32(\mathrm{~m}, 3 \mathrm{H}), 1.27(\mathrm{~m}, 1 \mathrm{H}), 0.47(\mathrm{q}, J=11.7 \mathrm{~Hz}, 1 \mathrm{H})$.

${ }^{13} \mathrm{C}$ NMR: $\left(125 \mathrm{MHz}, \mathrm{CDCl}_{3}\right) \delta 179.5,172.5,159.6,142.5,136.3,133.8,133.4,130.2,129.0,128.4$, $127.6,127.5,127.3,124.8,122.4,114.7,112.9,108.8,75.5,72.1,67.2,59.1,56.4,55.7,53.9,52.8$, $51.4,44.0,40.5,36.1,35.4,31.1,28.1,23.8$.

HRMS (ESI): calc. for $\mathrm{C}_{36} \mathrm{H}_{40} \mathrm{CIN}_{2} \mathrm{O}_{5}[\mathrm{M}+\mathrm{H}]^{+}: 615.2620$, found: 615.2602 .

MP: $63-65^{\circ} \mathrm{C}$.

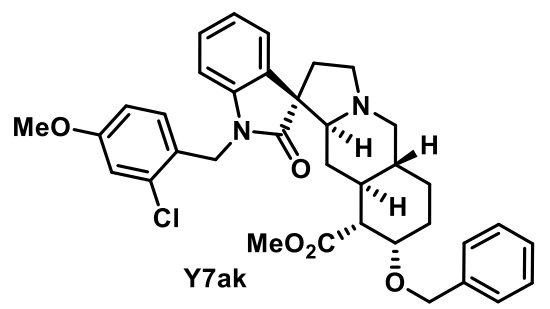

Yield: 79\%; $26.4 \mathrm{mg}$ of Y7ak isolated as a colorless film.

1H NMR: $\left(500 \mathrm{MHz}, \mathrm{CDCl}_{3}\right) \delta 7.40(\mathrm{~d}, J=7.3 \mathrm{~Hz}, 1 \mathrm{H}), 7.34-7.29(\mathrm{~m}$, $2 \mathrm{H}), 7.28-7.23(\mathrm{~m}, 3 \mathrm{H}), 7.13(\mathrm{t}, J=7.7 \mathrm{~Hz}, 1 \mathrm{H}), 7.03-6.97(\mathrm{~m}, 2 \mathrm{H})$, $6.92(\mathrm{~d}, J=2.6 \mathrm{~Hz}, 1 \mathrm{H}), 6.81(\mathrm{dd}, J=8.6,2.7 \mathrm{~Hz}, 1 \mathrm{H}), 6.68(\mathrm{~d}, J=7.7$ $\mathrm{Hz}, 1 \mathrm{H}), 5.12(\mathrm{~d}, J=16.1 \mathrm{~Hz}, 1 \mathrm{H}), 4.81(\mathrm{~d}, J=16.1 \mathrm{~Hz}, 1 \mathrm{H}), 4.56(\mathrm{~d}, J$ $=12.2 \mathrm{~Hz}, 1 \mathrm{H}), 4.29(\mathrm{~d}, J=12.2 \mathrm{~Hz}, 1 \mathrm{H}), 3.93(\mathrm{~m}, 1 \mathrm{H}), 3.75(\mathrm{~s}, 3 \mathrm{H}), 3.48(\mathrm{~s}, 3 \mathrm{H}), 3.31(\mathrm{t}, J=8.7 \mathrm{~Hz}$, $1 \mathrm{H}), 3.12$ (dd, $J=10.7,3.4 \mathrm{~Hz}, 1 \mathrm{H}), 2.70(\mathrm{~d}, J=11.0 \mathrm{~Hz}, 1 \mathrm{H}), 2.55(\mathrm{q}, J=8.8 \mathrm{~Hz}, 1 \mathrm{H}), 2.43$ (ddd, $J=$ 11.9, 9.5, $2.2 \mathrm{~Hz}, 1 \mathrm{H}), 2.11-2.01(\mathrm{~m}, 3 \mathrm{H}), 1.98(\mathrm{t}, J=10.7 \mathrm{~Hz}, 1 \mathrm{H}), 1.85(\mathrm{q}, J=10.9 \mathrm{~Hz}, 1 \mathrm{H}), 1.53$ (dd, $J=12.0,2.8 \mathrm{~Hz}, 1 \mathrm{H}), 1.45(\mathrm{~m}, 1 \mathrm{H}), 1.40-1.21(\mathrm{~m}, 3 \mathrm{H}), 0.48(\mathrm{q}, J=11.6 \mathrm{~Hz}, 1 \mathrm{H})$.

${ }^{13} \mathrm{C}$ NMR: $\left(125 \mathrm{MHz}, \mathrm{CDCl}_{3}\right) \delta 179.6,172.5,159.5,142.3,138.7,133.6,133.4,129.2,128.4,127.6$, $127.6,127.5,125.3,124.8,122.5,114.9,113.9,108.8,74.9,72.1,70.4,59.0,56.5,55.6,53.8,52.6$, $51.3,40.7,40.4,36.0,35.4,31.1,28.0,23.8$.

HRMS (ESI): calc. for $\mathrm{C}_{36} \mathrm{H}_{40} \mathrm{CIN}_{2} \mathrm{O}_{5}[\mathrm{M}+\mathrm{H}]^{+}: 615.2620$, found: 615.2640 .

MP: $54-56^{\circ} \mathrm{C}$.

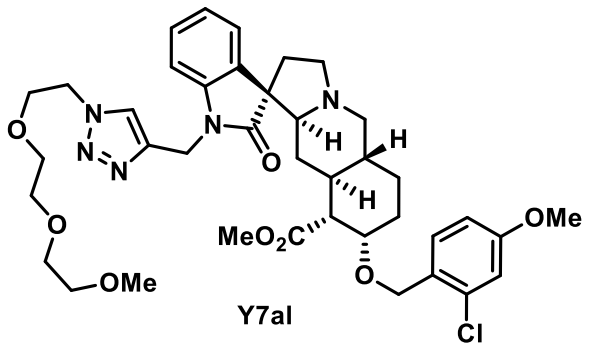

Yield: $57 \% ; 37.9 \mathrm{mg}$ of $\mathrm{Y7al}$ isolated as a colorless, amorphous solid.

'H NMR: $\left(500 \mathrm{MHz}, \mathrm{CDCl}_{3}\right) \delta 7.58(\mathrm{~s}, 1 \mathrm{H}), 7.33(\mathrm{~m}, 1 \mathrm{H}), 7.28(\mathrm{~m}$, $1 \mathrm{H}), 7.17(\mathrm{t}, J=7.6 \mathrm{~Hz}, 1 \mathrm{H}), 7.03(\mathrm{~d}, J=7.6 \mathrm{~Hz}, 1 \mathrm{H}), 6.98(\mathrm{t}, J=7.6$ $\mathrm{Hz}, 1 \mathrm{H}), 6.85(\mathrm{~s}, 1 \mathrm{H}), 6.79(\mathrm{~d}, J=8.7 \mathrm{~Hz}, 1 \mathrm{H}), 5.08(\mathrm{~d}, J=15.8 \mathrm{~Hz}$, 1H), $4.91(\mathrm{~d}, J=15.8 \mathrm{~Hz}, 1 \mathrm{H}), 4.58-4.45(\mathrm{~m}, 3 \mathrm{H}), 4.26(\mathrm{~d}, J=12.5$ 
$\mathrm{Hz}, 1 \mathrm{H}), 3.94(\mathrm{~m}, 1 \mathrm{H}), 3.87-3.80(\mathrm{~m}, 2 \mathrm{H}), 3.77(\mathrm{~s}, 3 \mathrm{H}), 3.59-3.48(\mathrm{~m}, 8 \mathrm{H}), 3.45(\mathrm{~s}, 3 \mathrm{H}), 3.35(\mathrm{~s}, 3 \mathrm{H})$, $3.27(\mathrm{t}, J=8.5 \mathrm{~Hz}, 1 \mathrm{H}), 3.09(\mathrm{~d}, J=10.7 \mathrm{~Hz}, 1 \mathrm{H}), 2.58(\mathrm{~d}, J=11.1 \mathrm{~Hz}, 1 \mathrm{H}), 2.49(\mathrm{q}, J=9.4,8.8 \mathrm{~Hz}$, $1 \mathrm{H}), 2.34(\mathrm{t}, J=11.3 \mathrm{~Hz}, 1 \mathrm{H}), 2.14(\mathrm{~d}, J=11.9 \mathrm{~Hz}, 1 \mathrm{H}), 2.07-1.88(\mathrm{~m}, 4 \mathrm{H}), 1.75(\mathrm{q}, J=11.6 \mathrm{~Hz}, 1 \mathrm{H})$, $1.43-1.30(\mathrm{~m}, 3 \mathrm{H}), 1.23(\mathrm{~m}, 1 \mathrm{H}), 0.37(\mathrm{q}, J=11.8 \mathrm{~Hz}, 1 \mathrm{H})$.

'H NMR: $\left(500 \mathrm{MHz}, d_{6}\right.$-DMSO) $\delta 7.88(\mathrm{~s}, 1 \mathrm{H}), 7.32-7.25(\mathrm{~m}, 2 \mathrm{H}), 7.19$ (t, $\left.J=7.7 \mathrm{~Hz}, 1 \mathrm{H}\right), 7.03$ (d, $J$ $=7.9 \mathrm{~Hz}, 1 \mathrm{H}), 7.01-6.97(\mathrm{~m}, 2 \mathrm{H}), 6.91(\mathrm{dd}, J=8.5,2.5 \mathrm{~Hz}, 1 \mathrm{H}), 4.96(\mathrm{~d}, J=15.0 \mathrm{~Hz}, 1 \mathrm{H}), 4.91(\mathrm{~d}, J$ $=15.0 \mathrm{~Hz}, 1 \mathrm{H}), 4.52-4.41(\mathrm{~m}, 3 \mathrm{H}), 4.19(\mathrm{~d}, J=11.9 \mathrm{~Hz}, 1 \mathrm{H}), 3.87(\mathrm{~m}, 1 \mathrm{H}), 3.78(\mathrm{~m}, 1 \mathrm{H}), 3.76(\mathrm{~s}, 3 \mathrm{H})$, $3.49-3.37(\mathrm{~m}, 12 \mathrm{H}), 3.22(\mathrm{~s}, 3 \mathrm{H}), 3.07(\mathrm{~d}, J=10.6 \mathrm{~Hz}, 1 \mathrm{H}), 2.40-2.29(\mathrm{~m}, 2 \mathrm{H}), 2.20(\mathrm{t}, J=11.1 \mathrm{~Hz}$, $1 \mathrm{H}), 2.15(\mathrm{~d}, J=11.9 \mathrm{~Hz}, 1 \mathrm{H}), 2.07(\mathrm{~d}, J=13.5 \mathrm{~Hz}, 1 \mathrm{H}), 1.85(\mathrm{~m}, 1 \mathrm{H}), 1.78(\mathrm{t}, J=10.0 \mathrm{~Hz}, 1 \mathrm{H}), 1.50$ $(\mathrm{q}, J=10.5 \mathrm{~Hz}, 1 \mathrm{H}), 1.39(\mathrm{t}, J=12.5 \mathrm{~Hz}, 1 \mathrm{H}), 1.34-1.17(\mathrm{~m}, 5 \mathrm{H}), 0.32(\mathrm{q}, J=11.6 \mathrm{~Hz}, 1 \mathrm{H})$.

${ }^{13} \mathrm{C}$ NMR: $\left(125 \mathrm{MHz}, \mathrm{CDCl}_{3}\right) \delta 179.2,172.5,159.6,143.3,141.9,133.5,130.3,128.3,127.7,124.7$, $123.5,122.5,114.6,112.9,109.0,75.3,72.4,72.1,70.7,70.7,70.7,69.5,67.1,59.2,59.1,56.3,55.7$, $54.0,52.4,51.4,50.3,40.4,36.1,35.8,35.1,30.9,28.0,23.8$. Note: Missing one aromatic ${ }^{13} \mathrm{C}$ NMR signal, most likely due to signal overlap.

${ }^{13} \mathrm{C}$ NMR: $\left(125 \mathrm{MHz}, d_{6}\right.$-DMSO) $\delta 177.8,171.8,159.4,142.0,141.7,133.0,132.9,130.9,127.6,127.4$, $124.1,123.3,122.1,114.3,113.0,108.8,74.7,71.5,71.2,69.6,69.5,69.5,68.6,66.5,58.5,58.0,55.5$, 55.4 , 53.0, 51.0, 50.9, 49.4, 35.8, 34.8, 34.6, 30.1, 26.9, 23.2. Notes: Missing one aliphatic ${ }^{13} \mathrm{C}$ NMR signal. Have HSQC of this compound in $d_{6}$-DMSO.

HRMS (ESI): calc. for $\mathrm{C}_{39} \mathrm{H}_{51} \mathrm{CIN}_{5} \mathrm{O}_{8}[\mathrm{M}+\mathrm{H}]^{+}:$752.3421, found: 752.3453 .

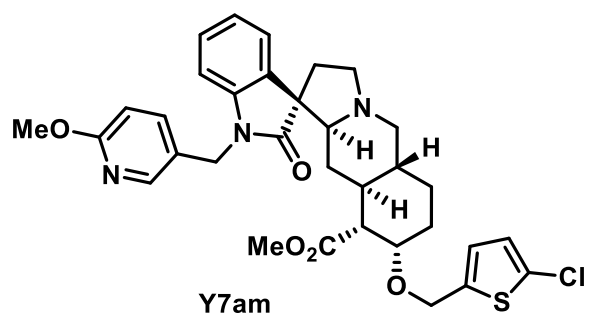

$15.4 \mathrm{~Hz}, 1 \mathrm{H}), 4.59(\mathrm{~d}, J=15.4 \mathrm{~Hz}, 1 \mathrm{H}), 4.57(\mathrm{~d}, J=12.8 \mathrm{~Hz}, 1 \mathrm{H}), 4.34(\mathrm{~d}, J=12.8 \mathrm{~Hz}, 1 \mathrm{H}), 3.93(\mathrm{~m}$, $1 \mathrm{H}), 3.89(\mathrm{~s}, 3 \mathrm{H}), 3.53(\mathrm{~s}, 3 \mathrm{H}), 3.27(\mathrm{t}, J=7.8 \mathrm{~Hz}, 1 \mathrm{H}), 3.09(\mathrm{~d}, J=9.5 \mathrm{~Hz}, 1 \mathrm{H}), 2.63(\mathrm{~d}, J=11.0 \mathrm{~Hz}$, 1H), $2.52(\mathrm{q}, J=8.4 \mathrm{~Hz}, 1 \mathrm{H}), 2.39(\mathrm{t}, J=11.2 \mathrm{~Hz}, 1 \mathrm{H}), 2.07-1.97(\mathrm{~m}, 3 \mathrm{H}), 1.94(\mathrm{t}, J=11.1 \mathrm{~Hz}, 1 \mathrm{H})$, $1.74(\mathrm{q}, J=11.6 \mathrm{~Hz}, 1 \mathrm{H}), 1.45-1.28(\mathrm{~m}, 4 \mathrm{H}), 1.22(\mathrm{~m}, 1 \mathrm{H}), 0.37(\mathrm{q}, J=11.6 \mathrm{~Hz}, 1 \mathrm{H})$.

${ }^{13} \mathrm{C}$ NMR: $\left(125 \mathrm{MHz}, \mathrm{CDCl}_{3}\right) \delta 179.5,172.3,164.0,145.8,142.0,140.4,138.5,133.8,130.3,127.6$, $125.7,125.4,125.0,124.9,122.6,112.0,108.6,74.8,72.2,65.4,59.0,56.4,53.8,53.6,52.5,51.6$, $41.0,40.4,36.0,35.2,31.0,28.0,23.7$.

HRMS (ESI): calc. for $\mathrm{C}_{33} \mathrm{H}_{37} \mathrm{CIN}_{3} \mathrm{O}_{5} \mathrm{~S}[\mathrm{M}+\mathrm{H}]^{+}:$622.2136, found: 622.2167 . 


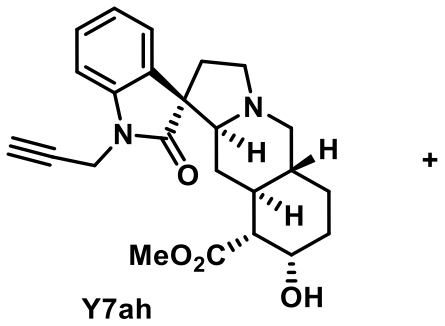

Y7ah
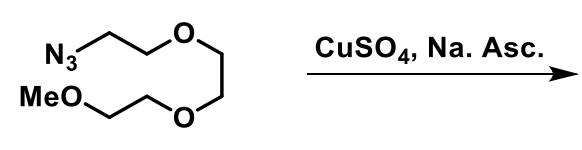

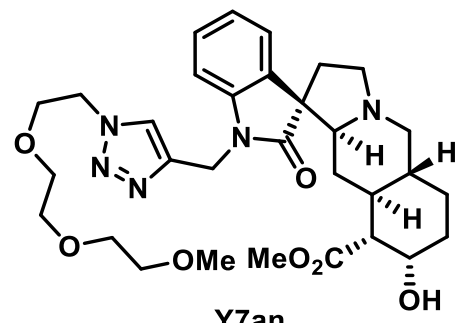

Y7an

Procedure for the synthesis of intermediate Y7an. Anhydrous copper sulfate $(11.7 \mathrm{mg}, 0.07 \mathrm{mmol})$ and sodium ascorbate $(45.3 \mathrm{mg}, 0.23 \mathrm{mmol})$ were added to a vial and dissolved in a 1:2 solution of tertbutanol:water $(4.2 \mathrm{~mL})$. This mixture was then added to a round-bottom flask containing Y7ah (63.5 $\mathrm{mg}, 0.16 \mathrm{mmol})$. Then, PEG-azide $(88.2 \mathrm{mg}, 0.47 \mathrm{mmol})$ was added to the reaction, followed by dichloromethane $(3 \mathrm{~mL})$. The reaction was then vigorously stirred at room temperature for 20 hours. Upon completion, the biphasic reaction mixture was quenched with brine and the product was extracted with dichloromethane using a separatory funnel. The organic layers were then collected, dried with sodium sulfate, filtered and concentrated. The crude product was purified via column chromatography using 99:1 ethyl acetate:triethylamine to ethyl acetate:methanol:triethylamine 97.5:1.5:1 to afford Y7an (54.2 $\mathrm{mg}, 58 \%)$ as a colorless, amorphous solid.

'H NMR: $\left(500 \mathrm{MHz}, \mathrm{CDCl}_{3}\right) \delta 7.61(\mathrm{~s}, 1 \mathrm{H}), 7.32(\mathrm{~d}, J=7.3 \mathrm{~Hz}, 1 \mathrm{H}), 7.18(\mathrm{t}, J=7.8 \mathrm{~Hz}, 1 \mathrm{H}), 7.06(\mathrm{~d}, J$ $=7.9 \mathrm{~Hz}, 1 \mathrm{H}), 6.99(\mathrm{t}, J=7.6 \mathrm{~Hz}, 1 \mathrm{H}), 5.01-4.90(\mathrm{~m}, 2 \mathrm{H}), 4.46(\mathrm{t}, J=5.1 \mathrm{~Hz}, 2 \mathrm{H}), 4.06(\mathrm{~s}, 1 \mathrm{H}), 3.81$ (t, $J=5.2 \mathrm{~Hz}, 2 \mathrm{H}), 3.59-3.52(\mathrm{~m}, 6 \mathrm{H}), 3.52-3.49(\mathrm{~m}, 2 \mathrm{H}), 3.48(\mathrm{~s}, 3 \mathrm{H}), 3.34(\mathrm{~s}, 3 \mathrm{H}), 3.24(\mathrm{t}, J=8.8$ $\mathrm{Hz}, 1 \mathrm{H}), 3.07(\mathrm{~d}, J=10.8 \mathrm{~Hz}, 1 \mathrm{H}), 2.95(\mathrm{~s}, 1 \mathrm{H}), 2.52-2.42(\mathrm{~m}, 2 \mathrm{H}), 2.31(\mathrm{t}, J=11.2 \mathrm{~Hz}, 1 \mathrm{H}), 2.03(\mathrm{~d}$, $J=11.7 \mathrm{~Hz}, 1 \mathrm{H}), 1.95(\mathrm{q}, J=10.3 \mathrm{~Hz}, 1 \mathrm{H}), 1.91-1.83(\mathrm{~m}, 2 \mathrm{H}), 1.64(\mathrm{q}, J=11.5 \mathrm{~Hz}, 1 \mathrm{H}), 1.48(\mathrm{~m}$, $1 \mathrm{H}), 1.41(\mathrm{~m}, 1 \mathrm{H}), 1.34(\mathrm{~m}, 1 \mathrm{H}), 1.23(\mathrm{q}, J=8.7 \mathrm{~Hz}, 1 \mathrm{H}), 0.86(\mathrm{~d}, J=12.3 \mathrm{~Hz}, 1 \mathrm{H}), 0.51(\mathrm{q}, J=11.9$ $\mathrm{Hz}, 1 \mathrm{H})$.

${ }^{13} \mathrm{C}$ NMR: $\left(125 \mathrm{MHz}, \mathrm{CDCl}_{3}\right) \delta 179.0,175.2,143.1,141.9,133.2,127.8,124.7,123.6,122.6,109.0$, $72.0,72.0,70.7,70.6,70.6,69.5,66.9,59.1,59.0,56.3,53.7,52.5,51.6,50.4,40.5,36.1,35.7,35.0$, 31.6, 30.5, 23.5 .

HRMS (ESI): calc. for $\mathrm{C}_{31} \mathrm{H}_{44} \mathrm{~N}_{5} \mathrm{O}_{7}[\mathrm{M}+\mathrm{H}]^{+}:$598.3235, found: 598.3255 . 
3. Supporting Figure 1. Dose-dependent antiplasmodial activity for selected yohimbine analogues in chloroquine-resistant $(\mathrm{Dd} 2)$ cells.
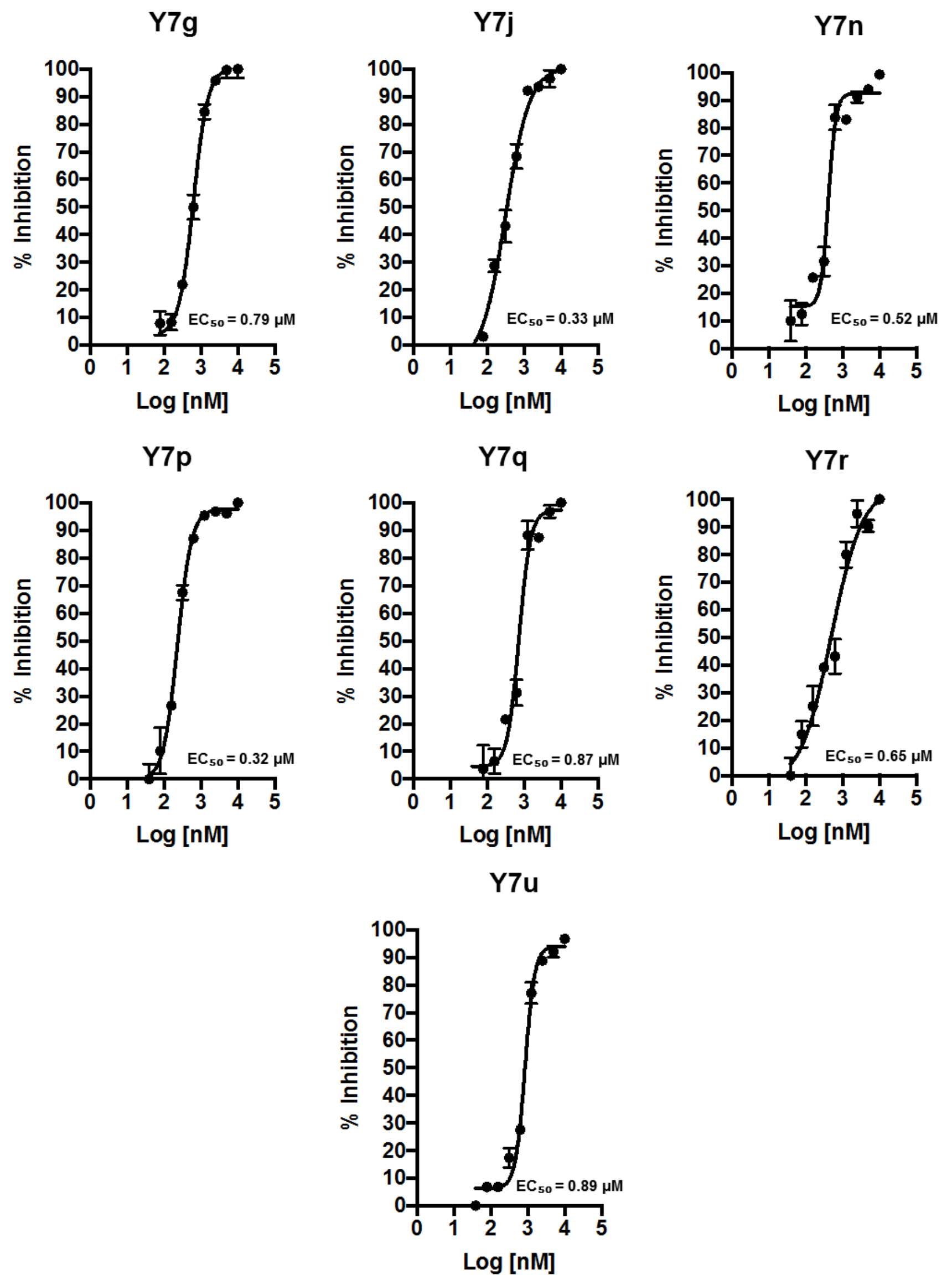
4. Supporting Figure 2. Dose-dependent antiplasmodial activity for selected yohimbine analogues in chloroquine-sensitive (3D7) cells.
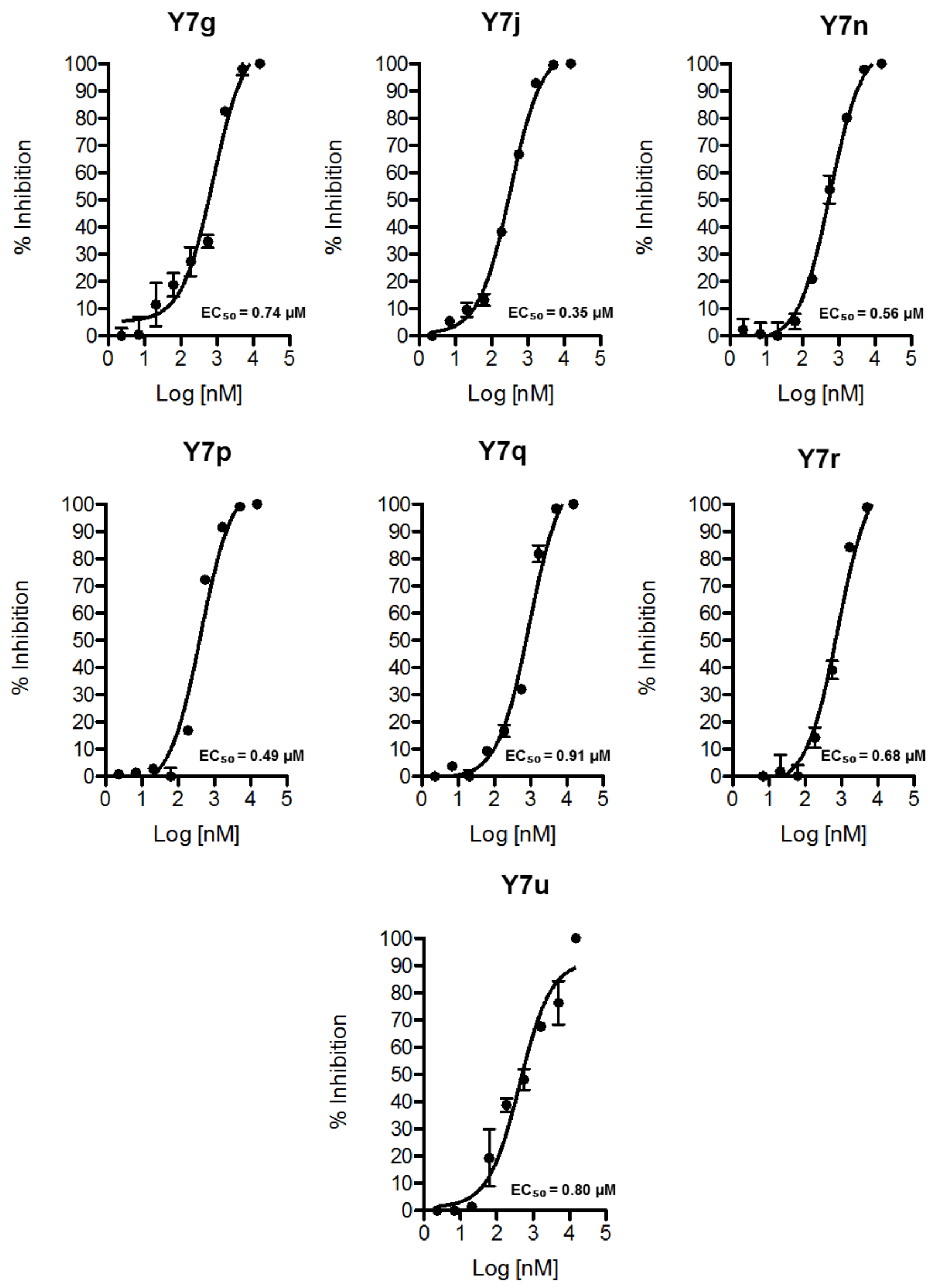
5. Supporting Table 1. Summary of antiplasmodial activities and cytotoxicity against HepG2 (liver) cells for $\mathbf{Y}$ and relevant $\mathbf{Y} 1$ and $\mathbf{Y} 7$ analogues. All concentrations are reported in micromolar $(\mu \mathrm{M})$.

\begin{tabular}{|c|c|c|c|c|c|}
\hline Y Code & $\begin{array}{c}E_{5 C_{50} \text { Dd2 cells }} \\
(\mu \mathrm{M})\end{array}$ & $\begin{array}{l}\mathrm{EC}_{50} \text { 3D7 } \\
\text { cells }(\mu \mathrm{M})\end{array}$ & $\begin{array}{c}\mathrm{EC}_{50} \text { HepG2 } \\
\text { cells }(\mu \mathrm{M})\end{array}$ & $\begin{array}{l}\text { Selectivity } \\
\text { Index (SI) }\end{array}$ & $\begin{array}{c}\text { Stage-Specific } \\
\text { Activity }\end{array}$ \\
\hline $\mathbf{Y}$ & $76.7 \pm 0.74$ & & $>100$ & - & n.a. \\
\hline Y1c & $2.58 \pm 0.07$ & - & - & - & - \\
\hline Y1d & $5.18 \pm 0.10$ & - & - & - & - \\
\hline Y1e & $2.98 \pm 0.20$ & - & - & - & - \\
\hline Y1f & $1.60 \pm 0.16$ & - & 18.9 & 12 & A \\
\hline Y1g & $3.18 \pm 0.11$ & - & - & - & - \\
\hline Y1h & $3.47 \pm 0.11$ & - & - & - & - \\
\hline Y1i & $>20$ & - & - & - & - \\
\hline Y1j & $>20$ & - & - & - & - \\
\hline Y7e & $1.50 \pm 0.09$ & - & - & - & - \\
\hline Y7f & $1.41 \pm 0.23$ & - & - & - & - \\
\hline Y7g & $0.79 \pm 0.06$ & $0.74 \pm 0.07$ & $>40$ & $>51$ & A \\
\hline Y7h & $1.05 \pm 0.08$ & - & - & - & - \\
\hline Y7i & $0.85 \pm 0.05$ & - & - & - & - \\
\hline Y7j & $0.33 \pm 0.03$ & $0.35 \pm 0.03$ & $>40$ & $>121$ & A \\
\hline Y7k & $0.64 \pm 0.07$ & $0.68 \pm 0.07$ & - & - & - \\
\hline Y7I & $2.57 \pm 0.05$ & - & - & - & - \\
\hline Y7m & $1.51 \pm 0.06$ & - & - & - & - \\
\hline Y7n & $0.52 \pm 0.04$ & $0.56 \pm 0.04$ & $>40$ & $>77$ & - \\
\hline Y7o & $3.51 \pm 0.32$ & - & - & - & - \\
\hline Y7p & $0.32 \pm 0.02$ & $0.49 \pm 0.05$ & $>40$ & $>125$ & A \\
\hline Y7q & $0.87 \pm 0.04$ & $0.91 \pm 0.03$ & $>40$ & $>46$ & - \\
\hline Y7r & $0.65 \pm 0.07$ & $0.68 \pm 0.09$ & $>40$ & $>62$ & - \\
\hline Y7s & $1.32 \pm 0.07$ & $1.13 \pm 0.09$ & - & - & - \\
\hline Y7t & $3.08 \pm 0.20$ & $4.31 \pm 0.16$ & - & - & - \\
\hline Y7u & $0.89 \pm 0.05$ & $0.80 \pm 0.09$ & $>40$ & $>45$ & - \\
\hline Y7v & $8.30 \pm 0.10$ & - & - & - & - \\
\hline Y7x & $>20$ & - & - & - & - \\
\hline Y7aa & $>20$ & - & - & - & - \\
\hline Y7ab & $>20$ & - & - & - & - \\
\hline Y7ac & $>20$ & - & - & - & - \\
\hline Y7ad & $>20$ & - & - & - & - \\
\hline Y7ae & $>20$ & - & - & - & - \\
\hline Y7af & $>20$ & - & - & - & - \\
\hline Y7aj & $2.38 \pm 0.24$ & - & - & - & - \\
\hline Y7ak & $0.94 \pm 0.10$ & - & - & - & - \\
\hline Y7al & $>20$ & - & - & - & - \\
\hline Y7am & $2.71 \pm 0.07$ & $3.00 \pm 0.13$ & - & - & - \\
\hline
\end{tabular}

Notes: "A" = stage-specific activity at the late ring/trophozoite phase of asexual blood stage $P$. falciparum. "n.a." $=$ yohimbine $(\mathrm{Y})$, which is inactive against $P$. falciparum. "-" = noted for analogues that were not tested for stage specific activity. Selectivity Index (SI) was generated according to $\mathrm{EC}_{50}$ against HepG2 cells divided by $\mathrm{EC}_{50}$ against Dd2 cells. All values reported in this table resulted from three independent experiments. 


\section{Kill Kinetics for Y1f, DHA and Atovaquone.}

Kill kinetics for analogue Y1f and comparator agents DHA and Atovaquone tested against Dd2 cells are included below. Each compound was tested at $5 \times \mathrm{EC}_{50}$ value in these experiments (test concentrations: DHA, $50 \mathrm{nM}$; Atovaquone, $6.6 \mathrm{nM}$ ).
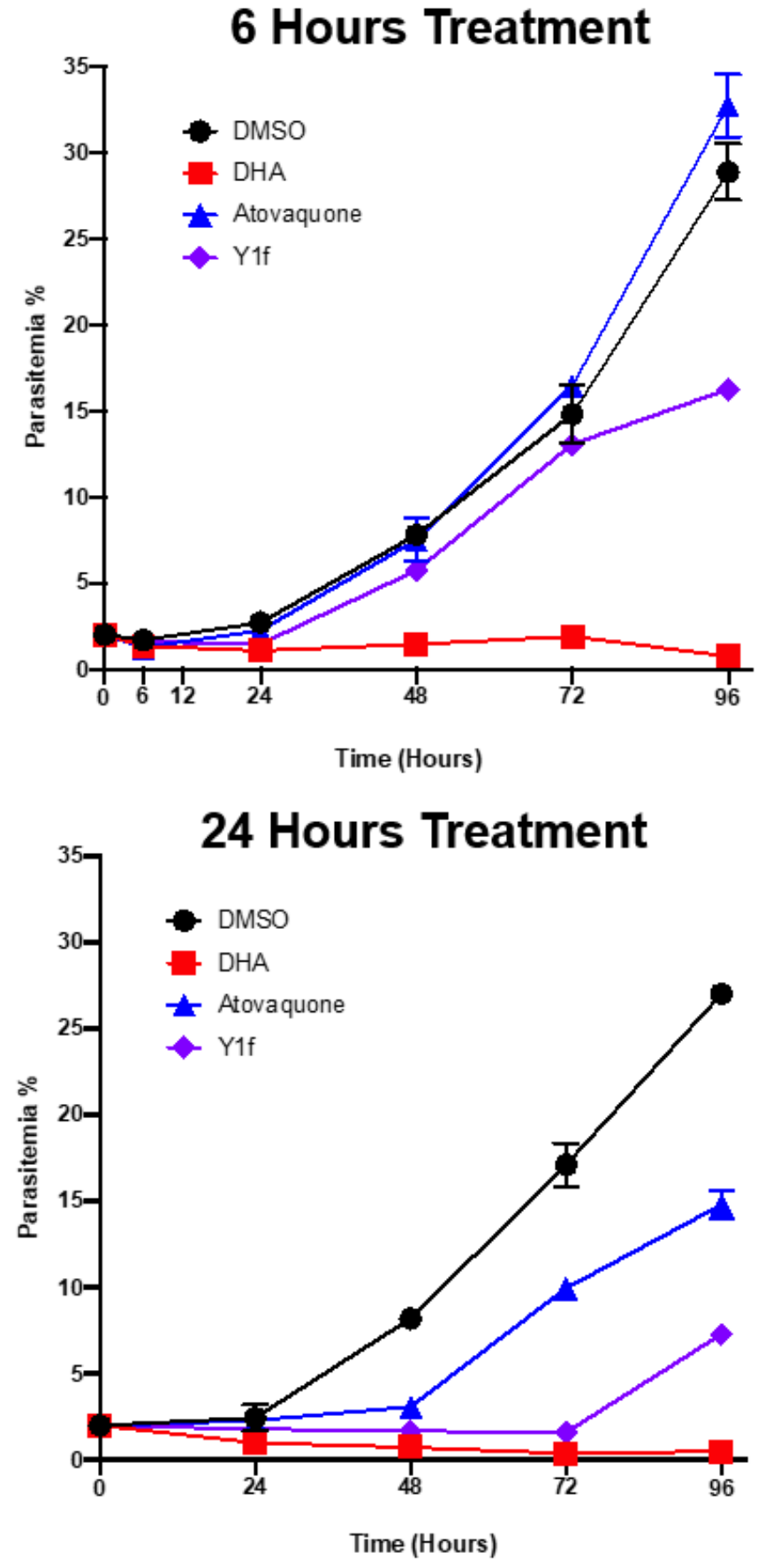

12 Hours Treatment
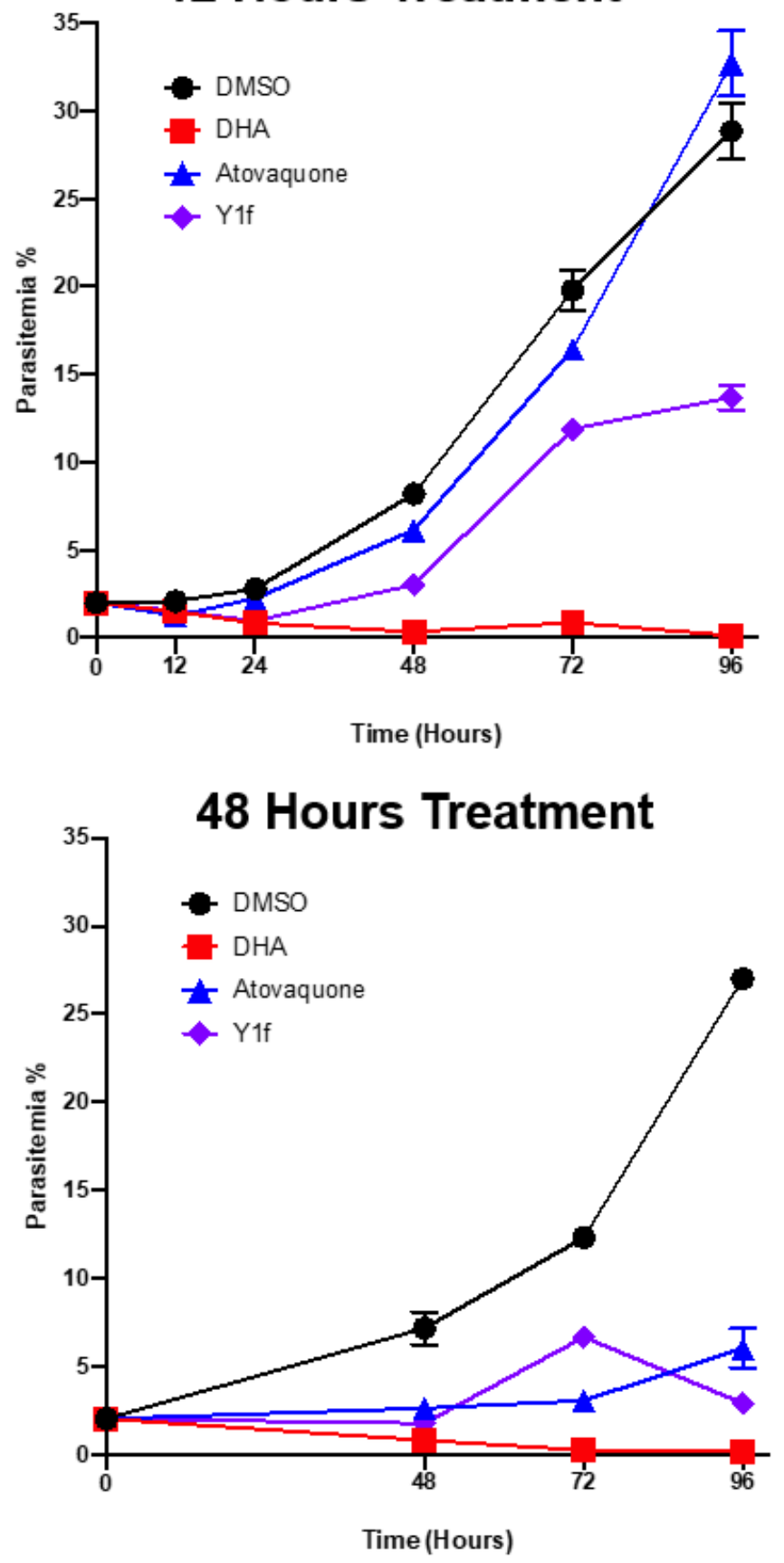


\section{Stage Specific Activity for Y1f.}

Y1f reports the same stage specific action as Y7j (late ring/trophozoite phase of asexual blood stage $P$. falciparum). In addition, Y1f also induces vacuolization in these experiments.

A

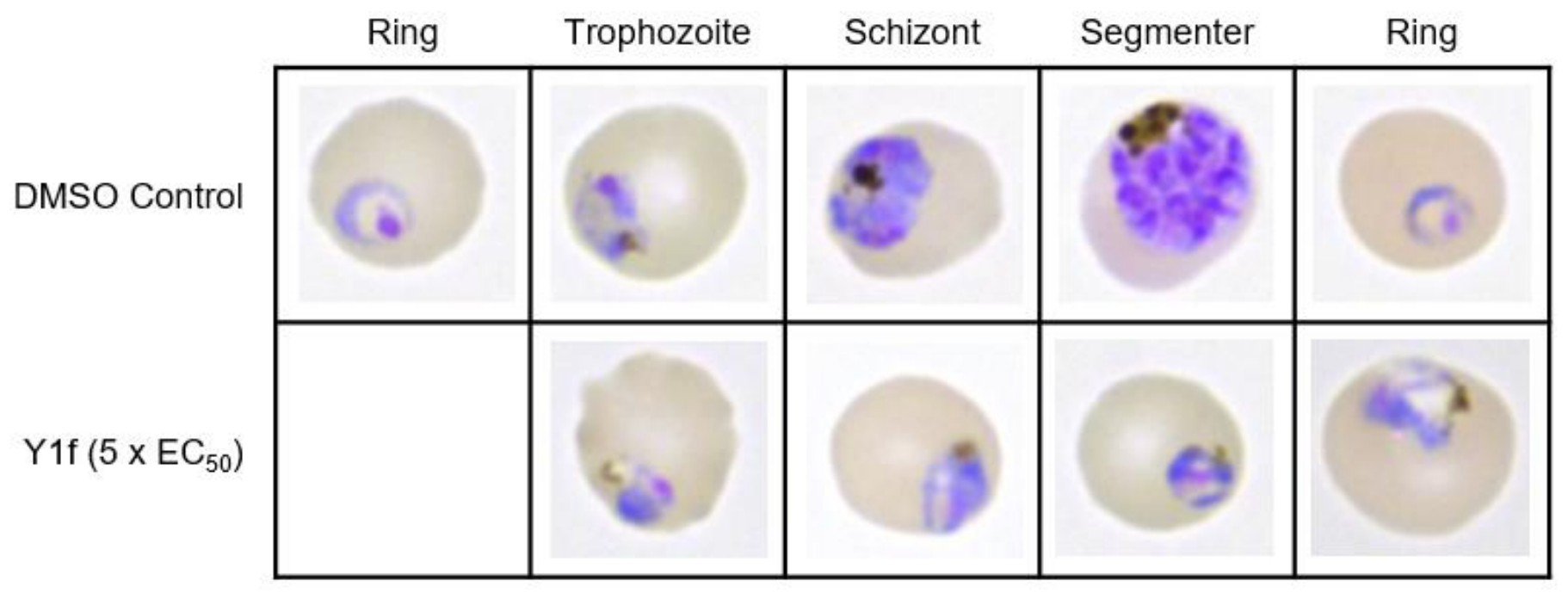

B

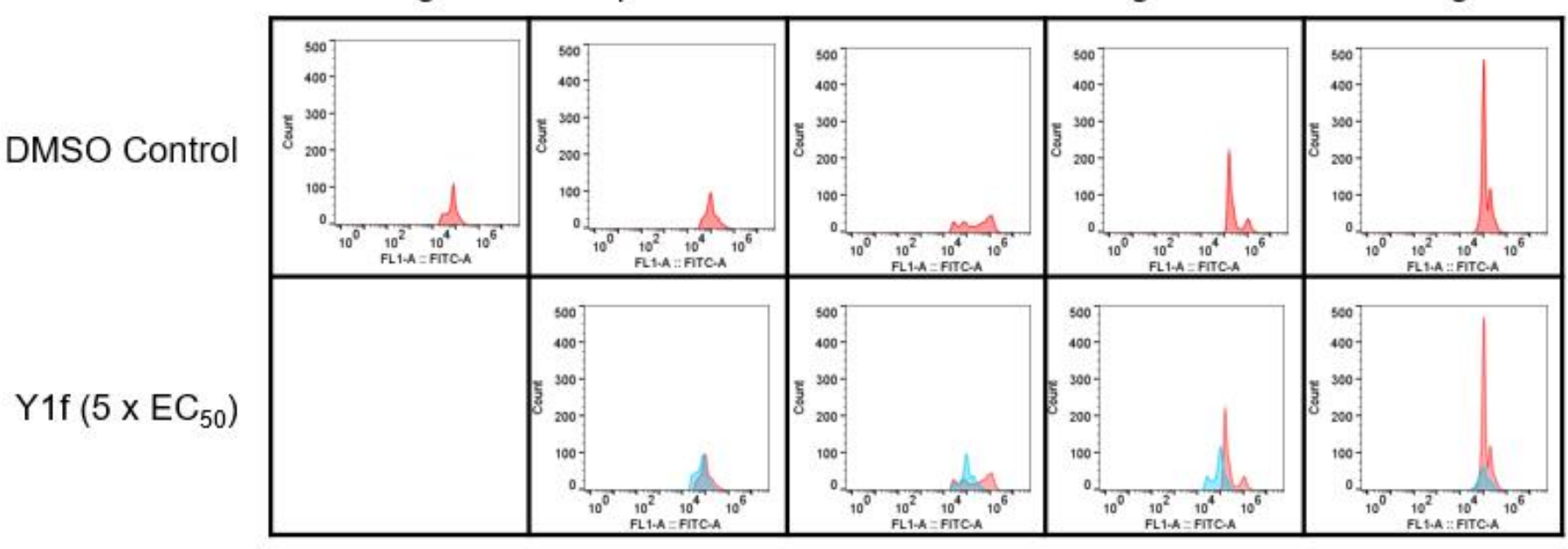

DMSO Control

Treated 
8. NMR Spectra. 


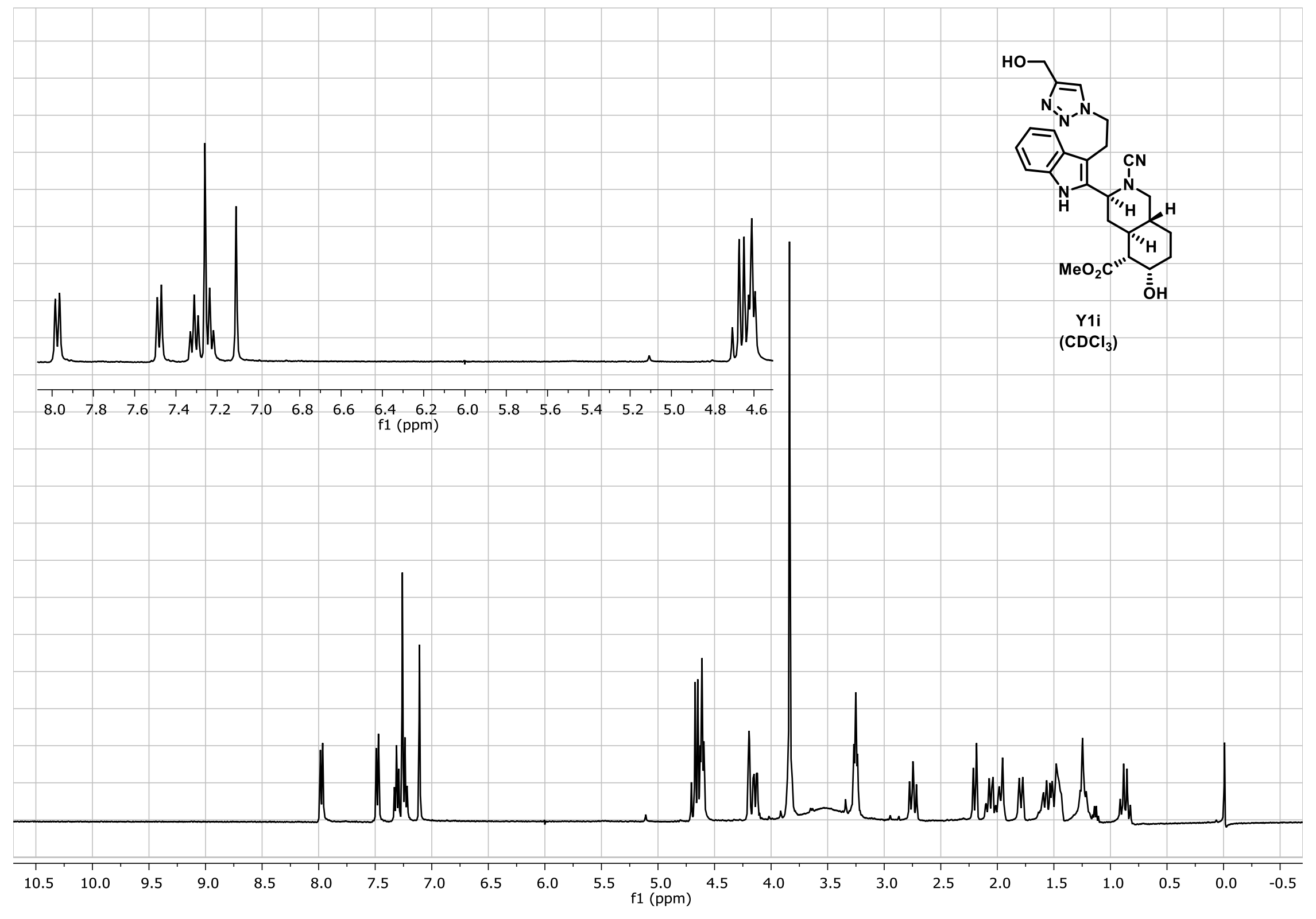



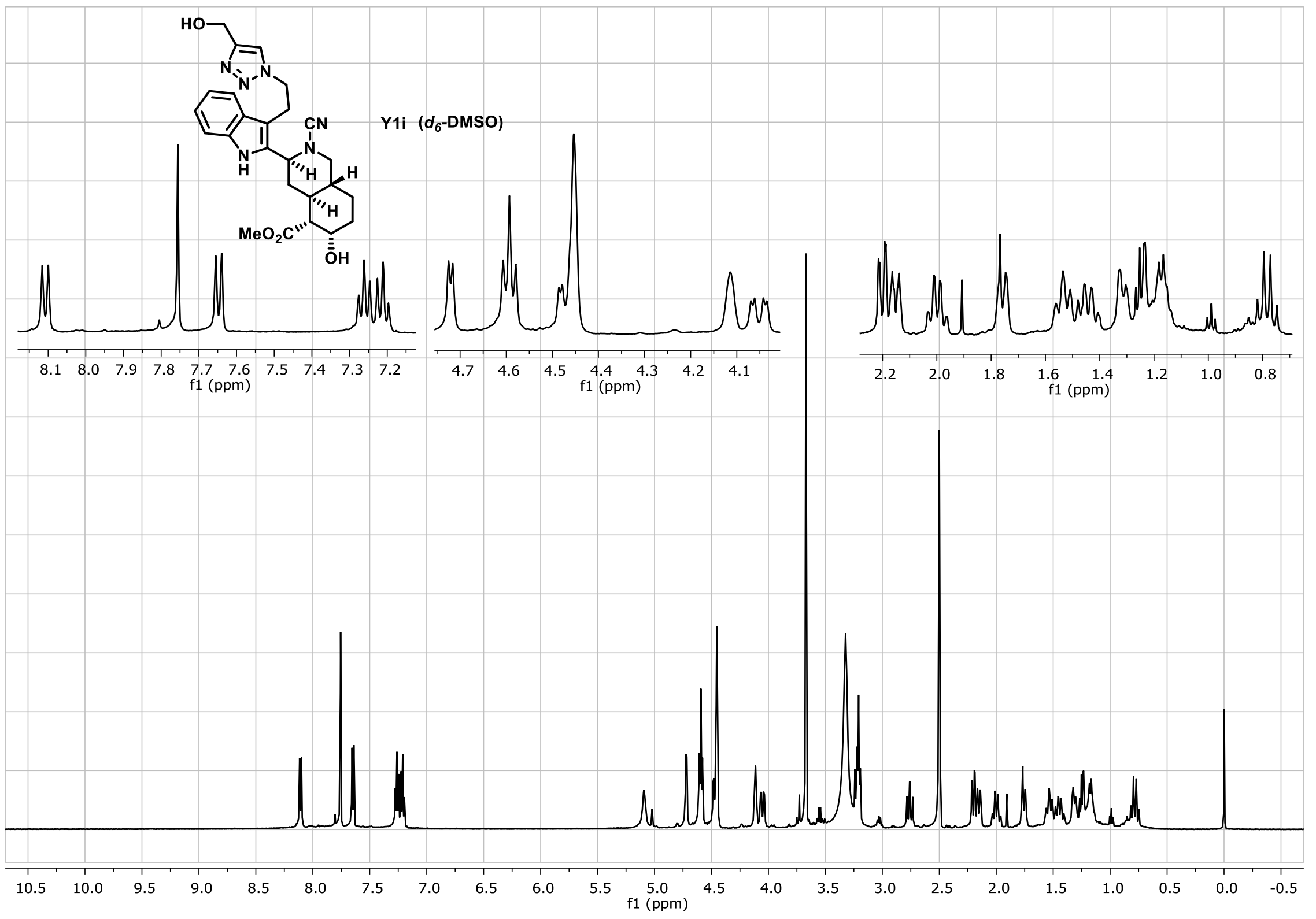

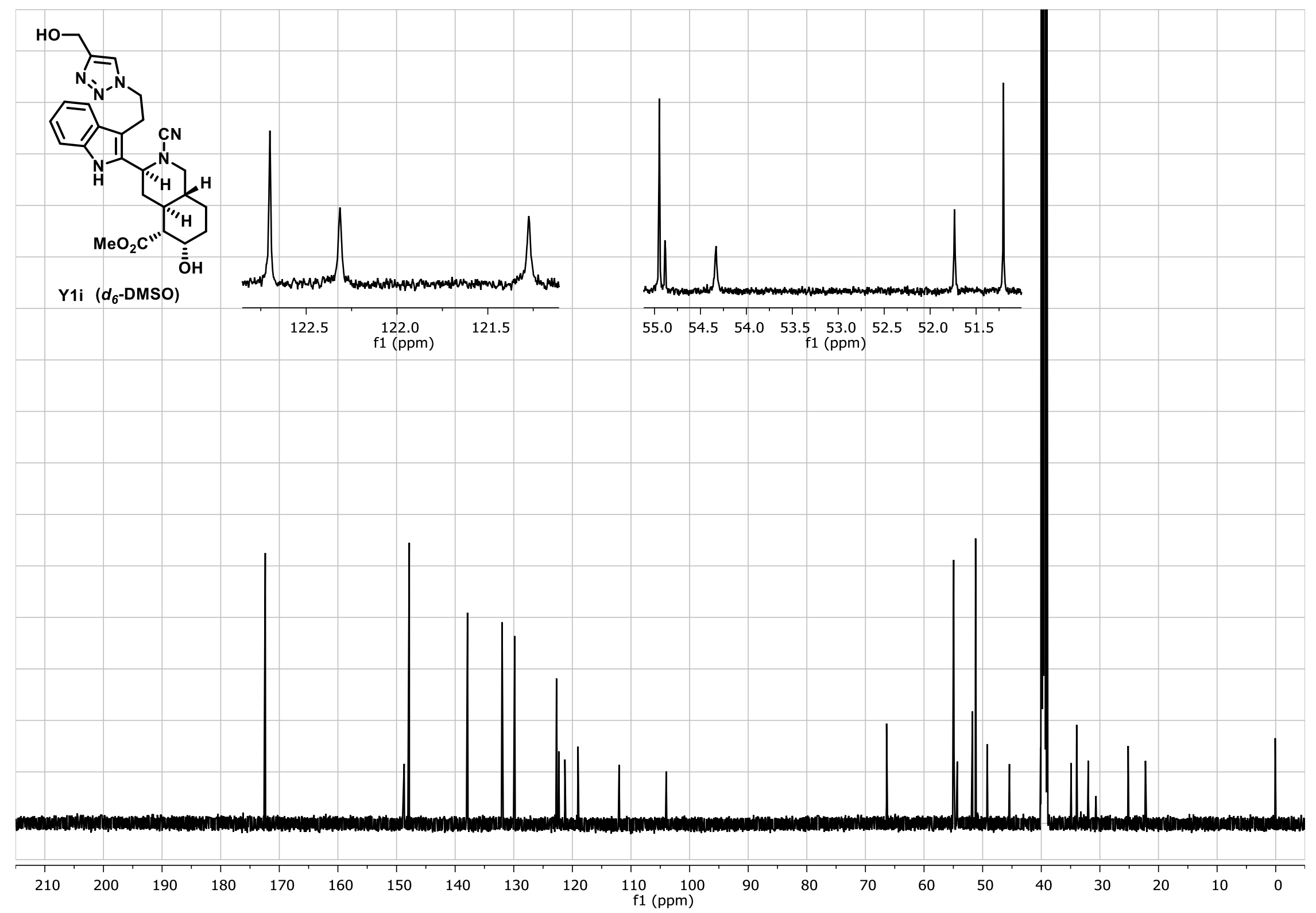


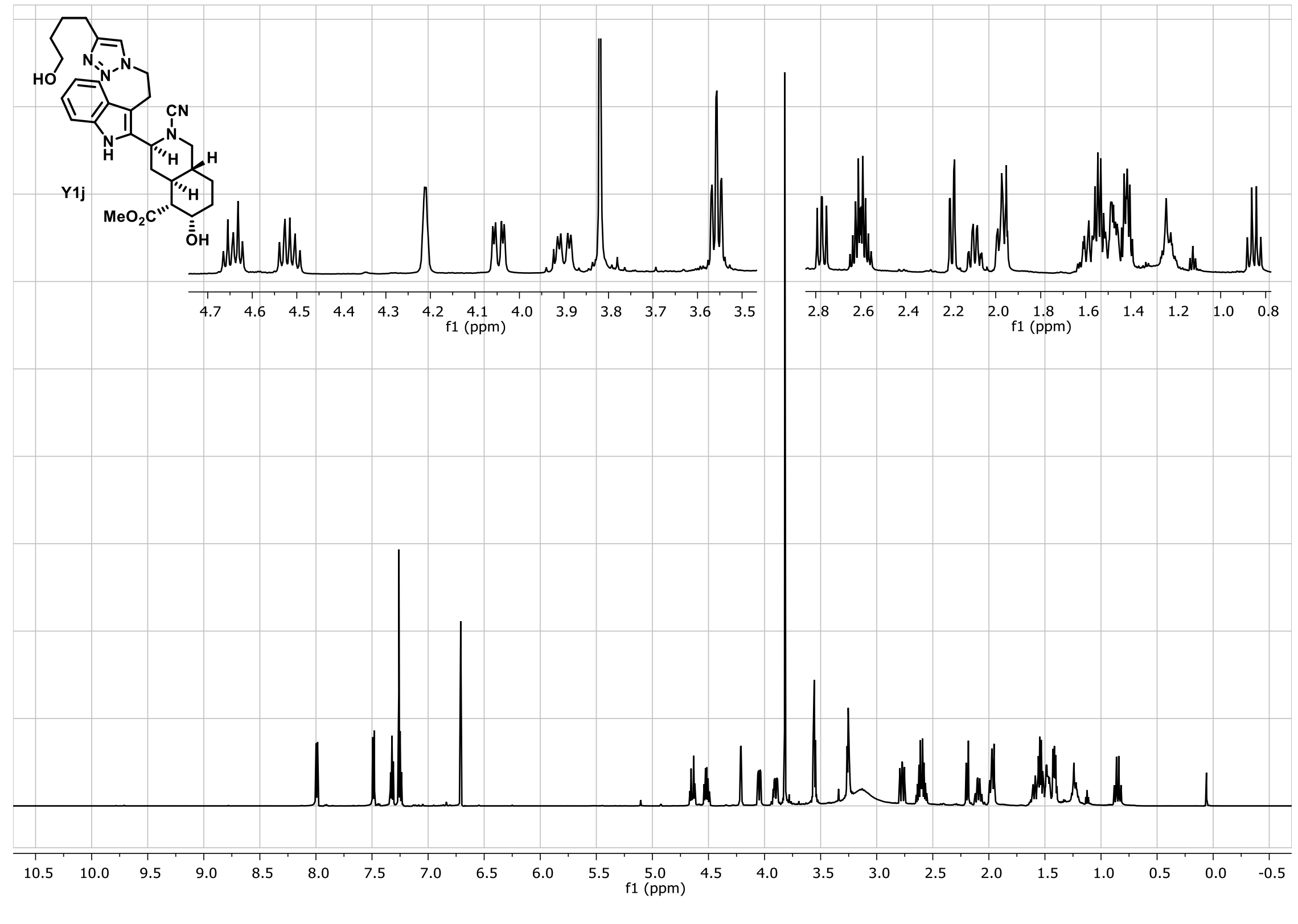




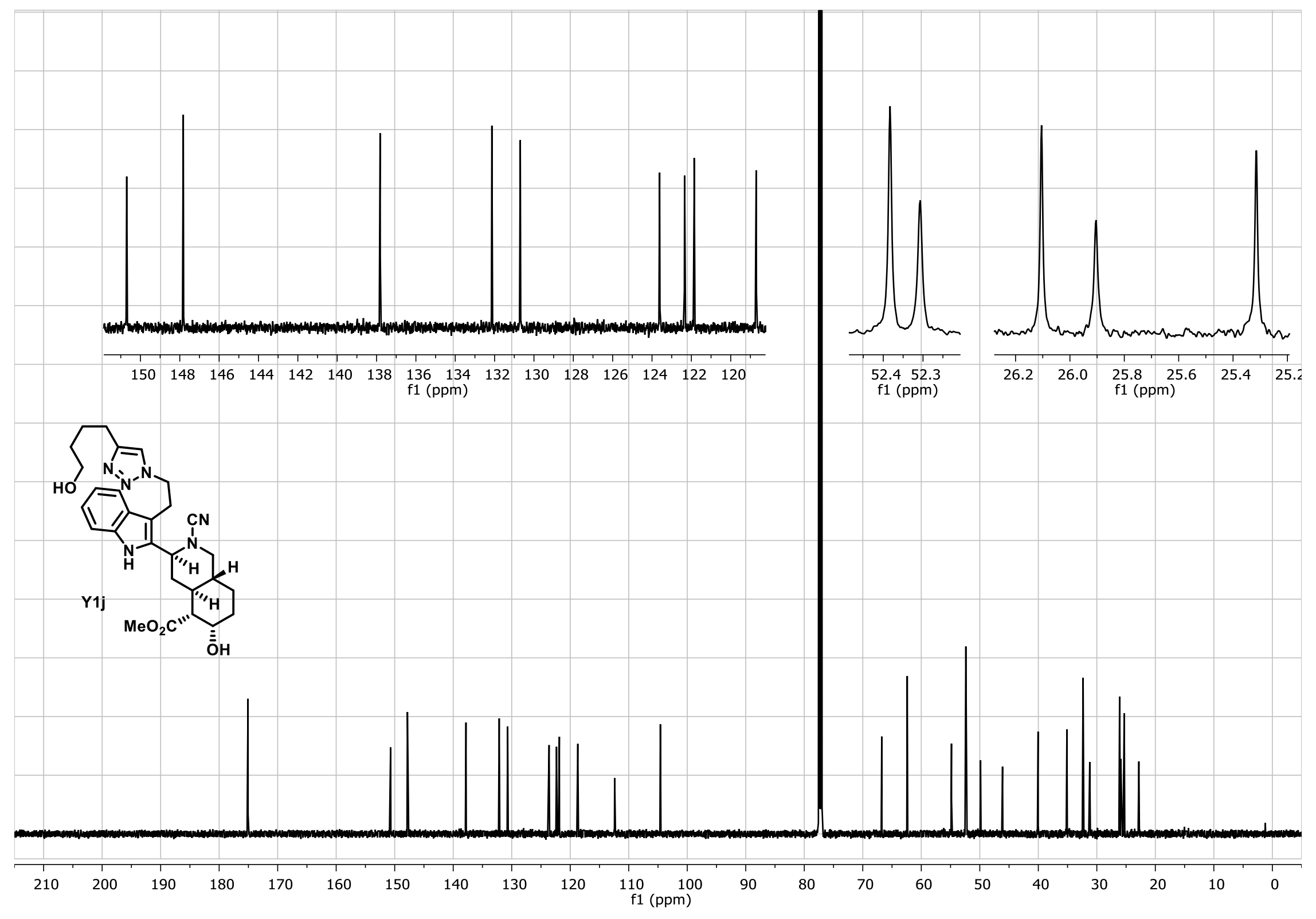




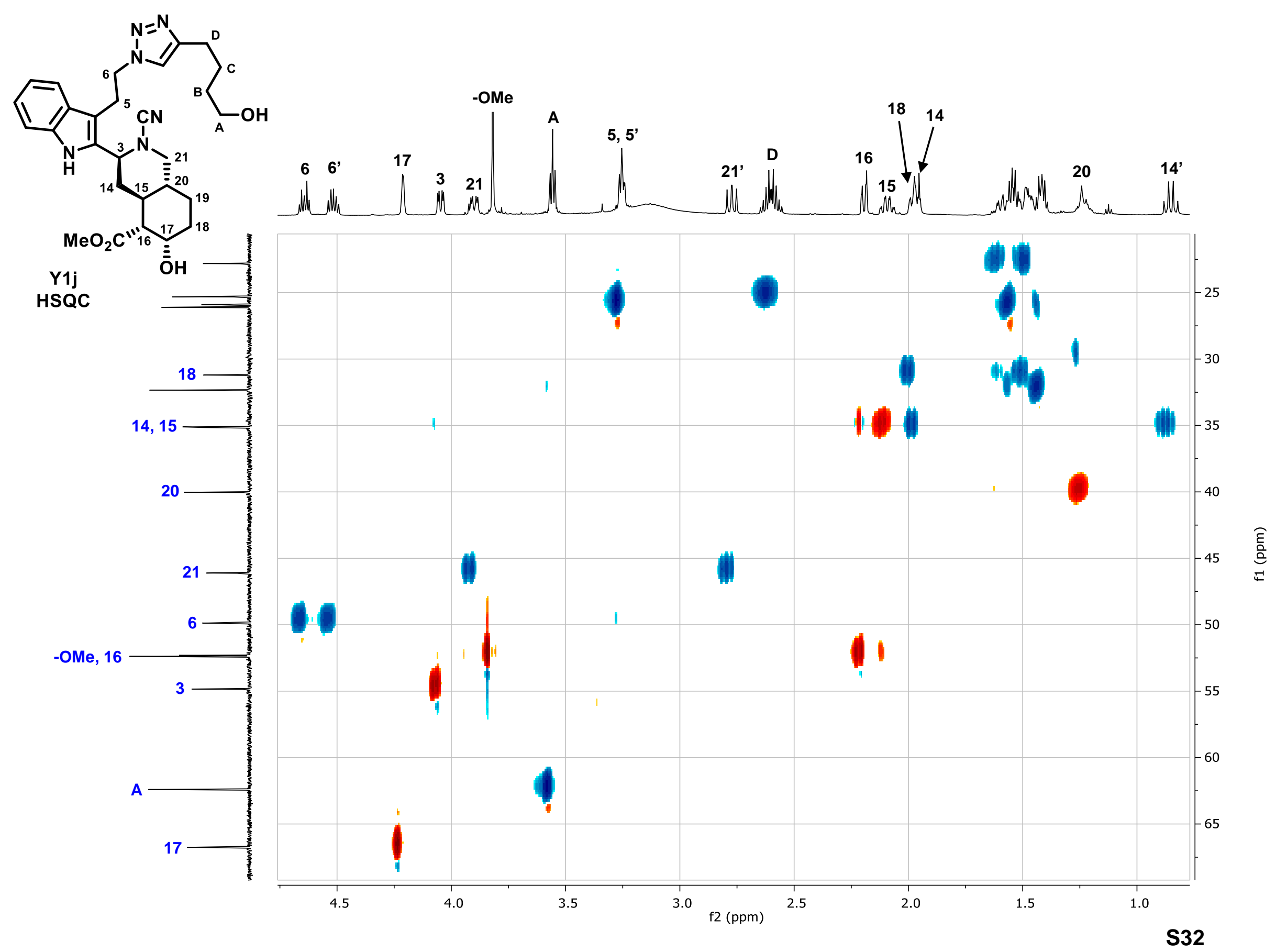




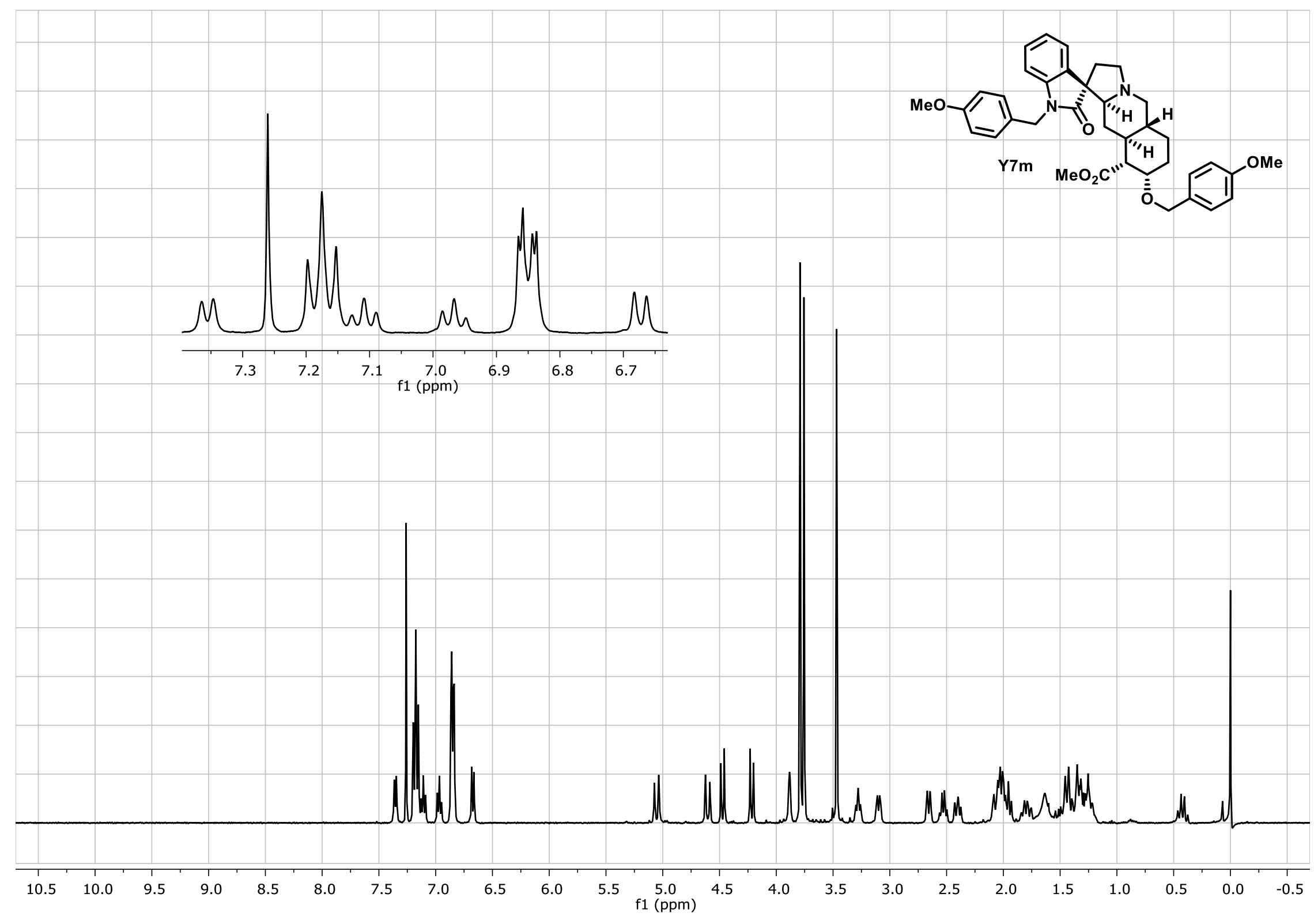




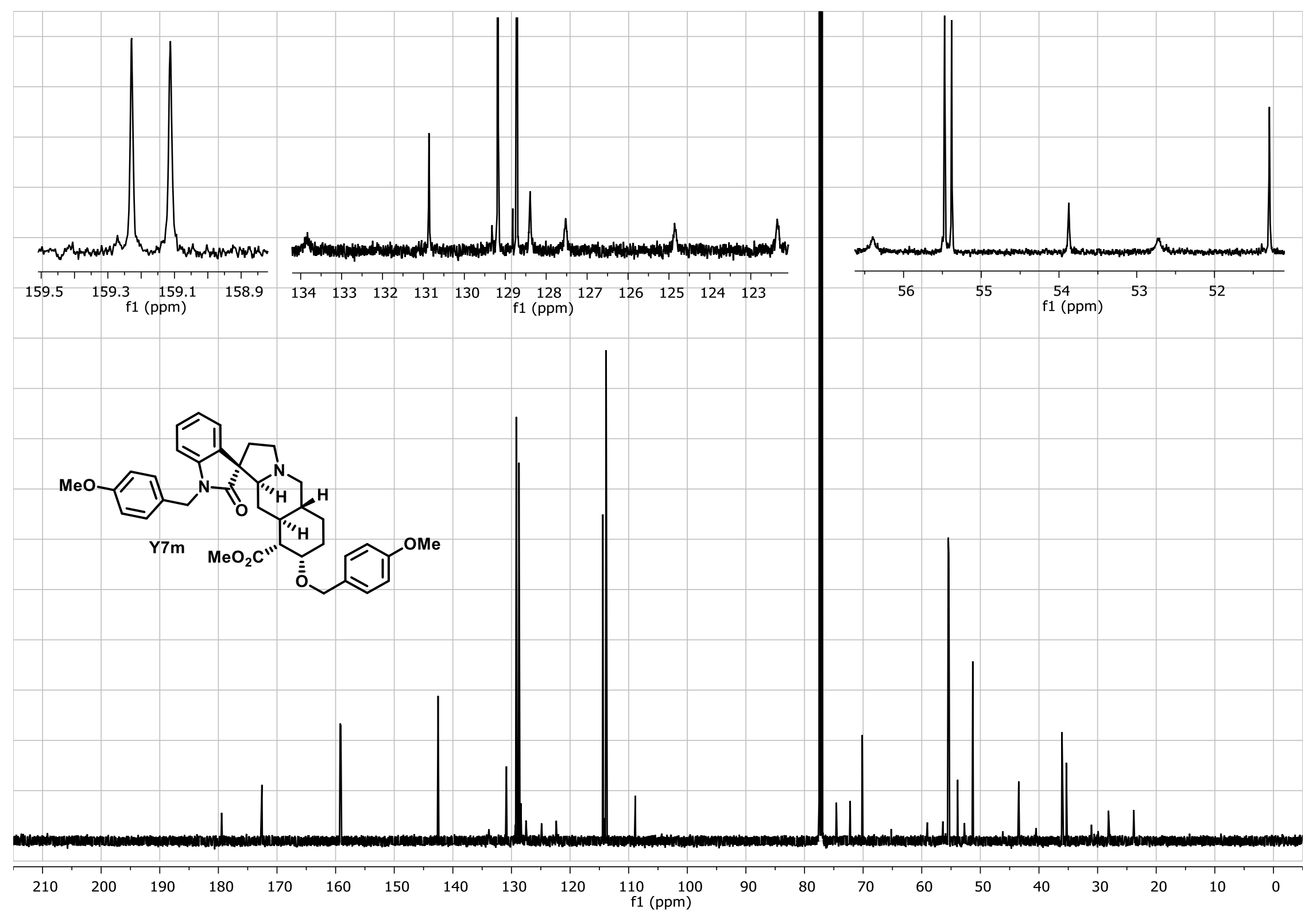




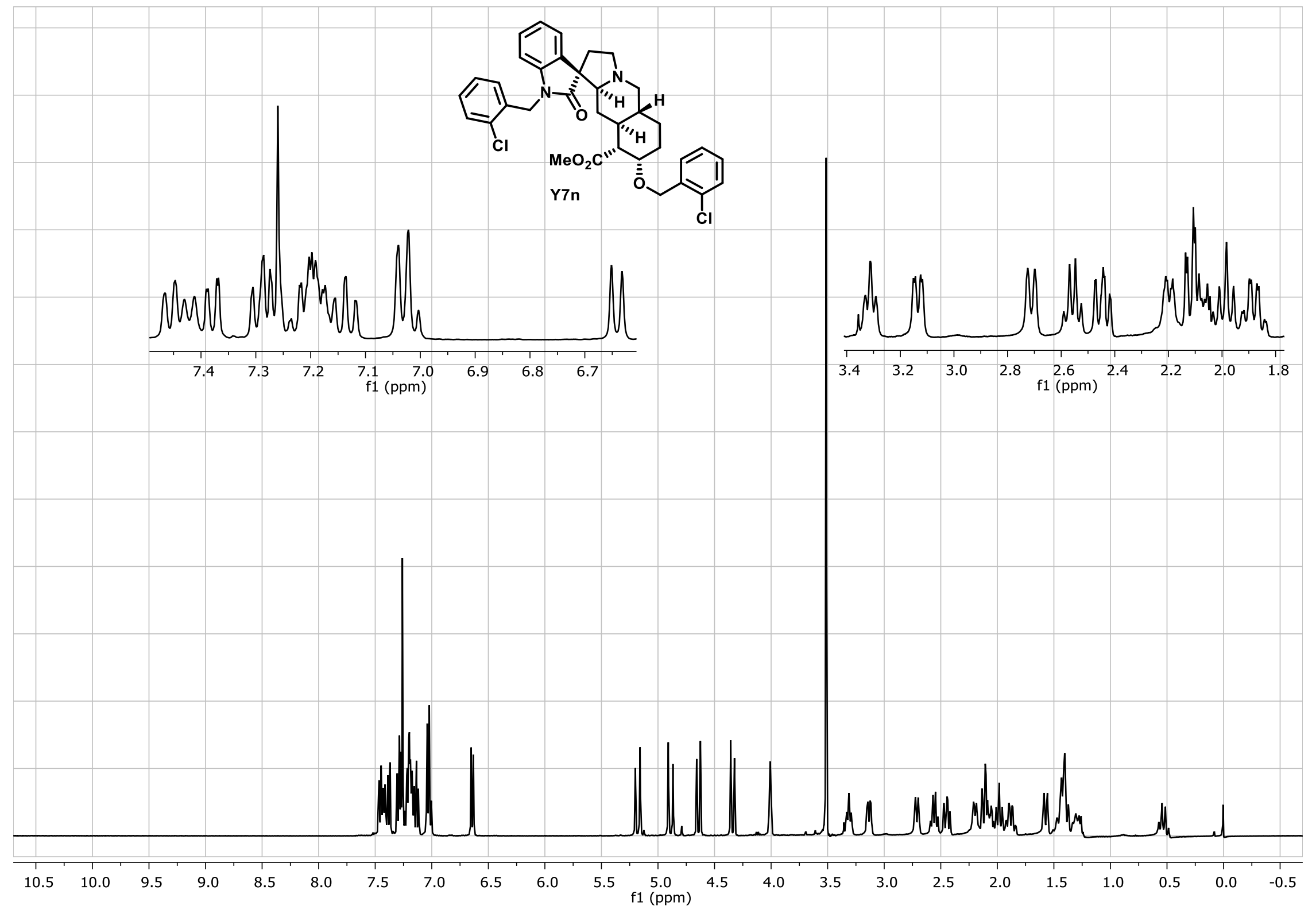

S35 


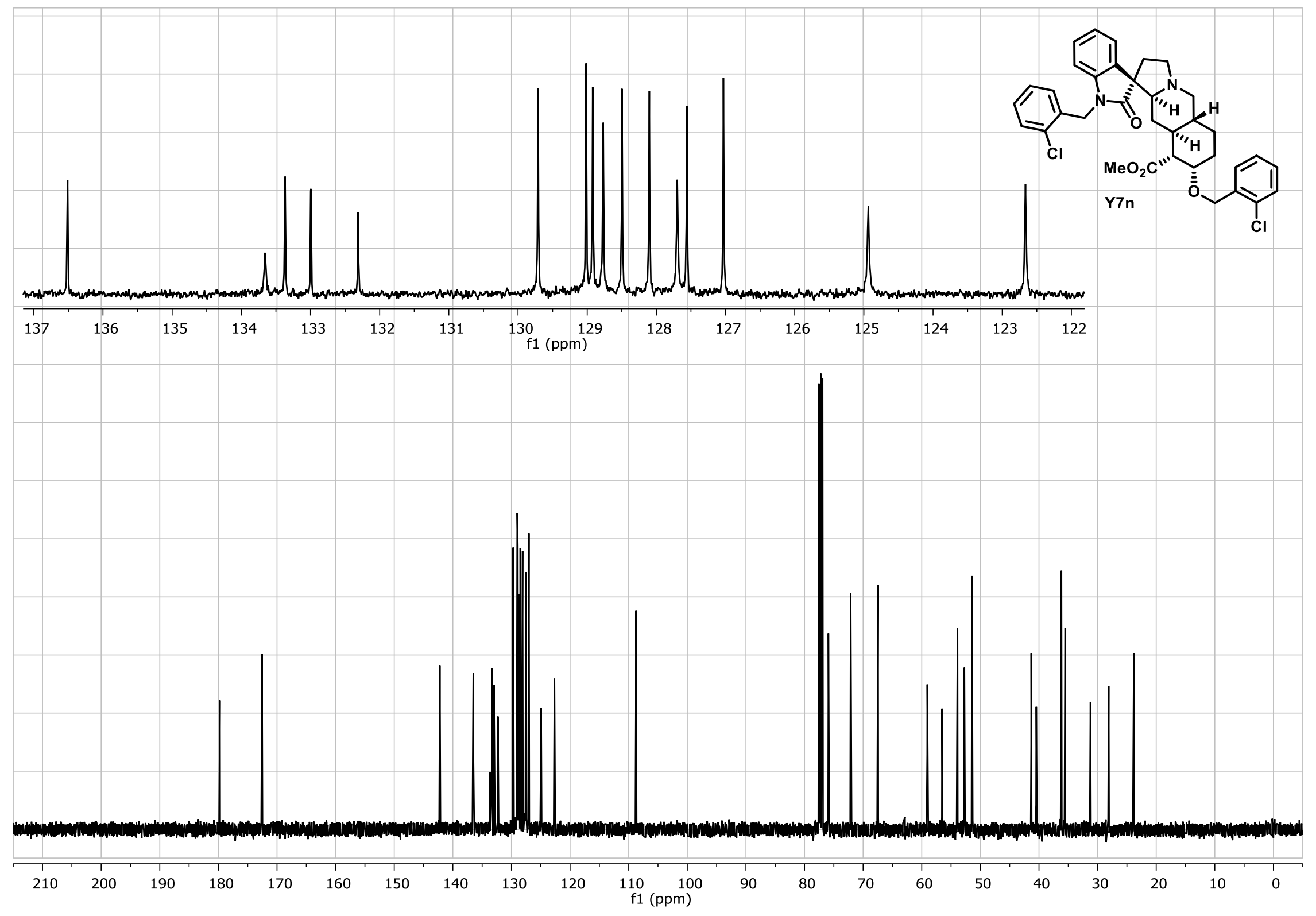




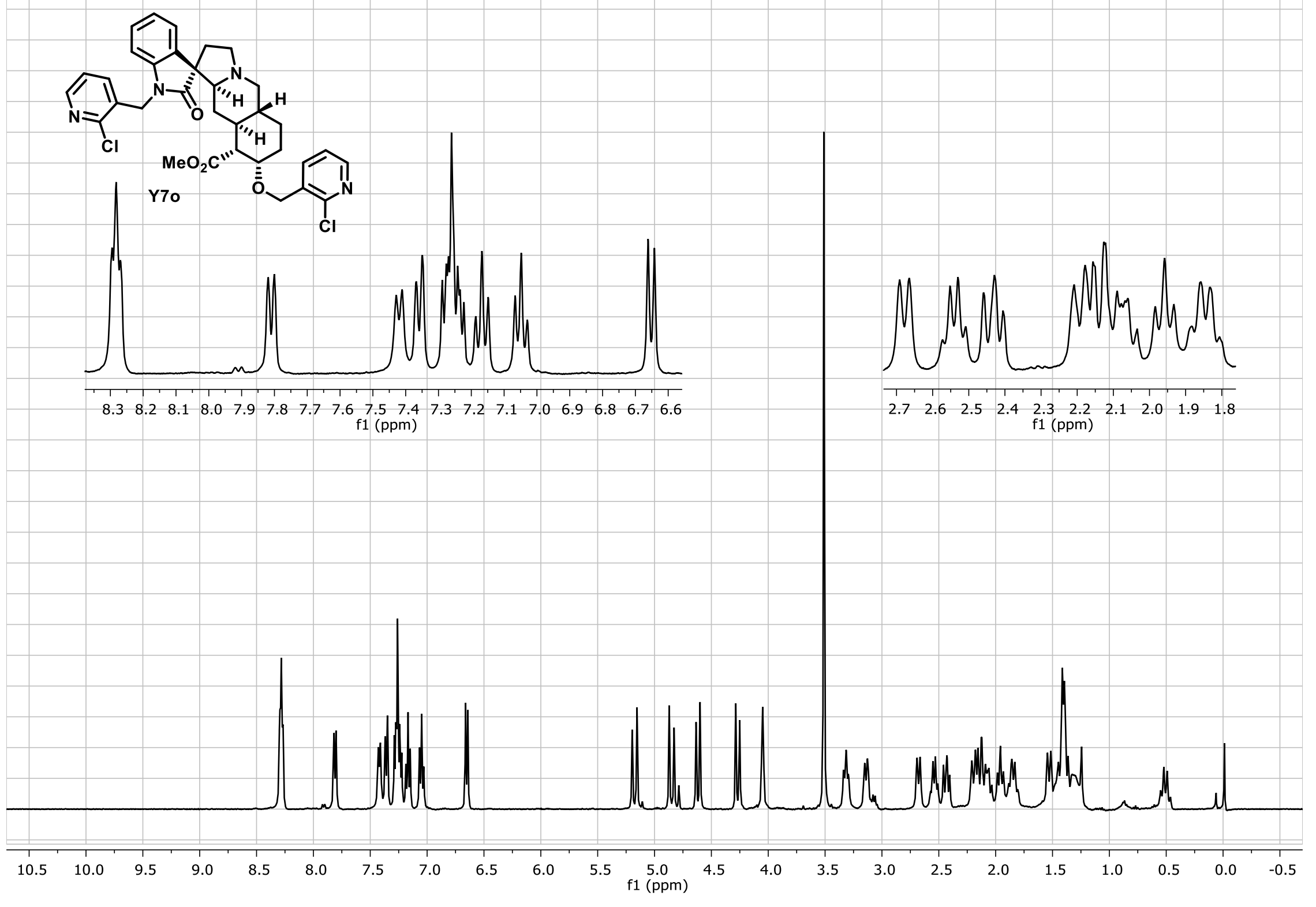




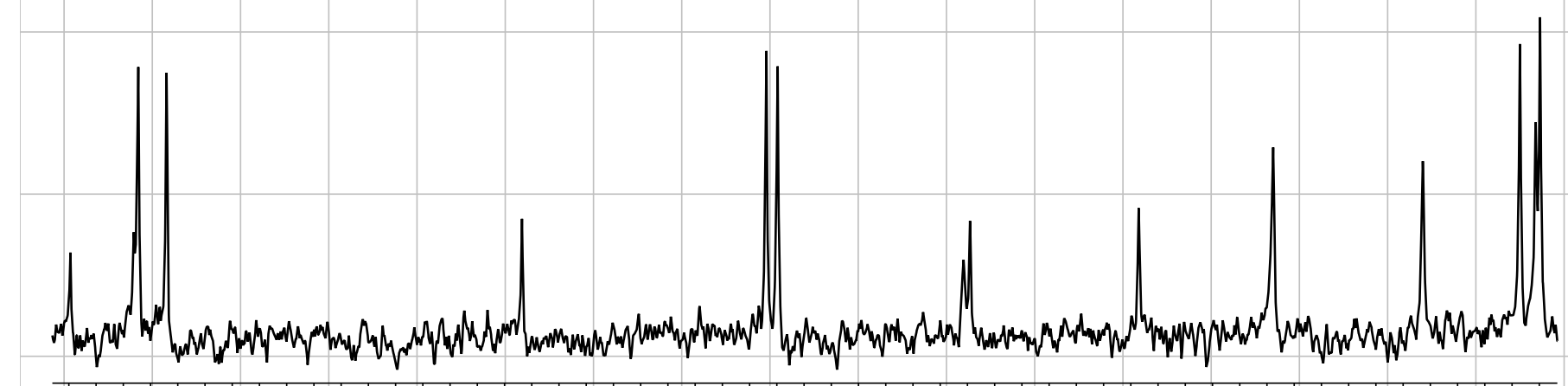

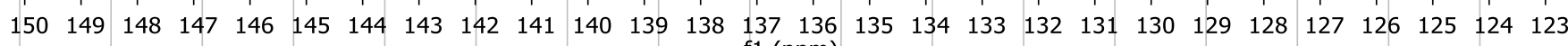
f1 (ppm)

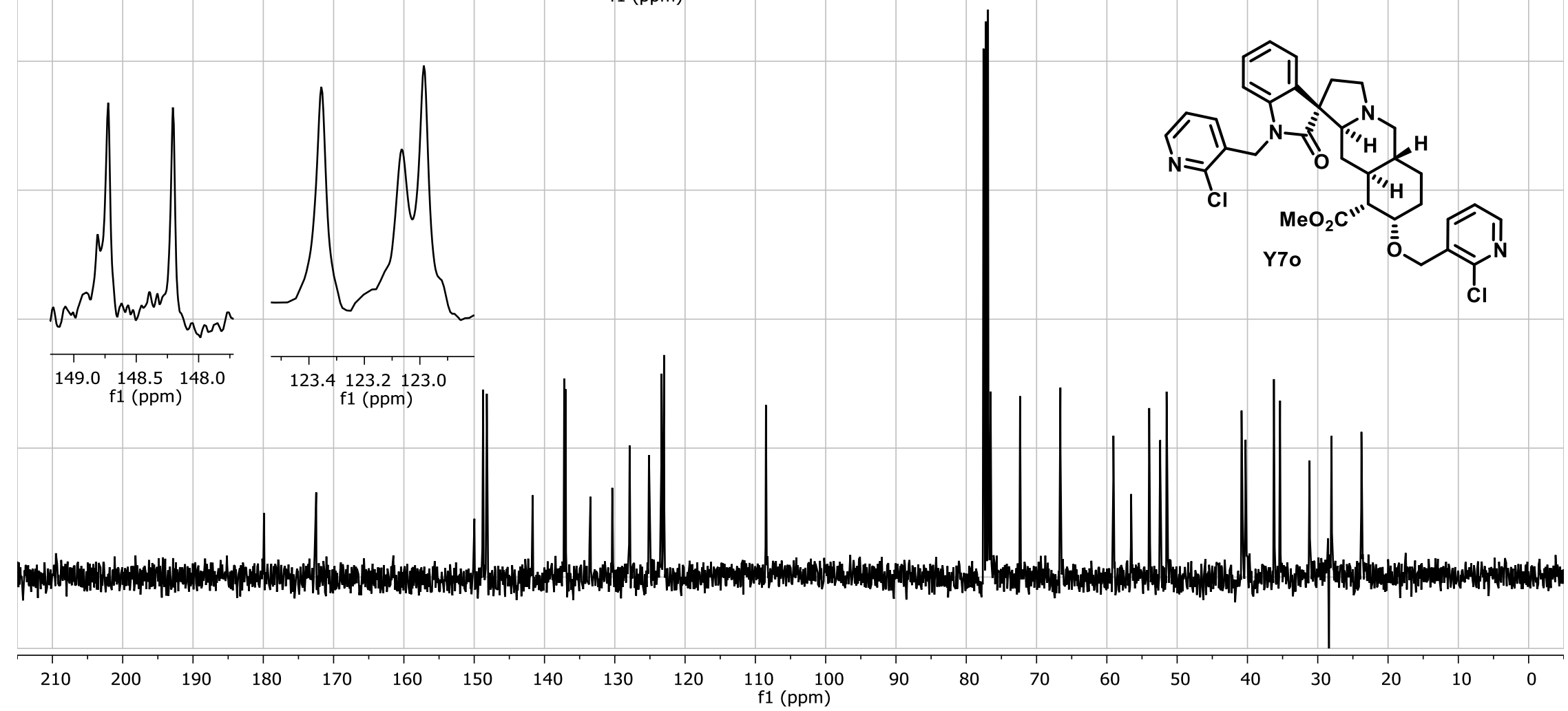




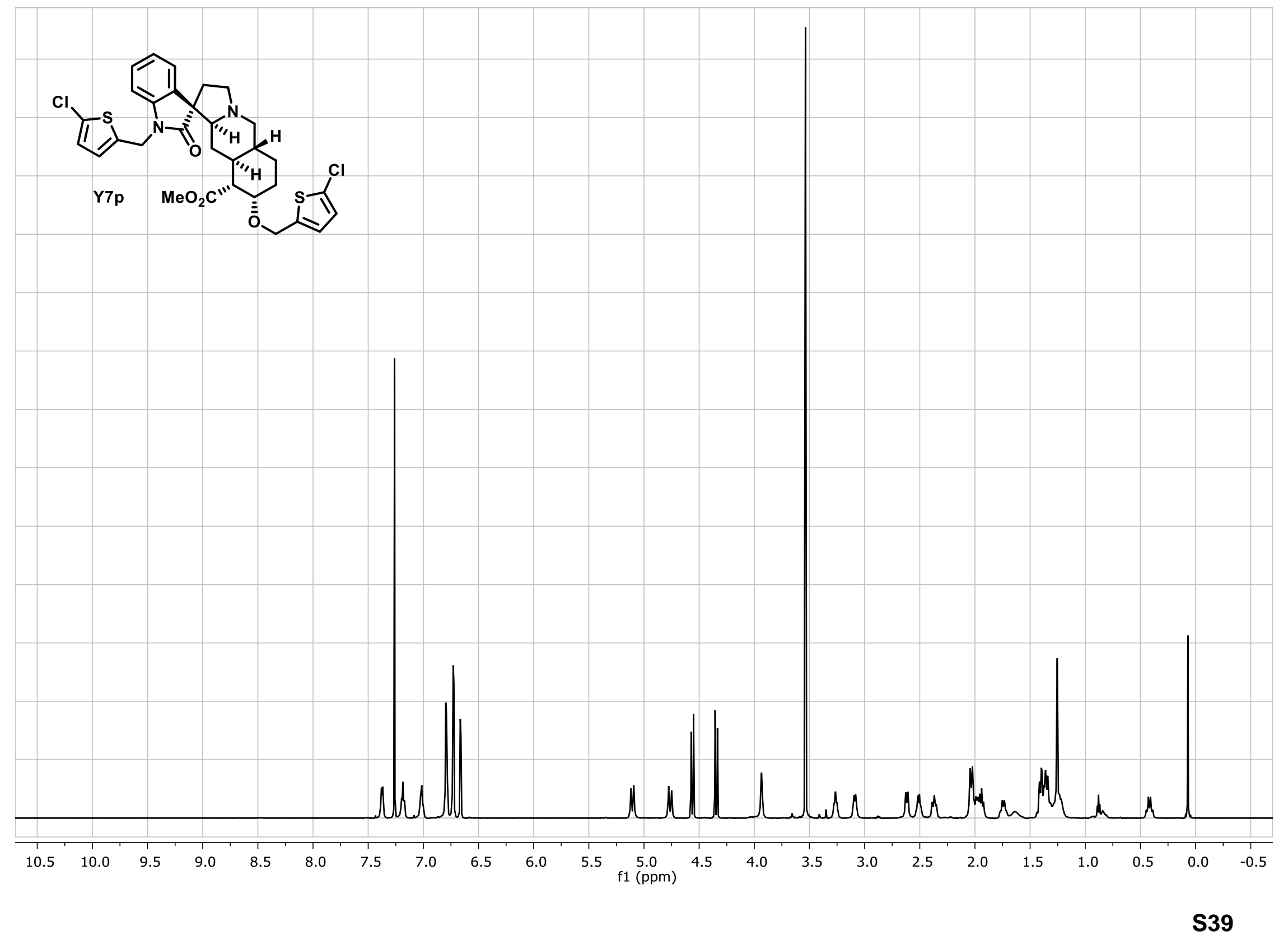




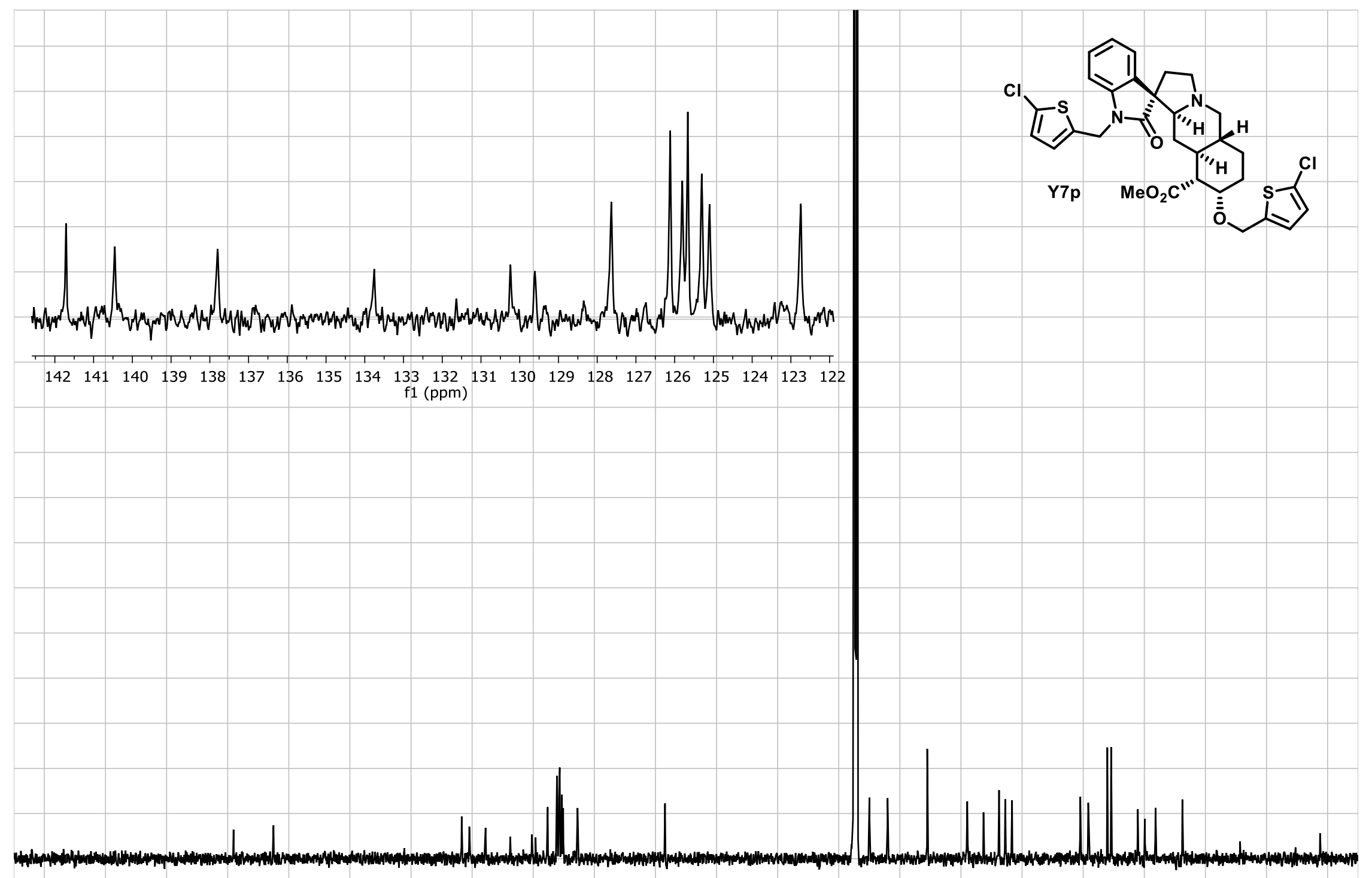

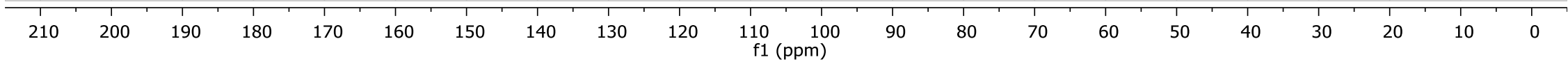



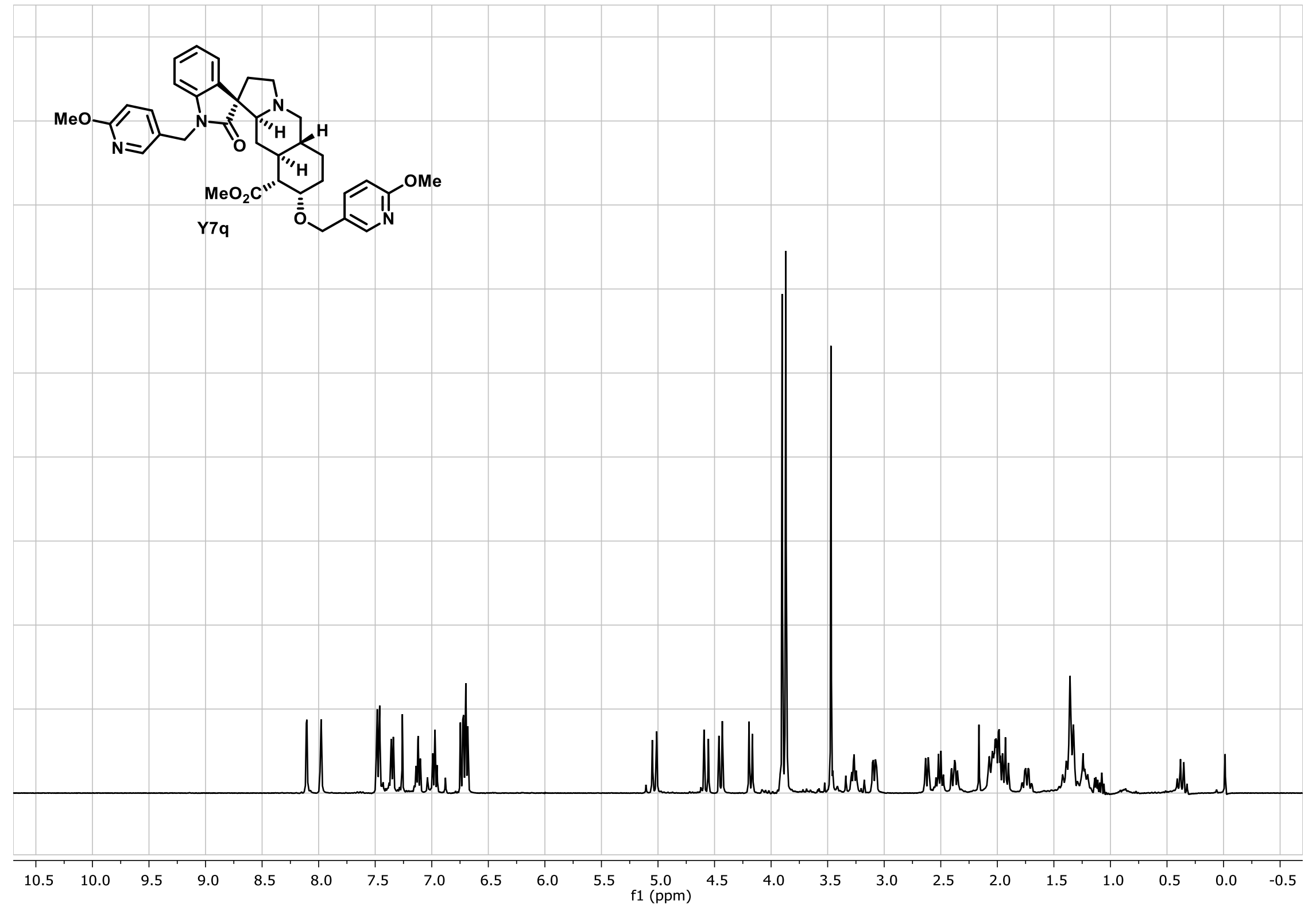


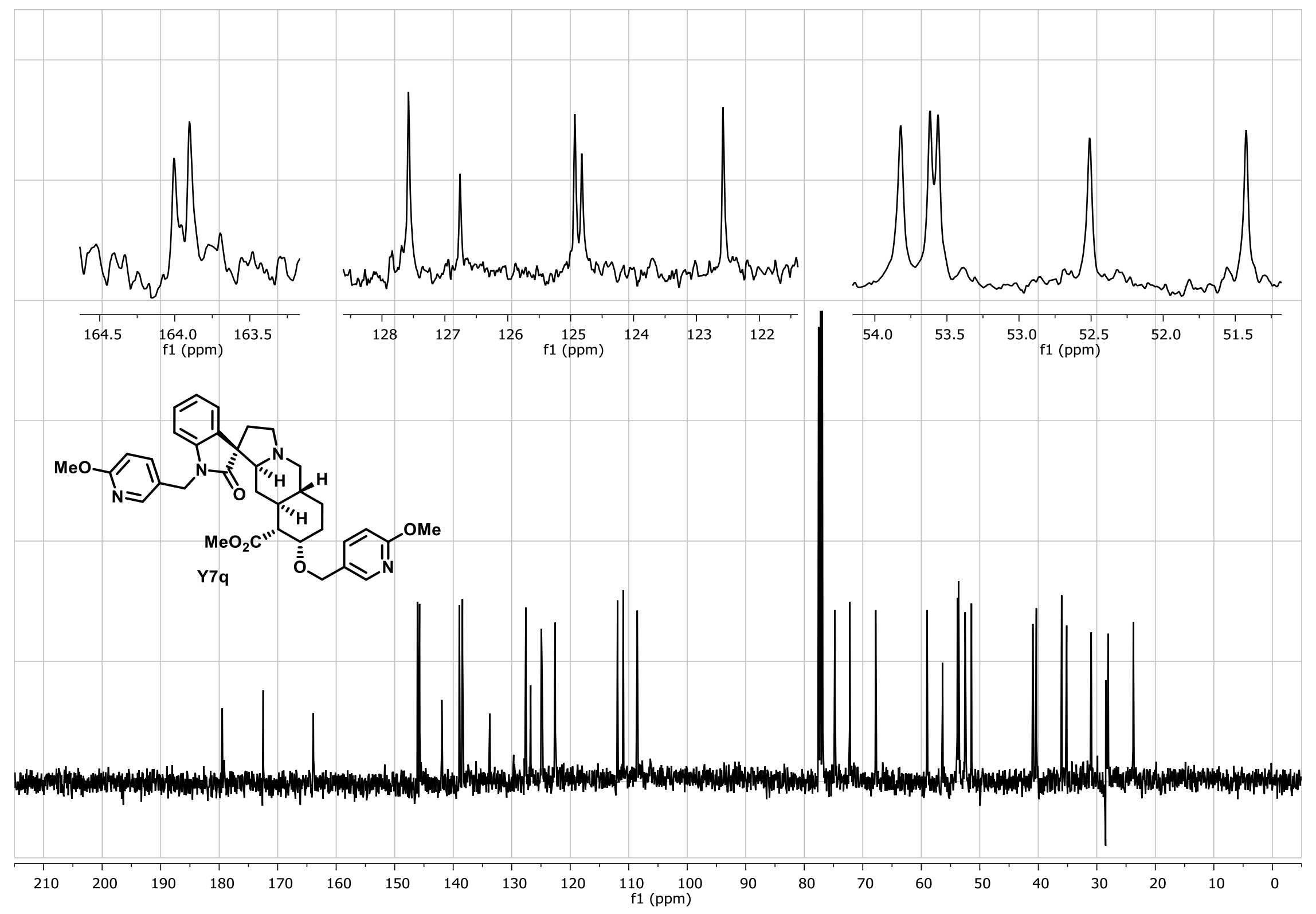




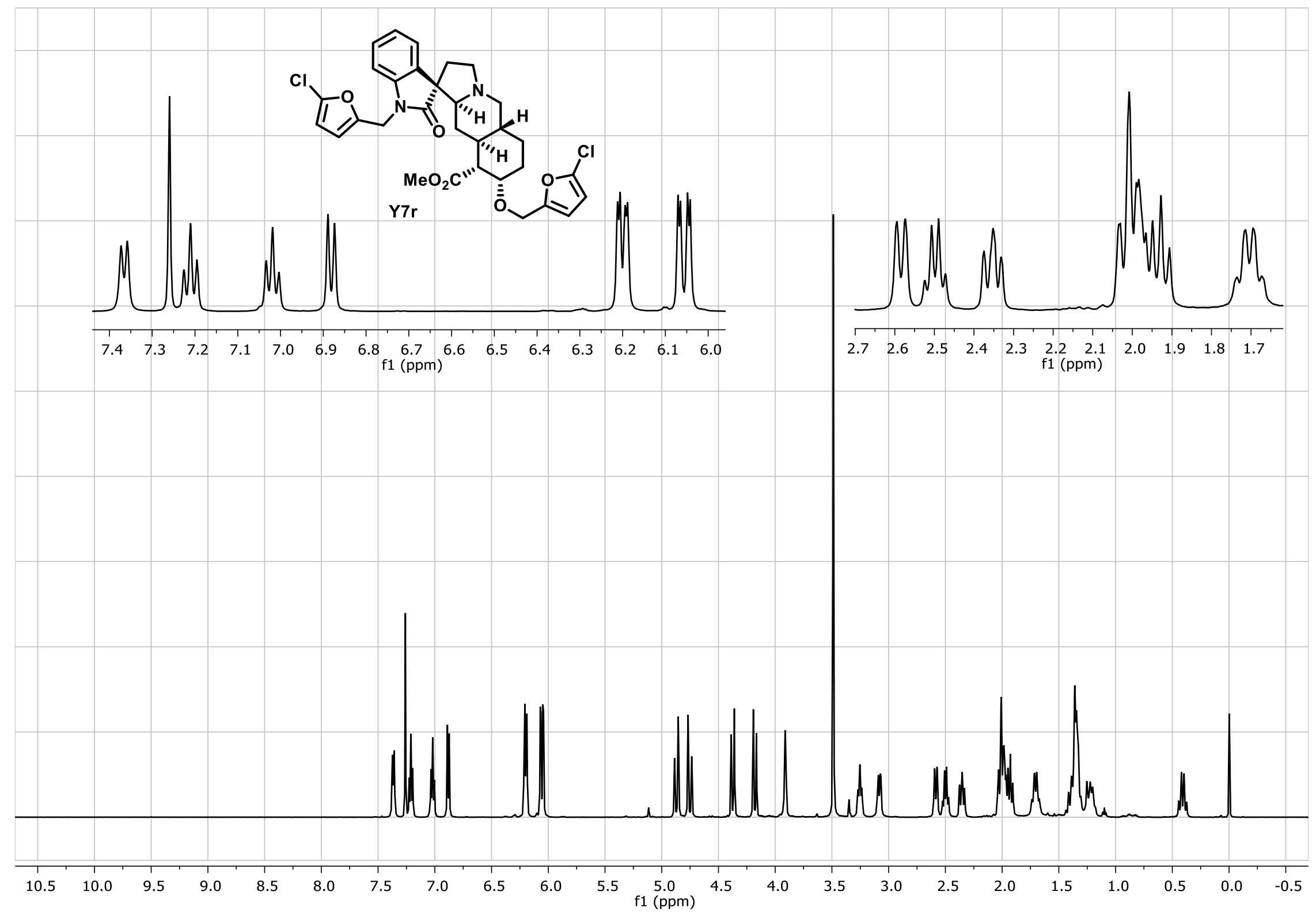




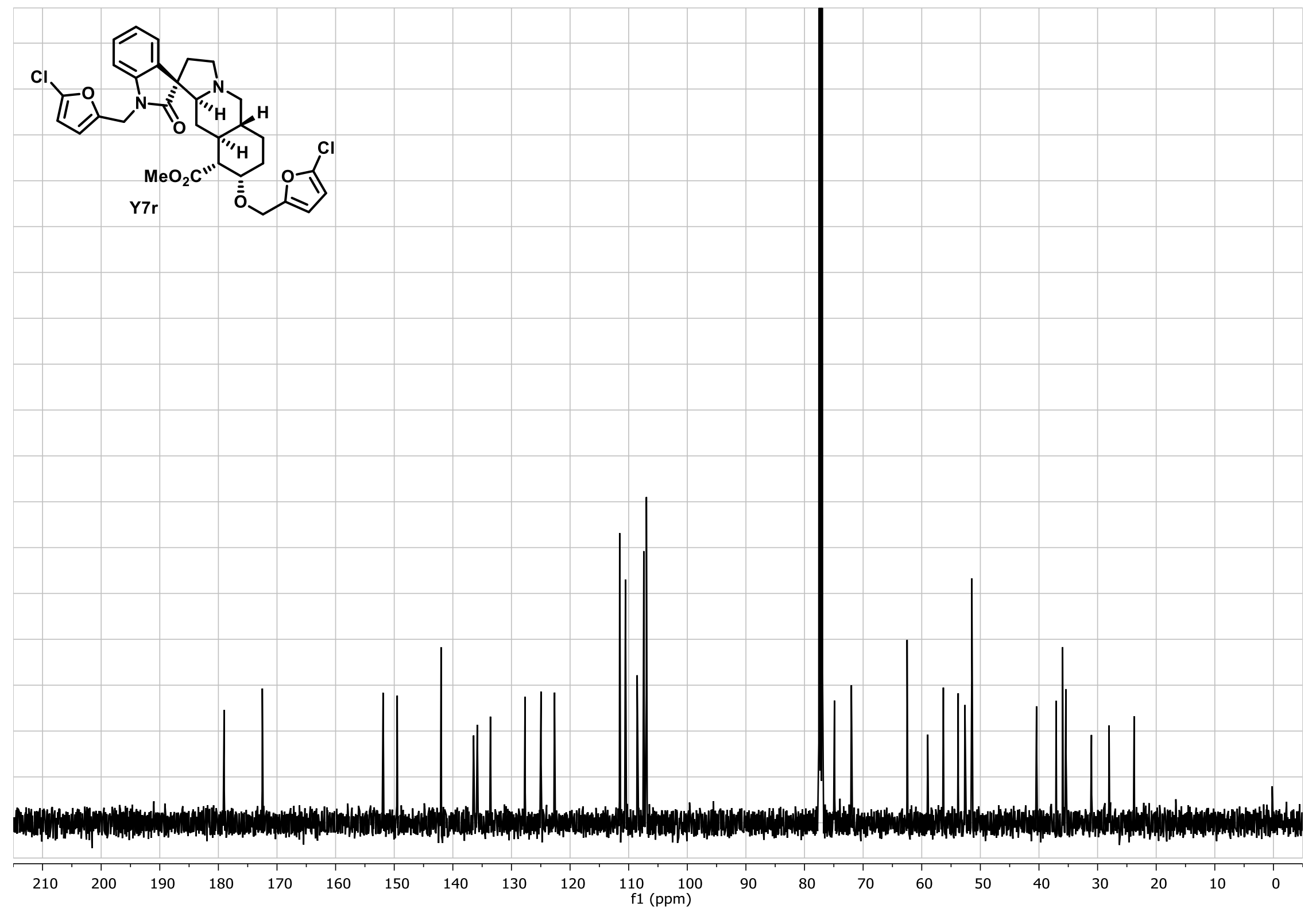




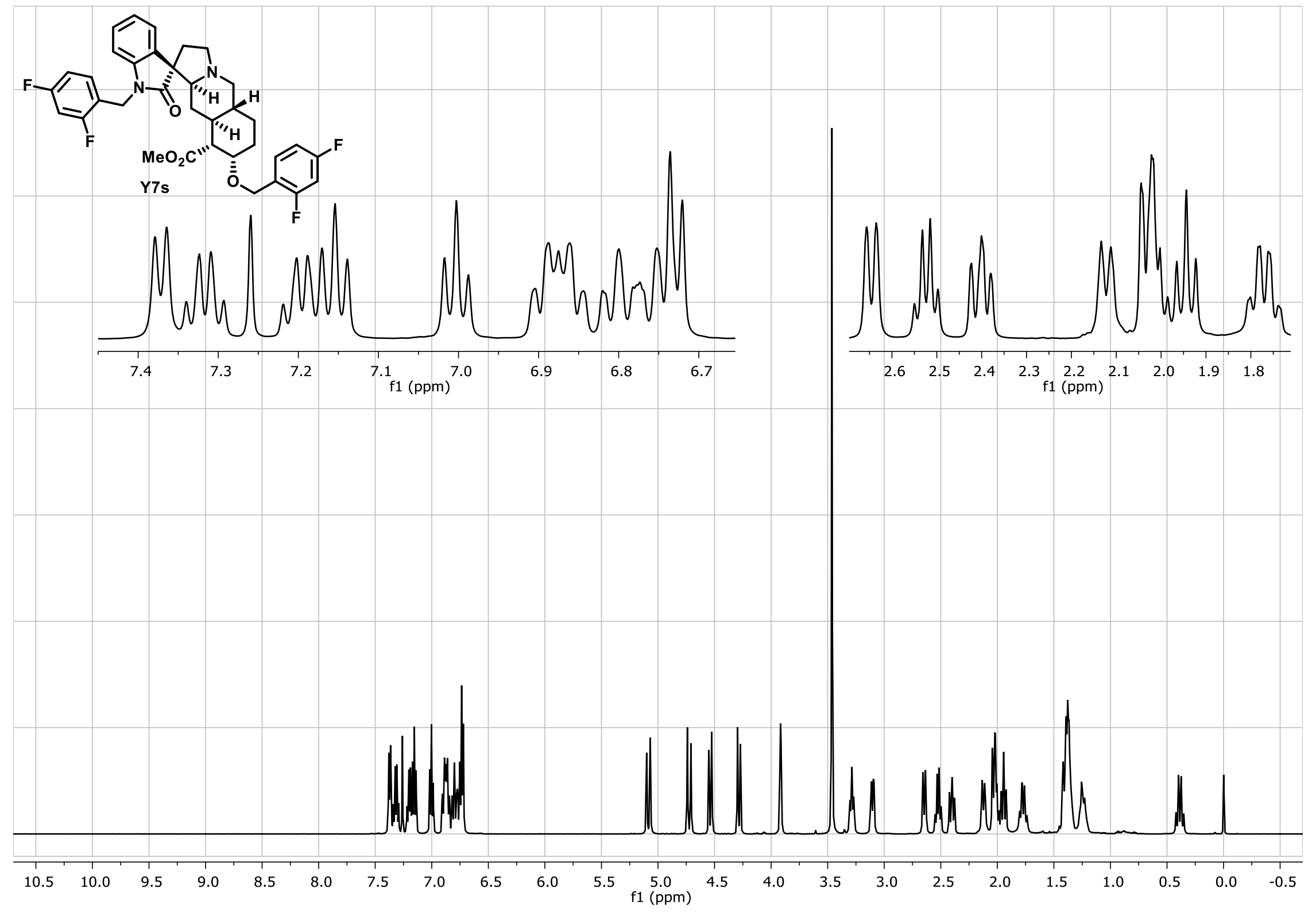

S45 


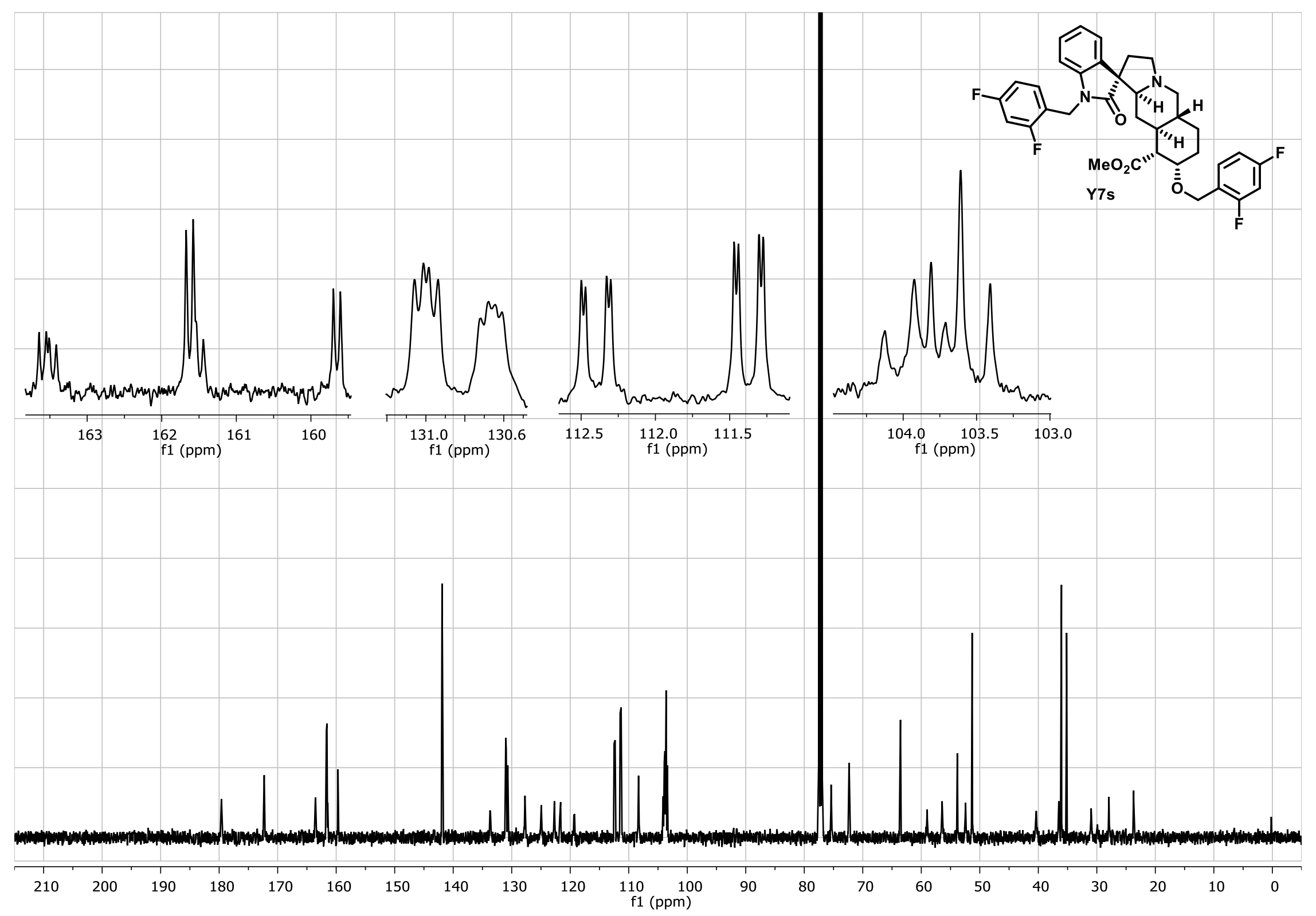




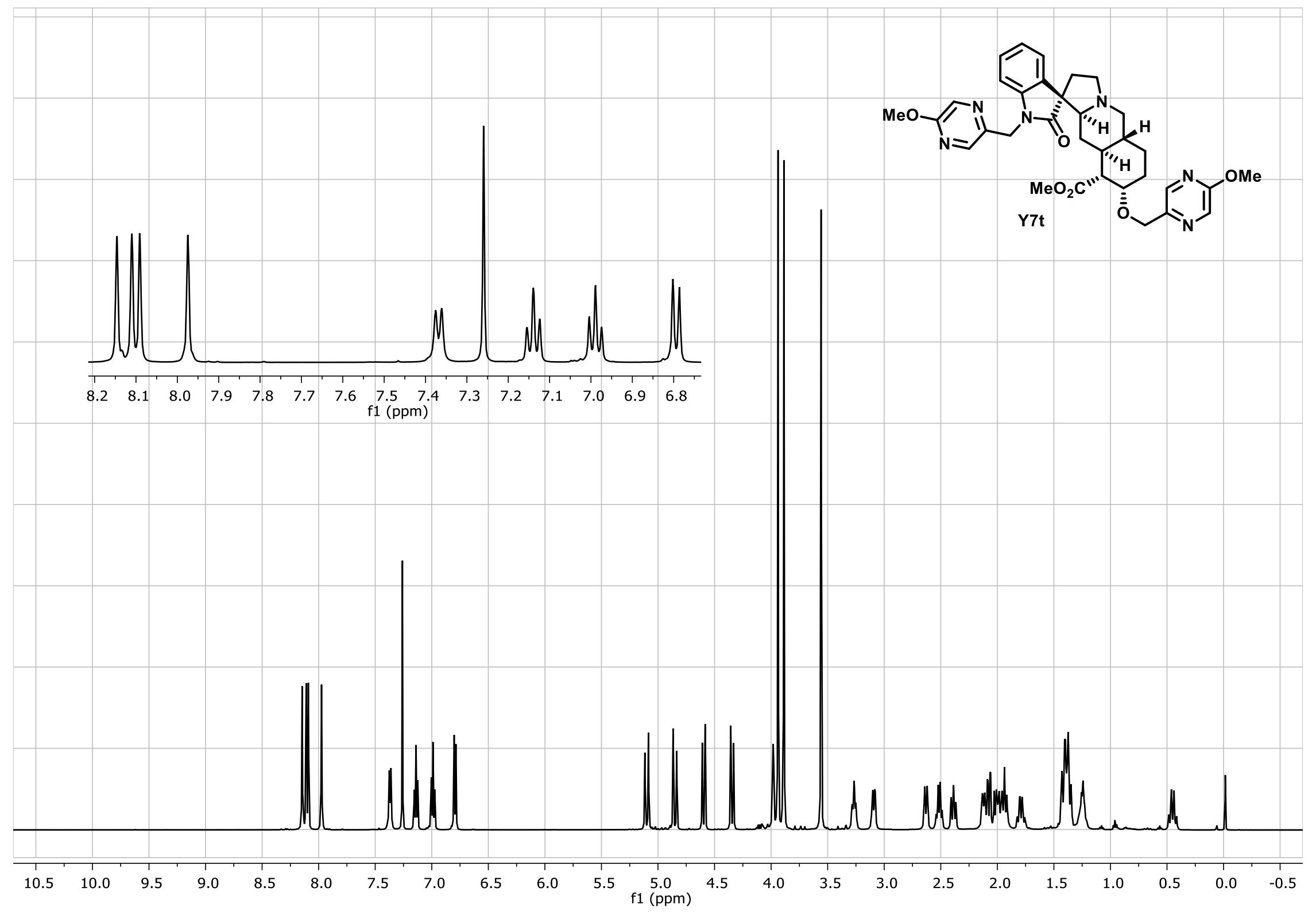




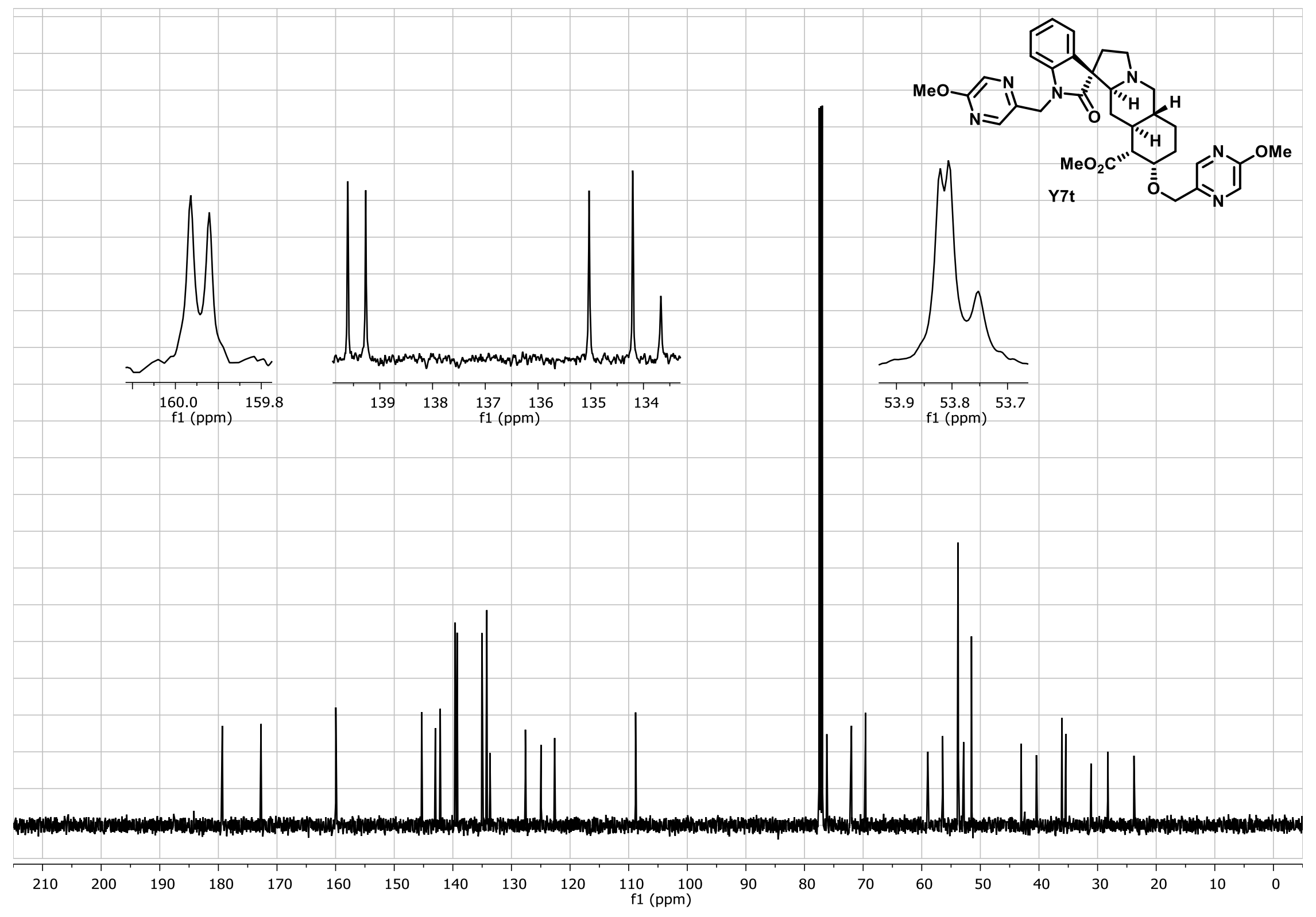




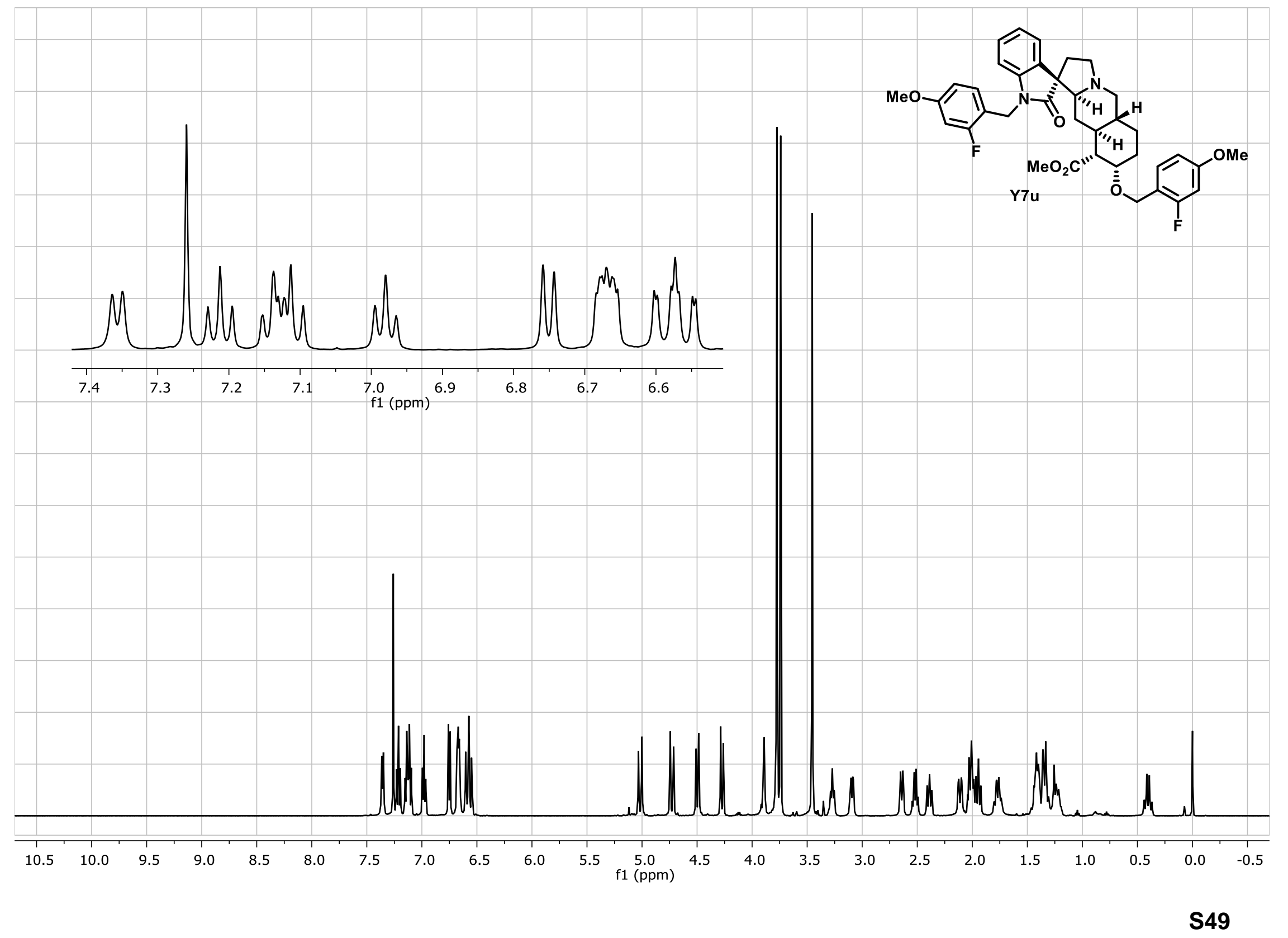




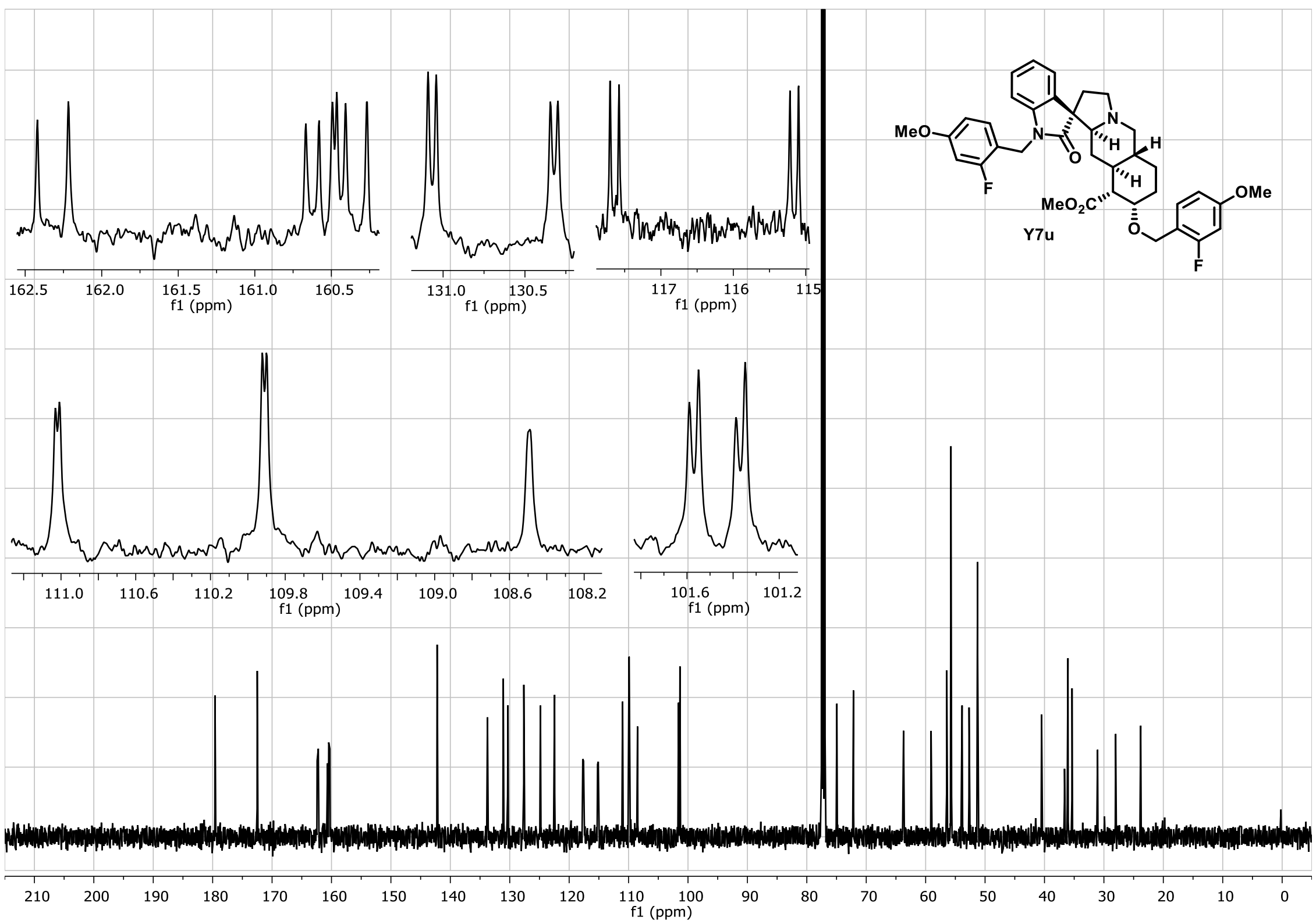

S50 

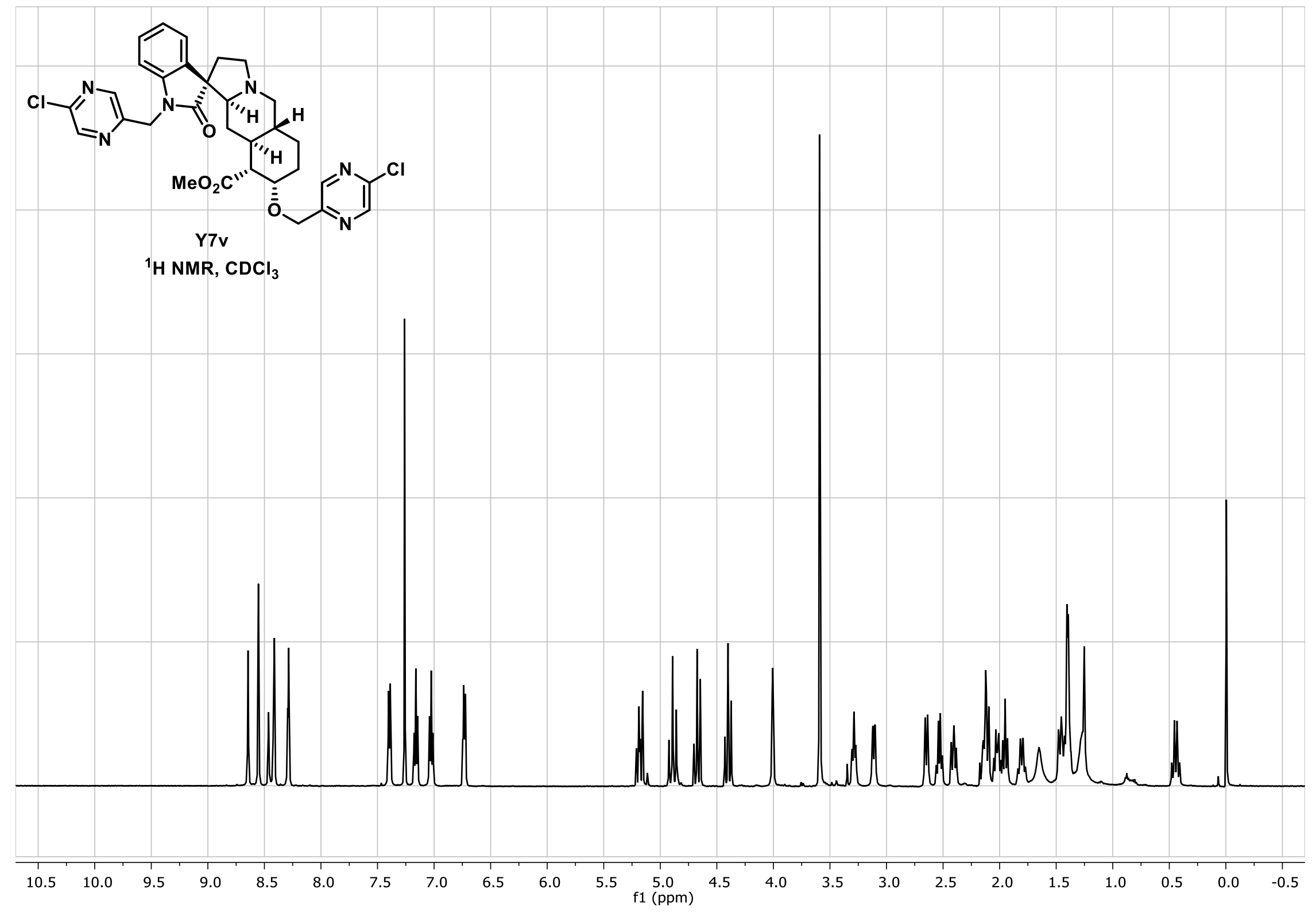


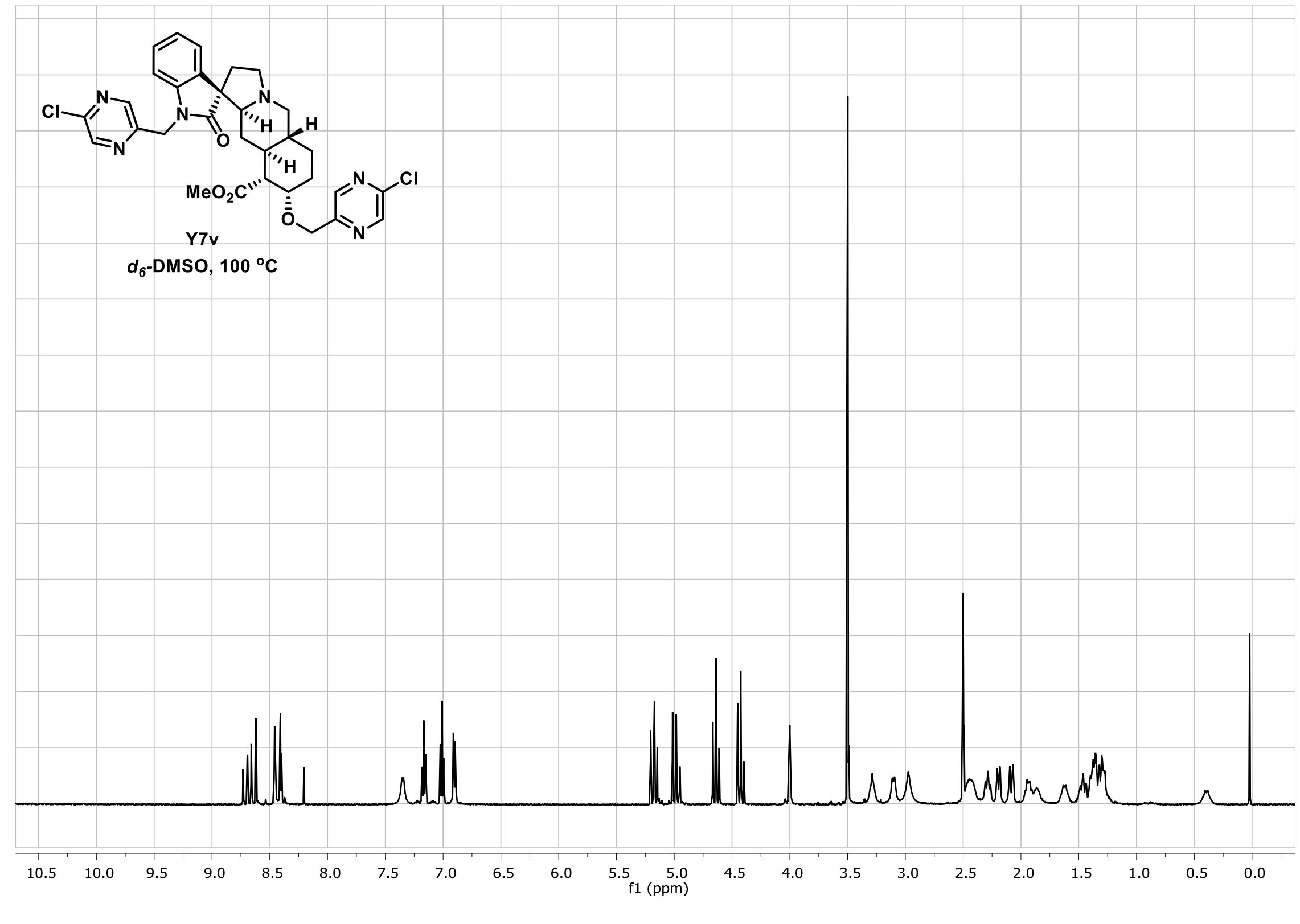

S52 


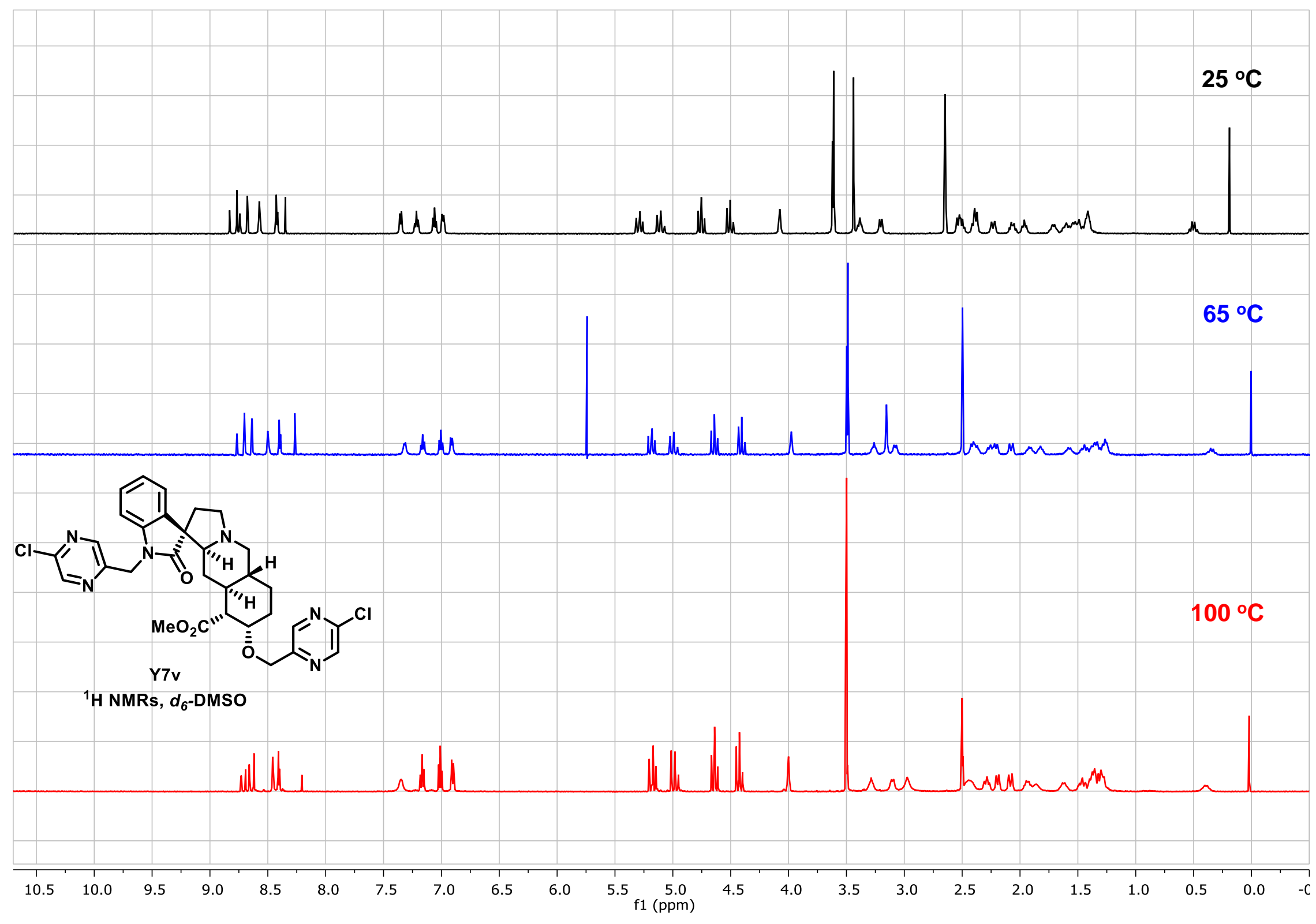




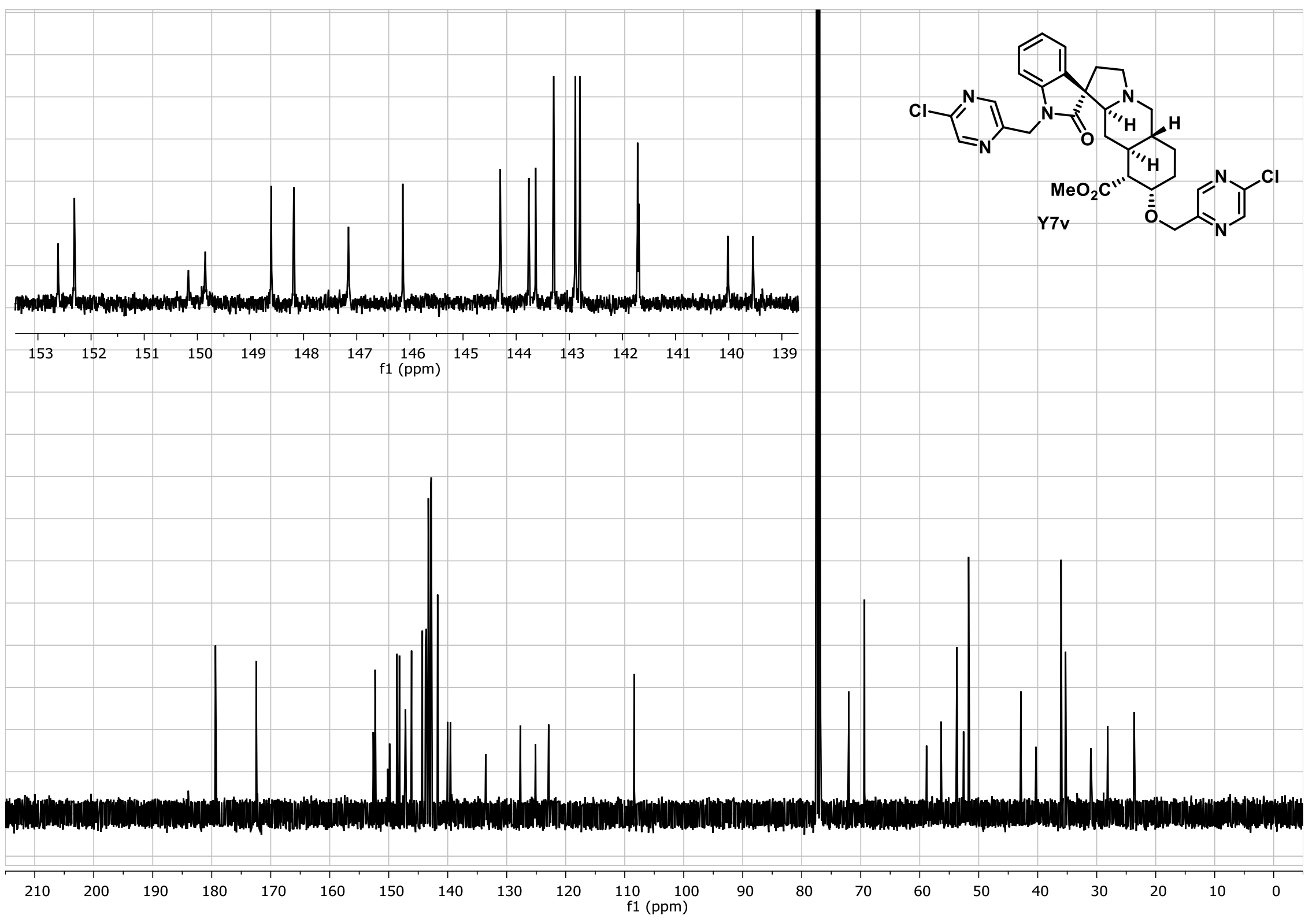



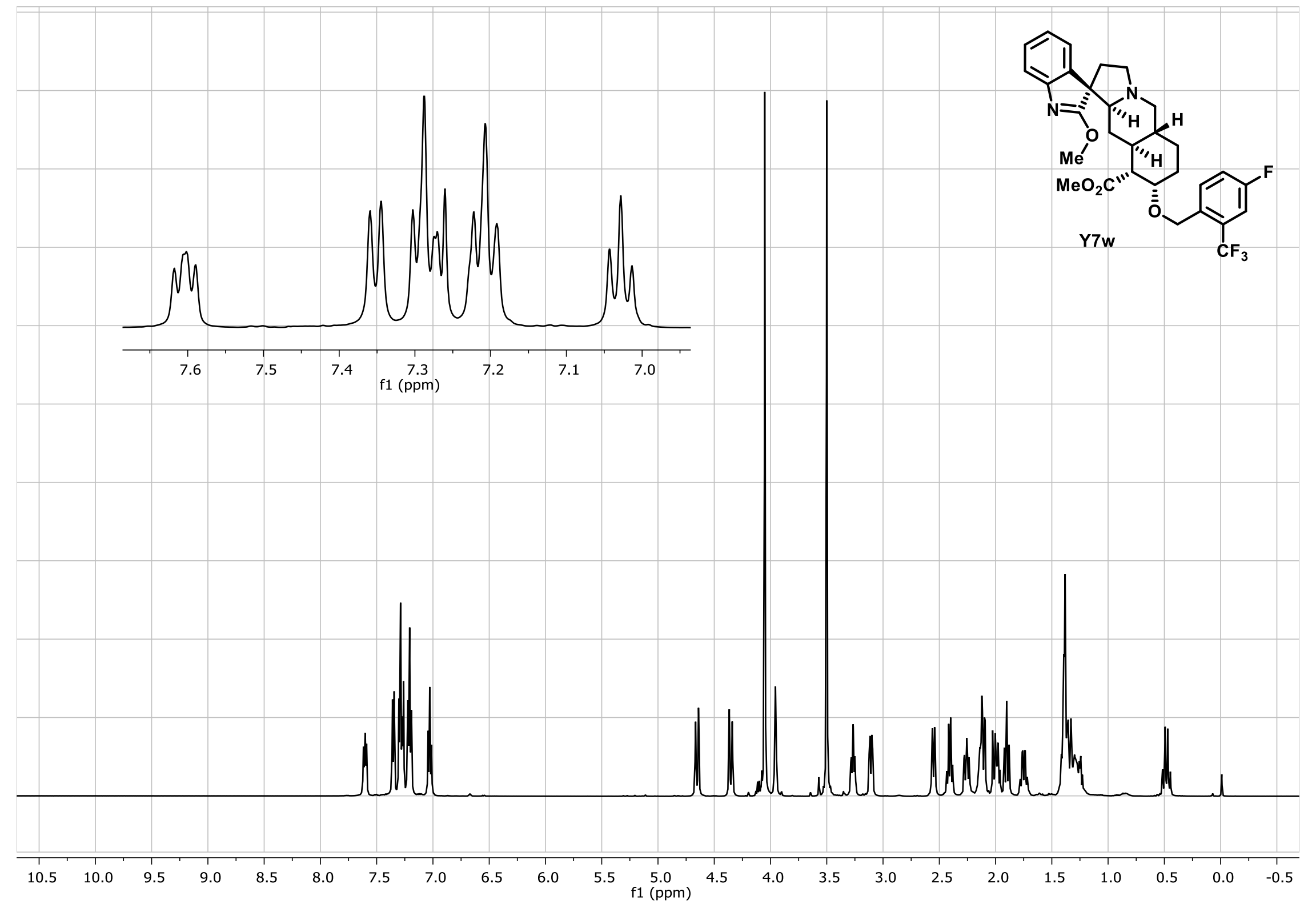

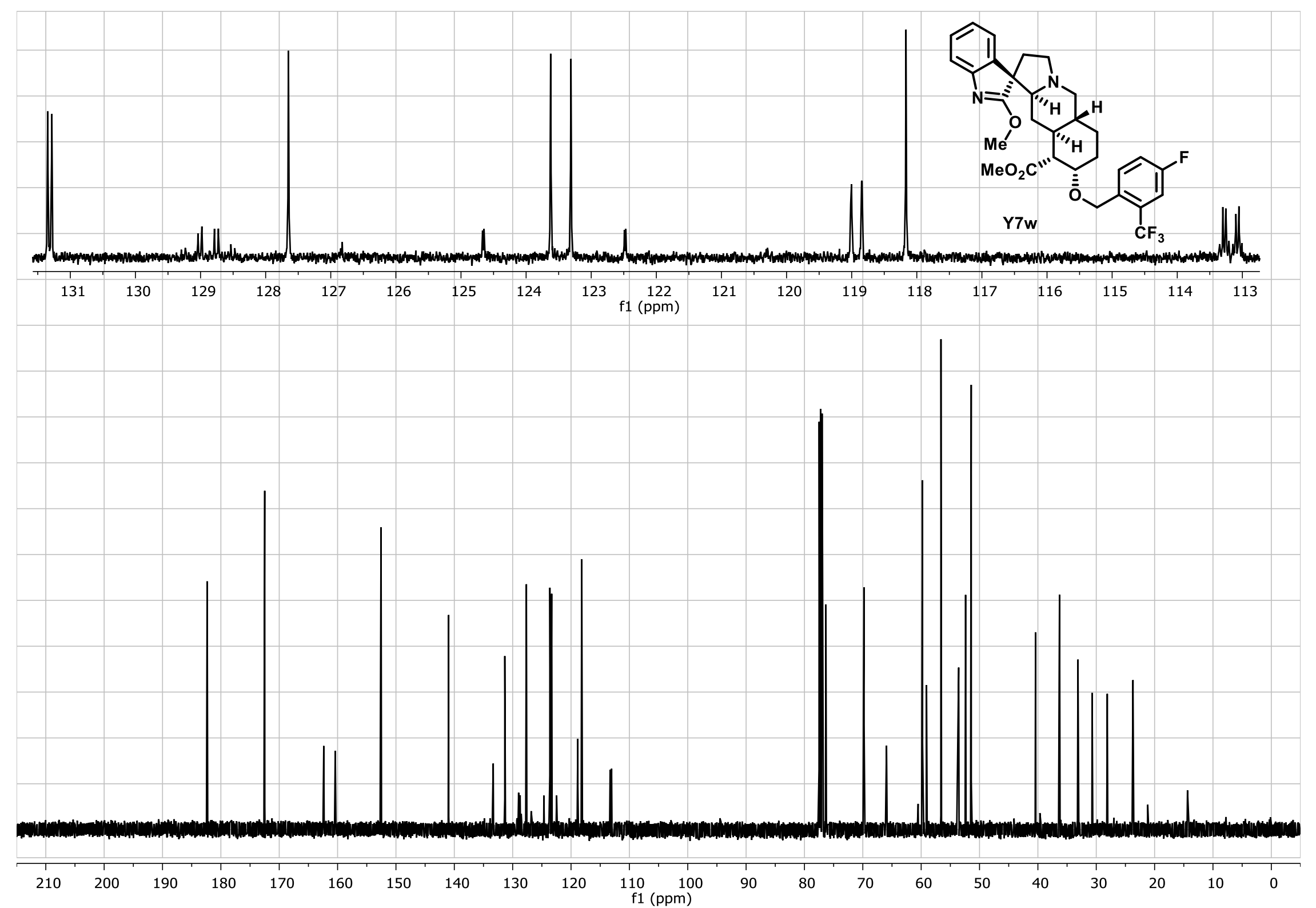


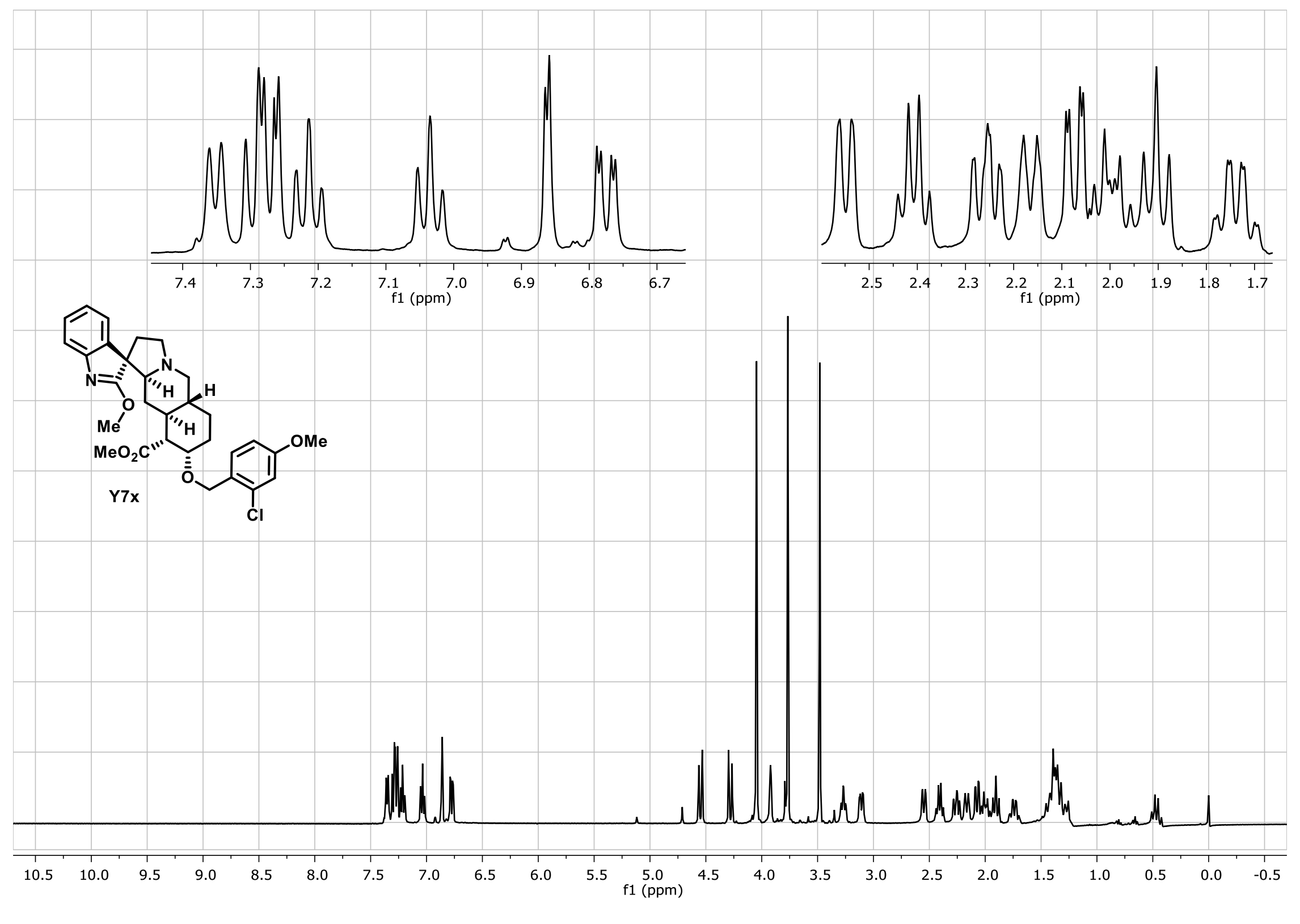




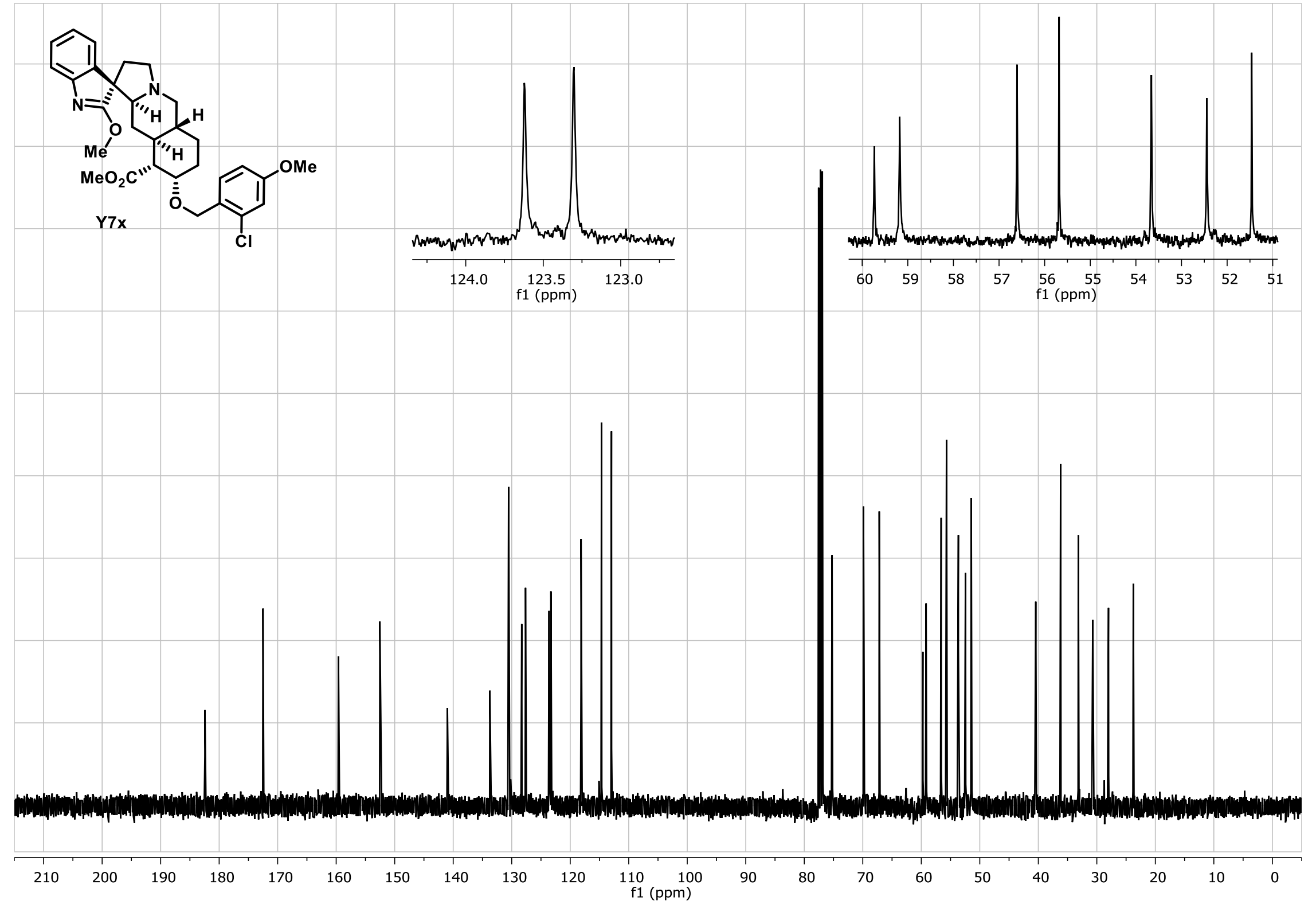

S58 


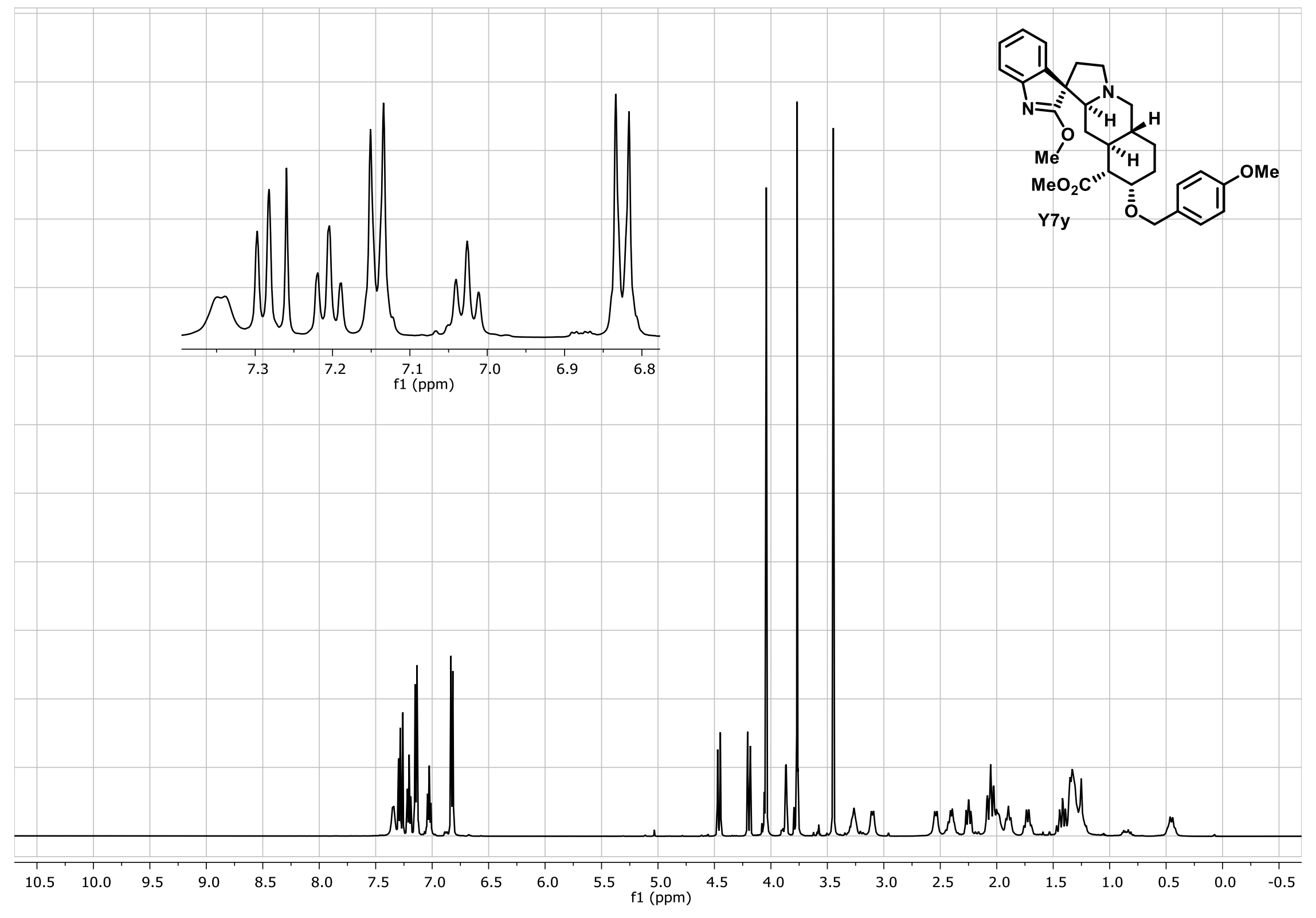

S59 

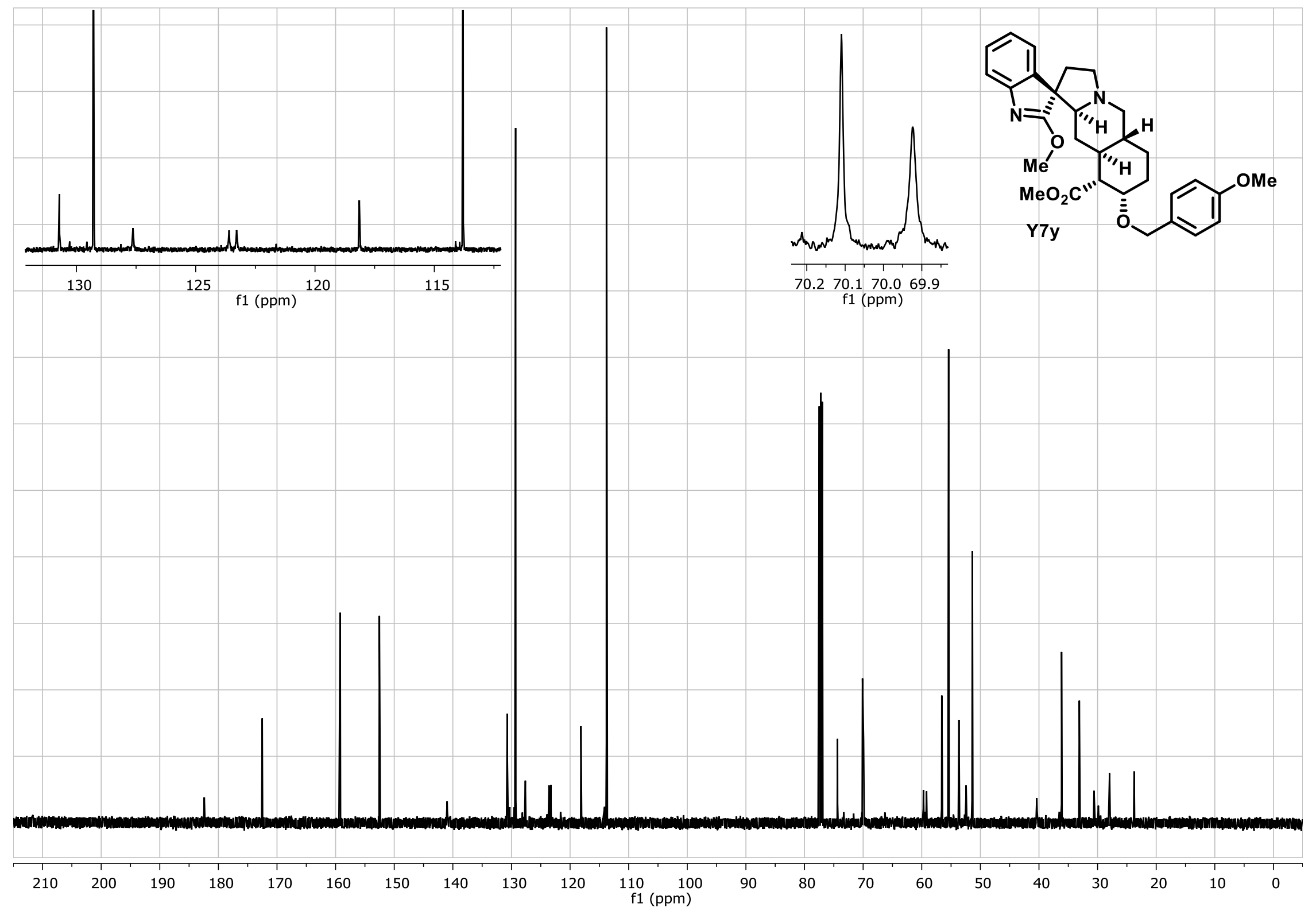


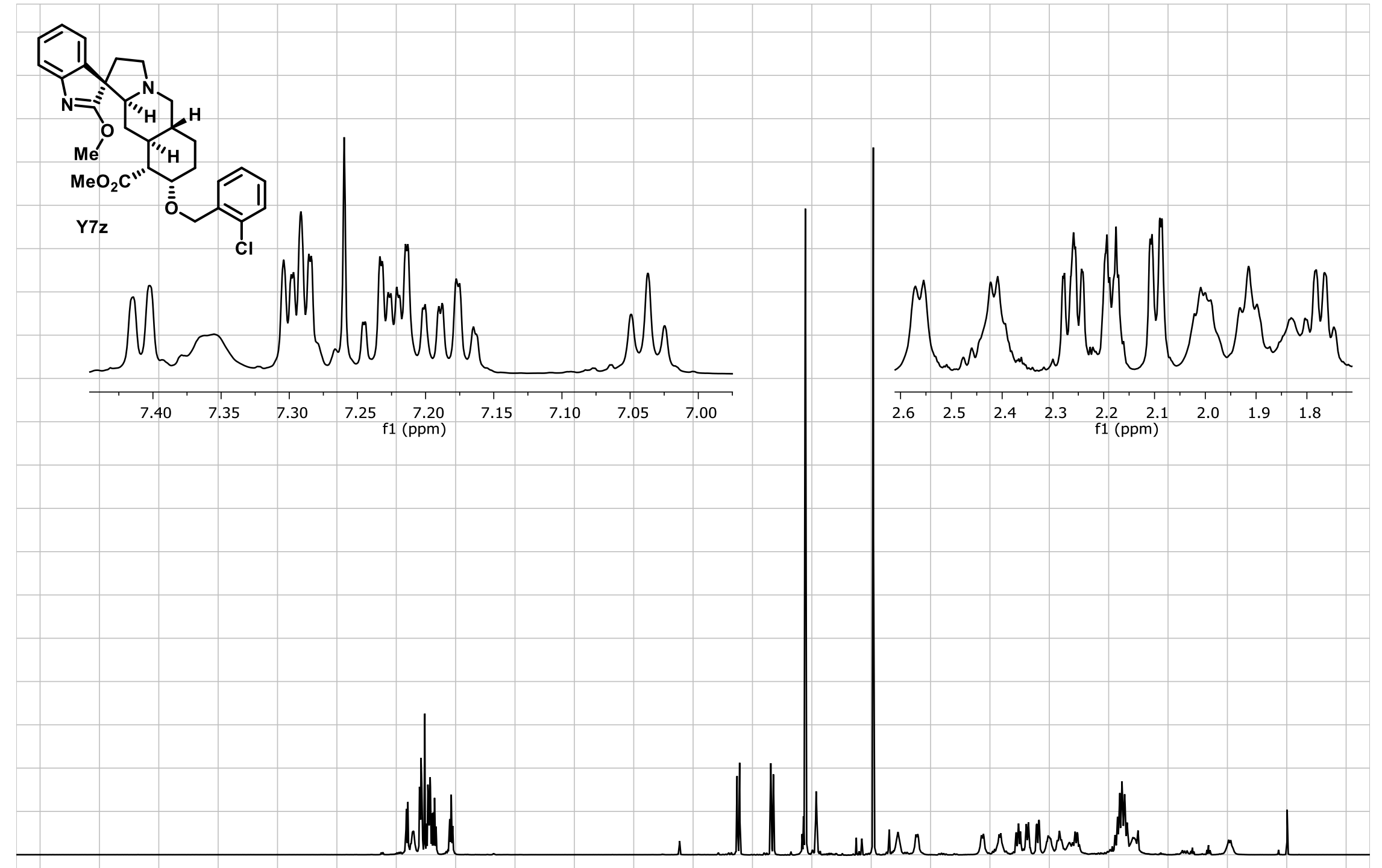

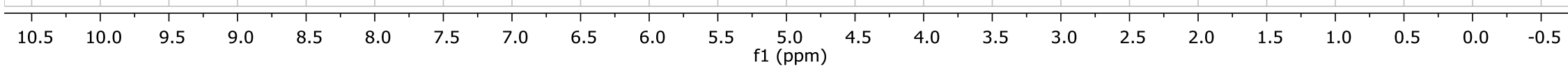




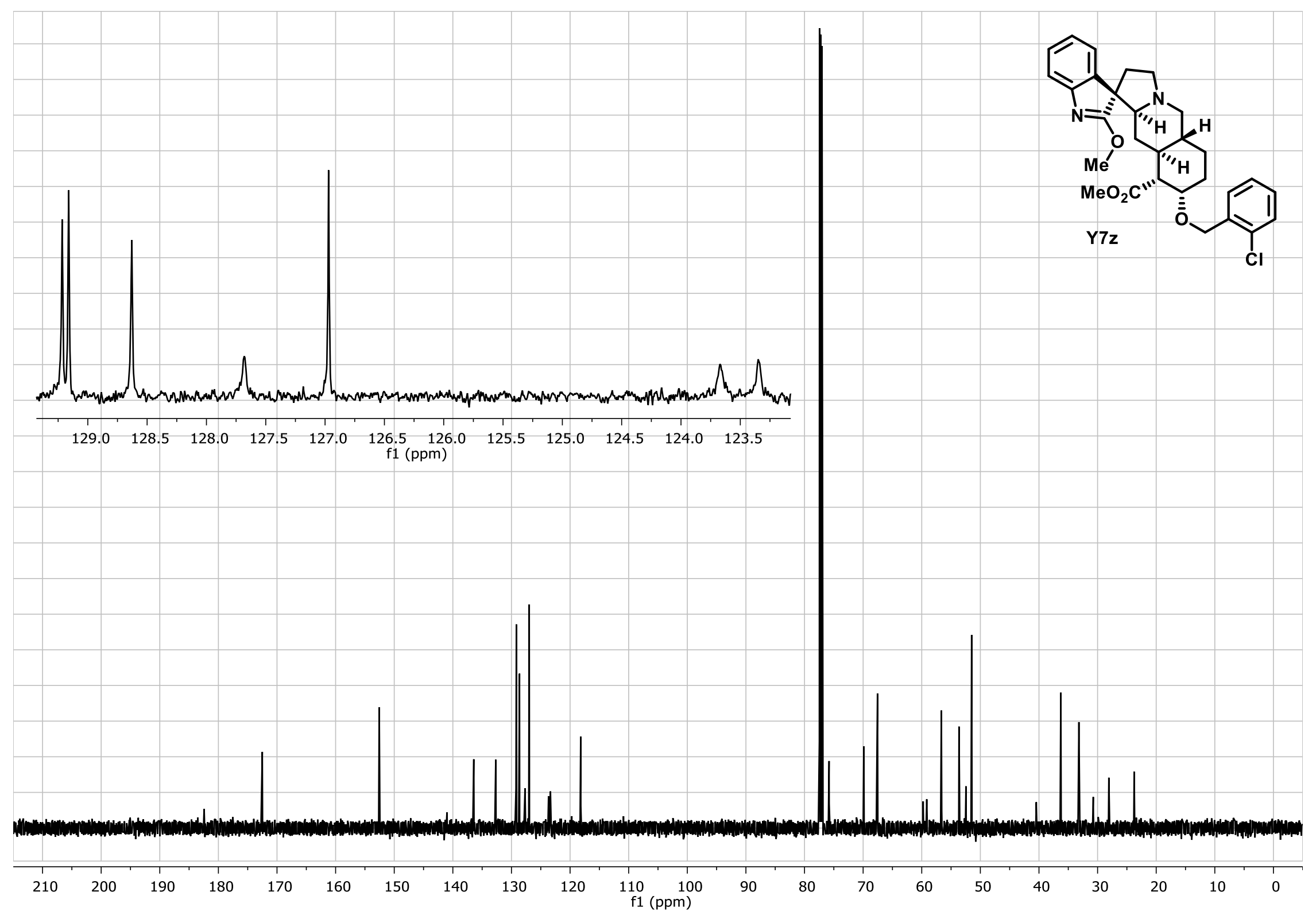




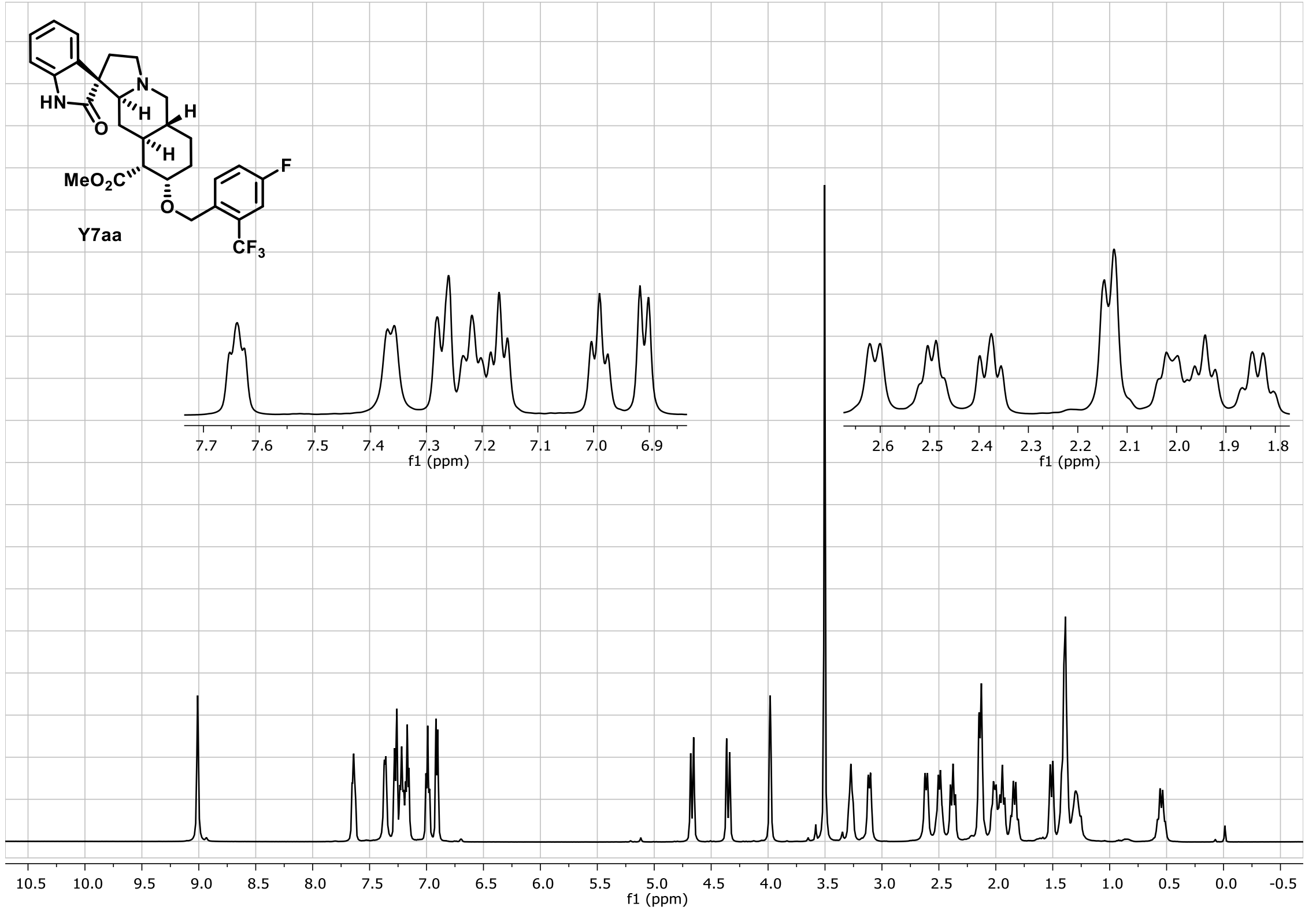

S63 


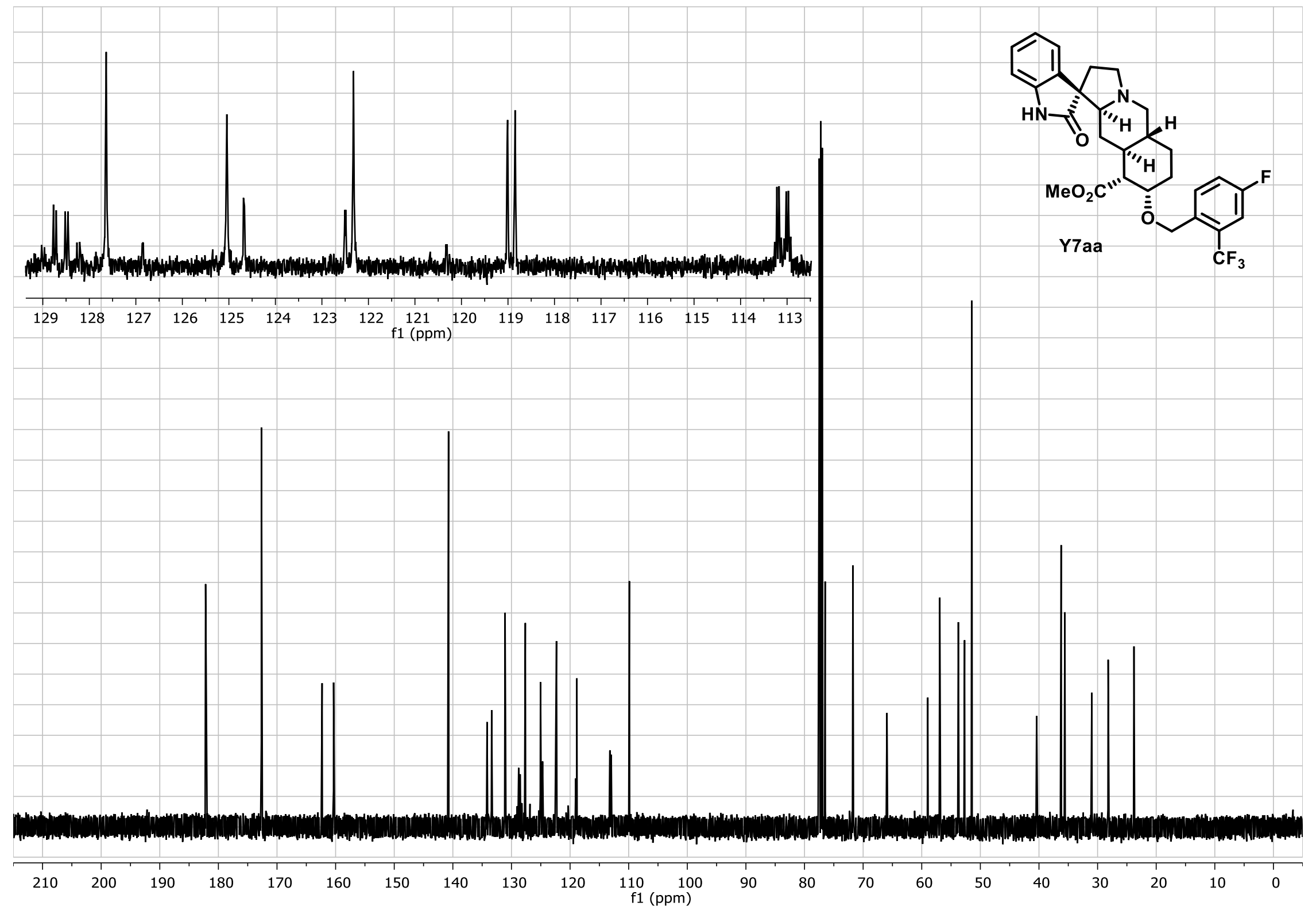




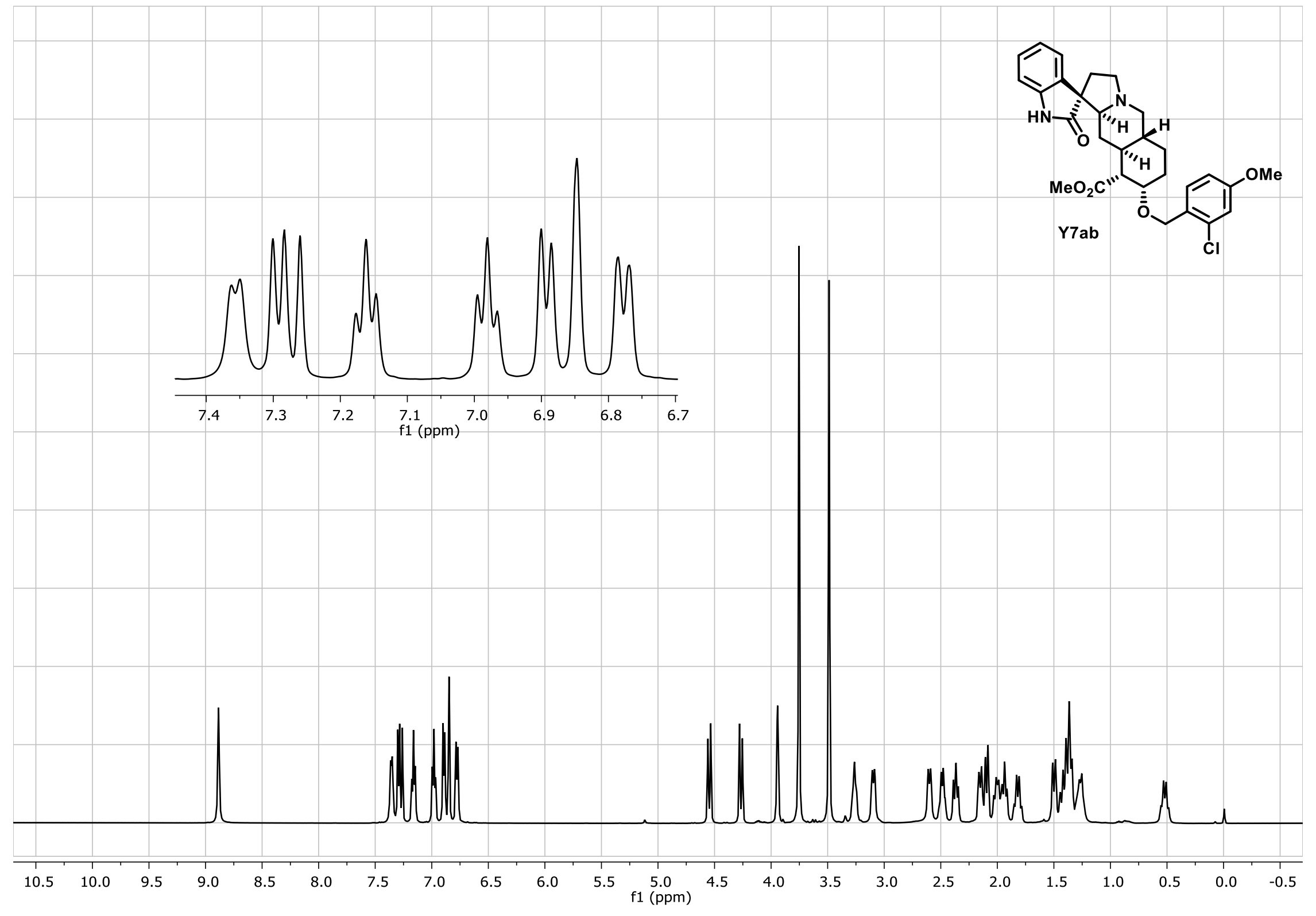

S65 

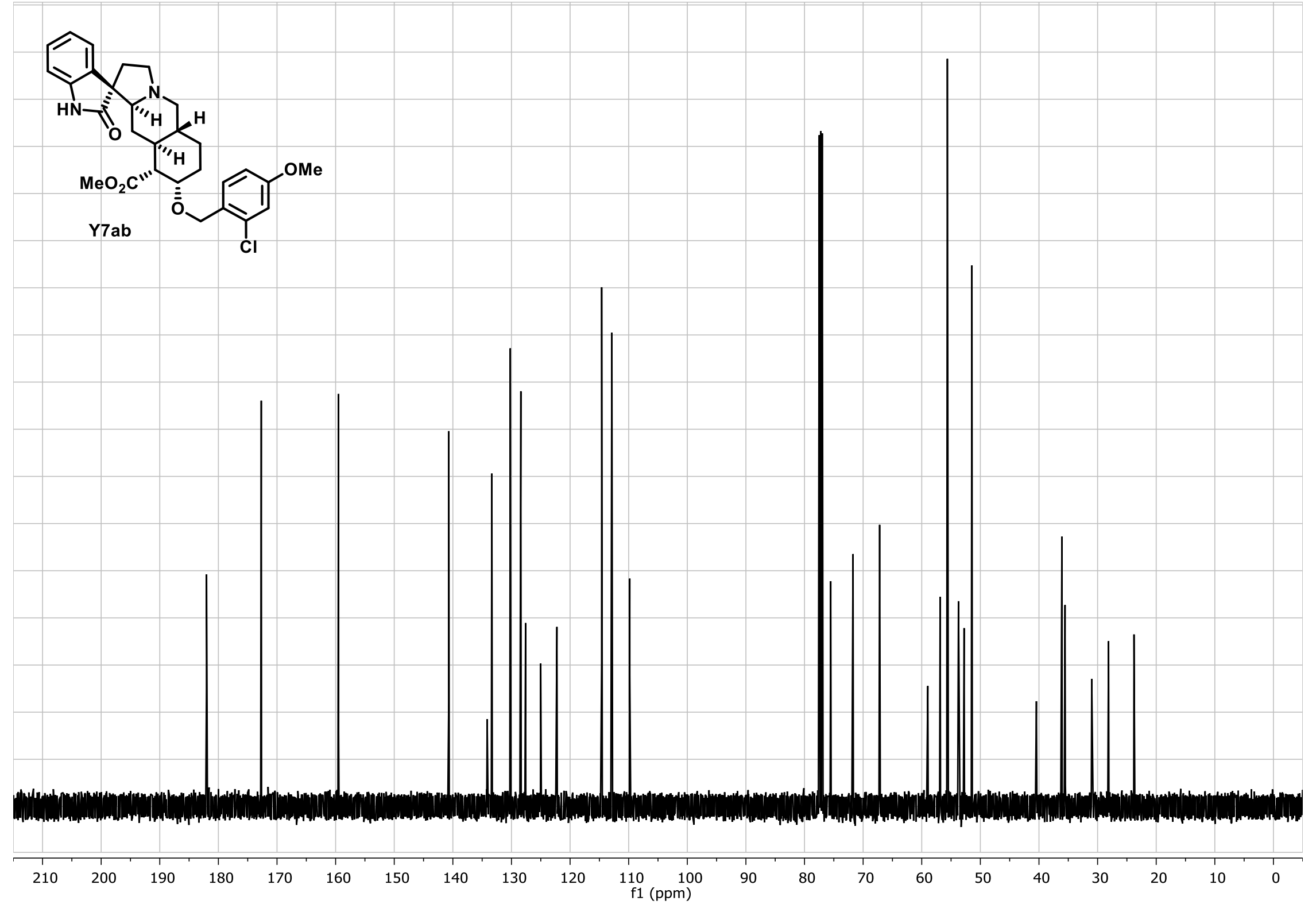

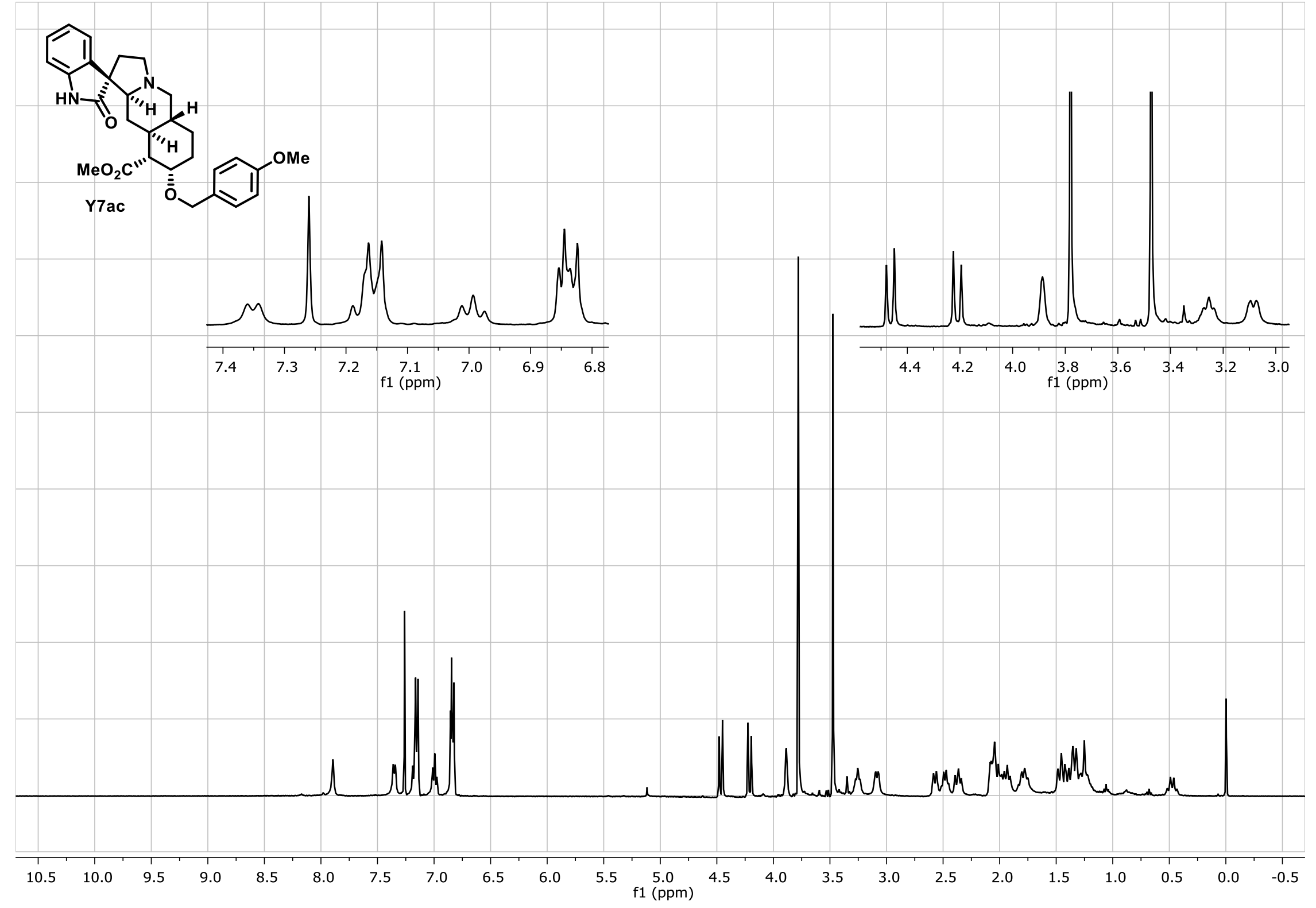


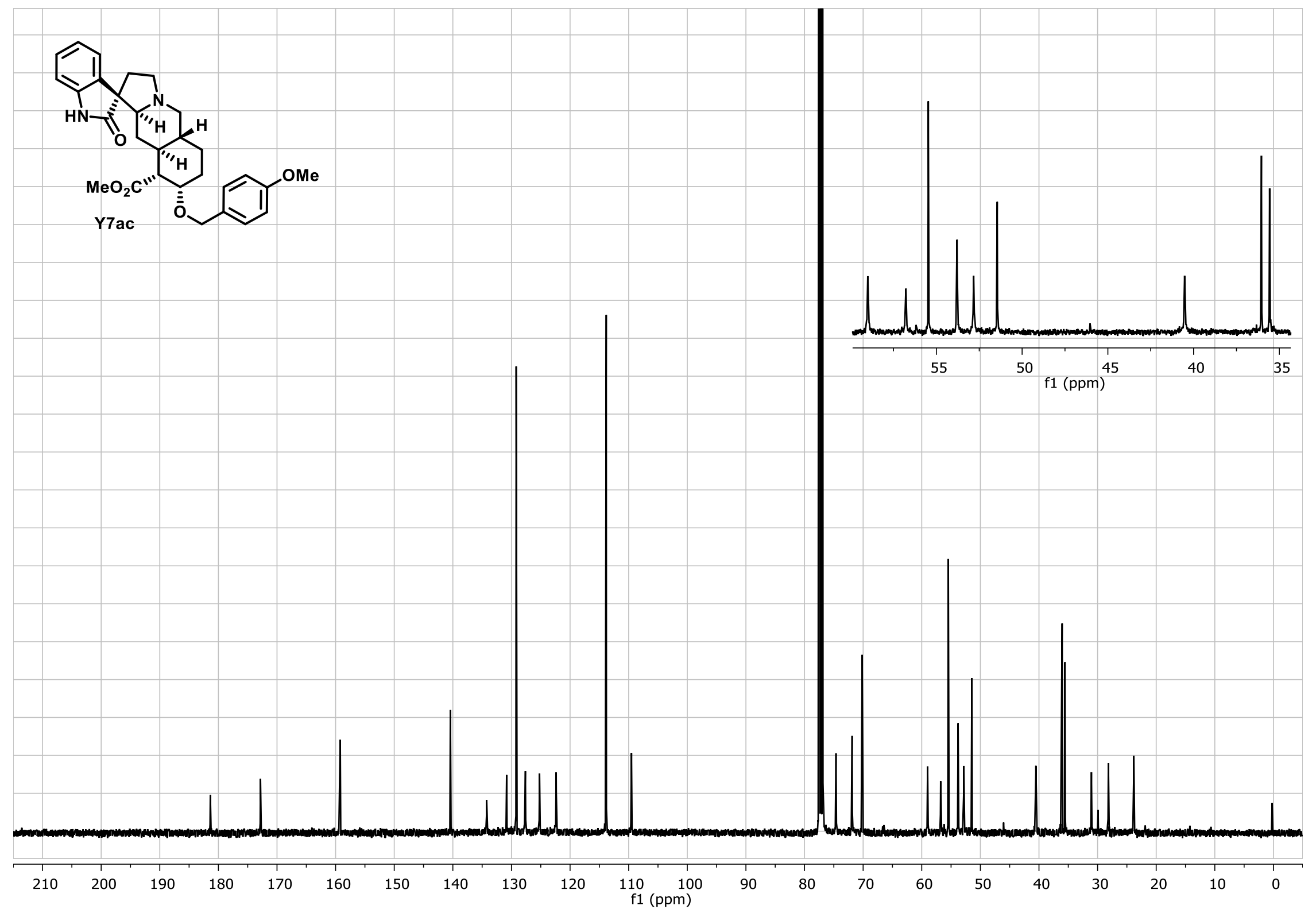



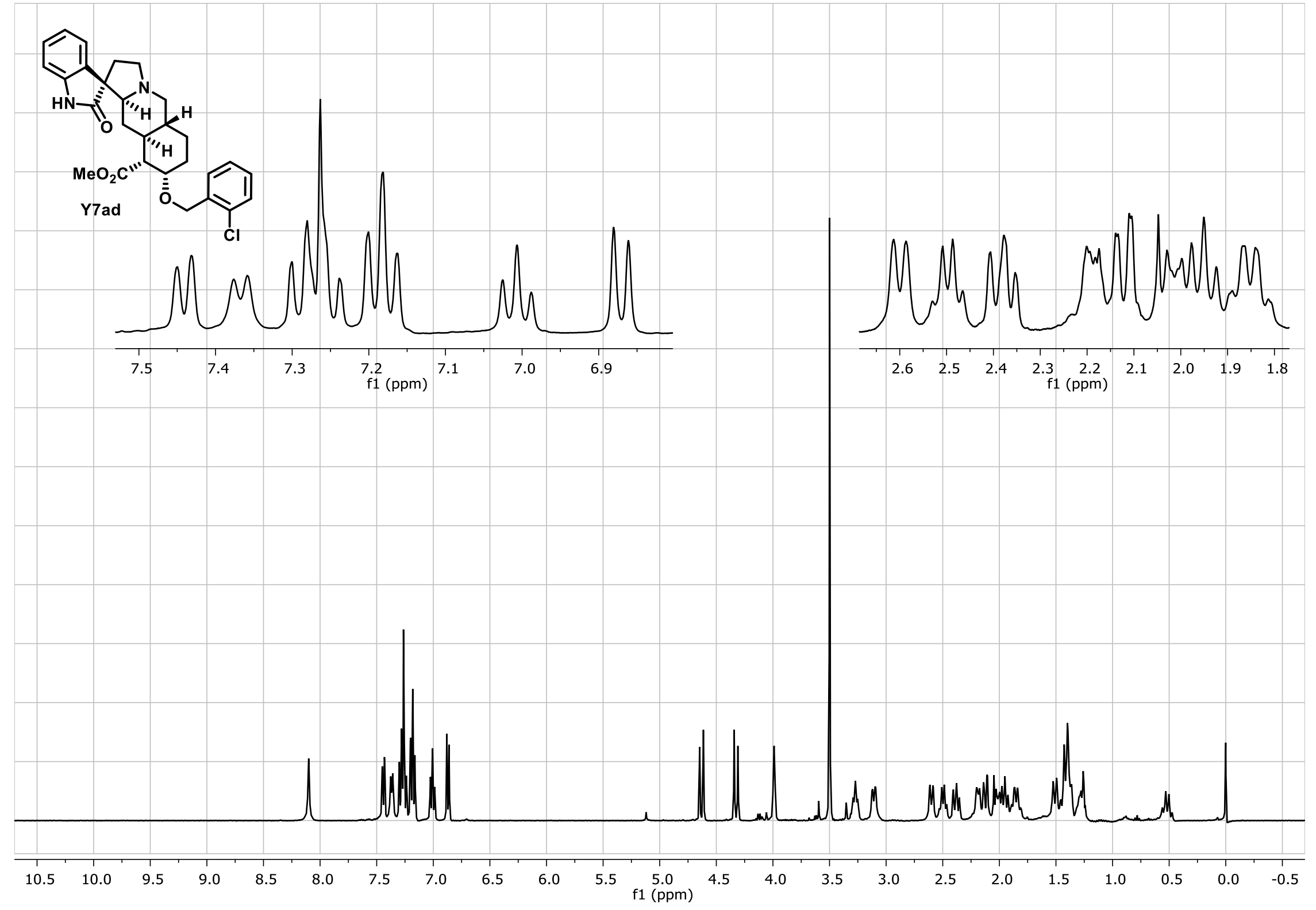


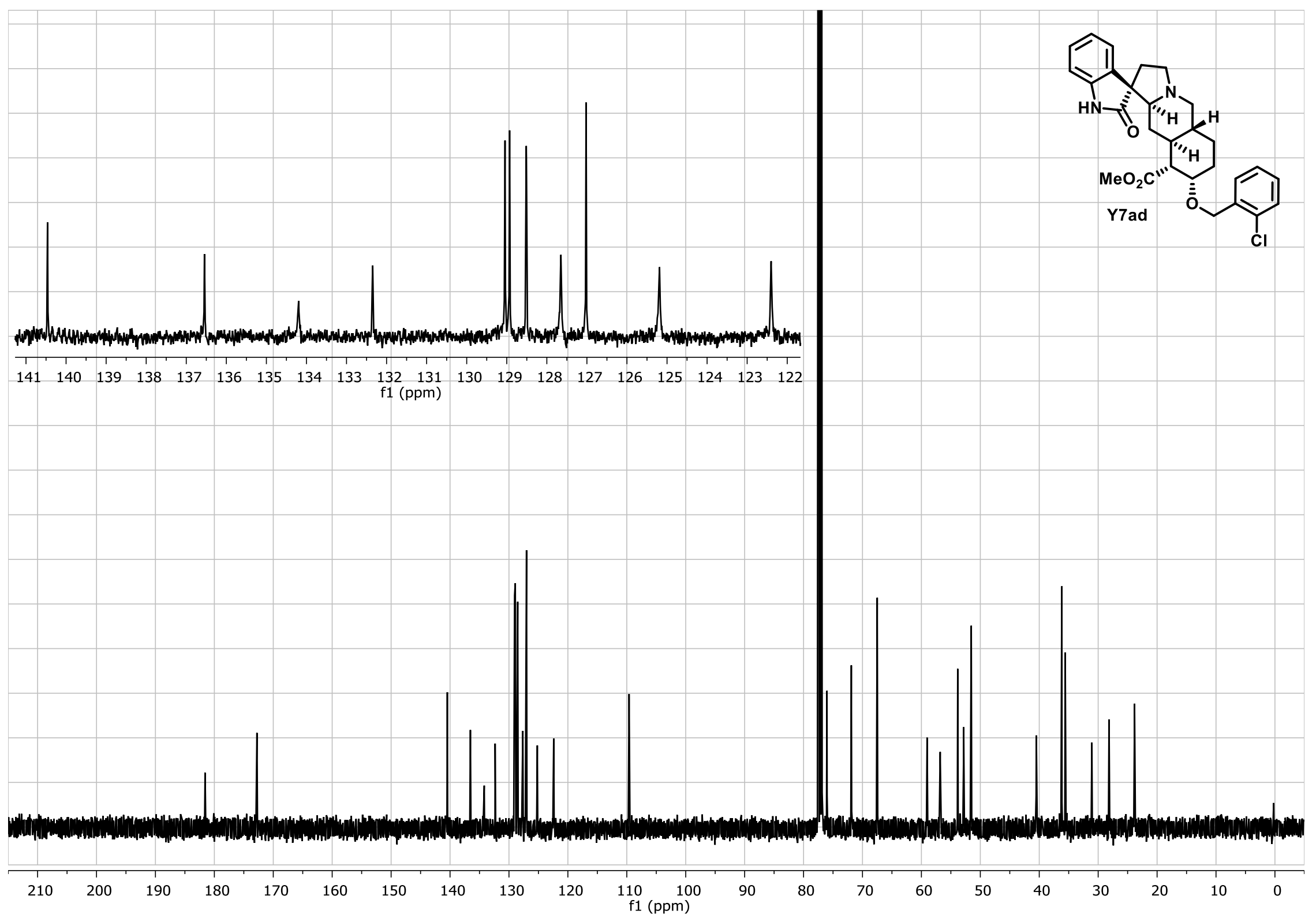




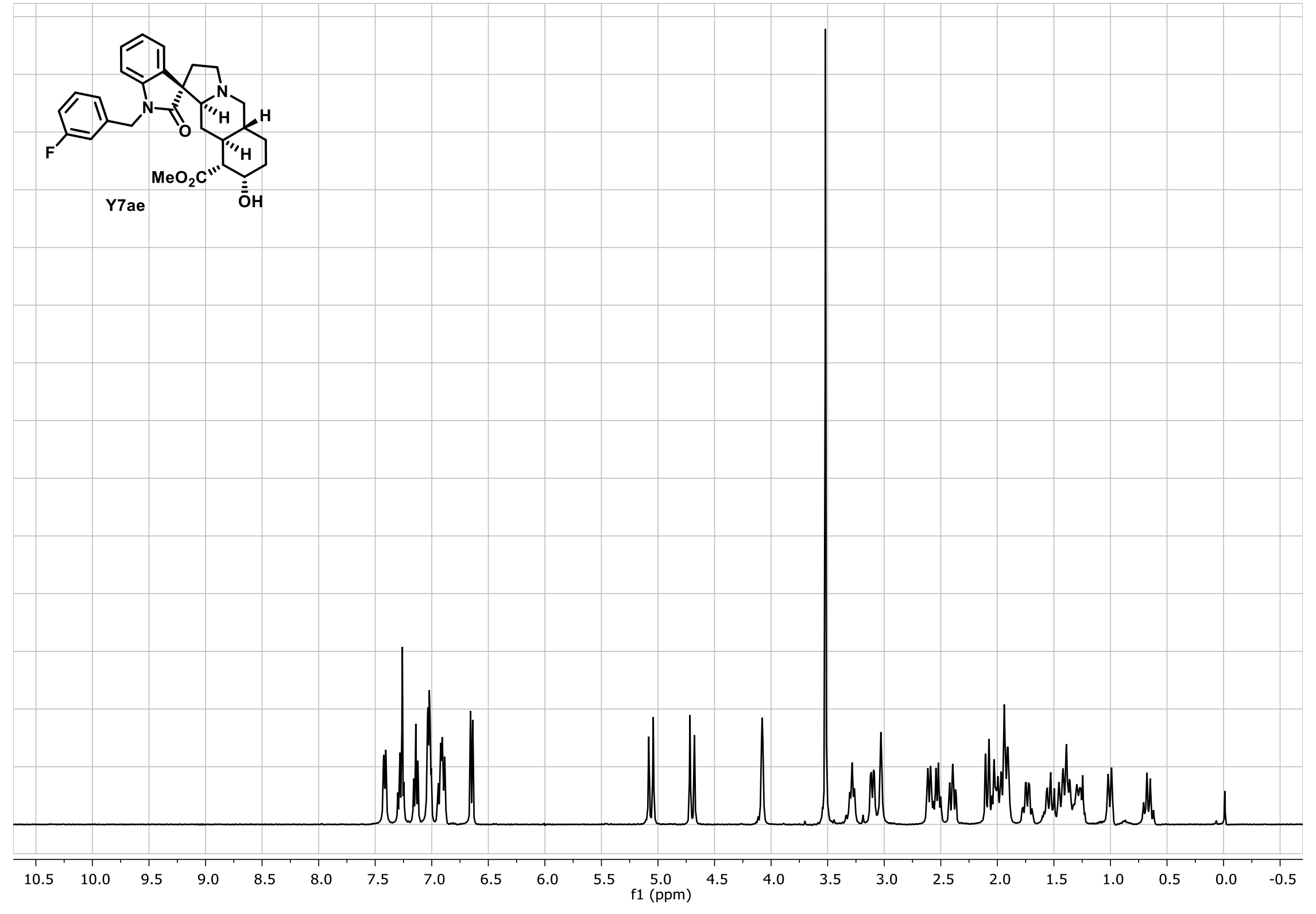




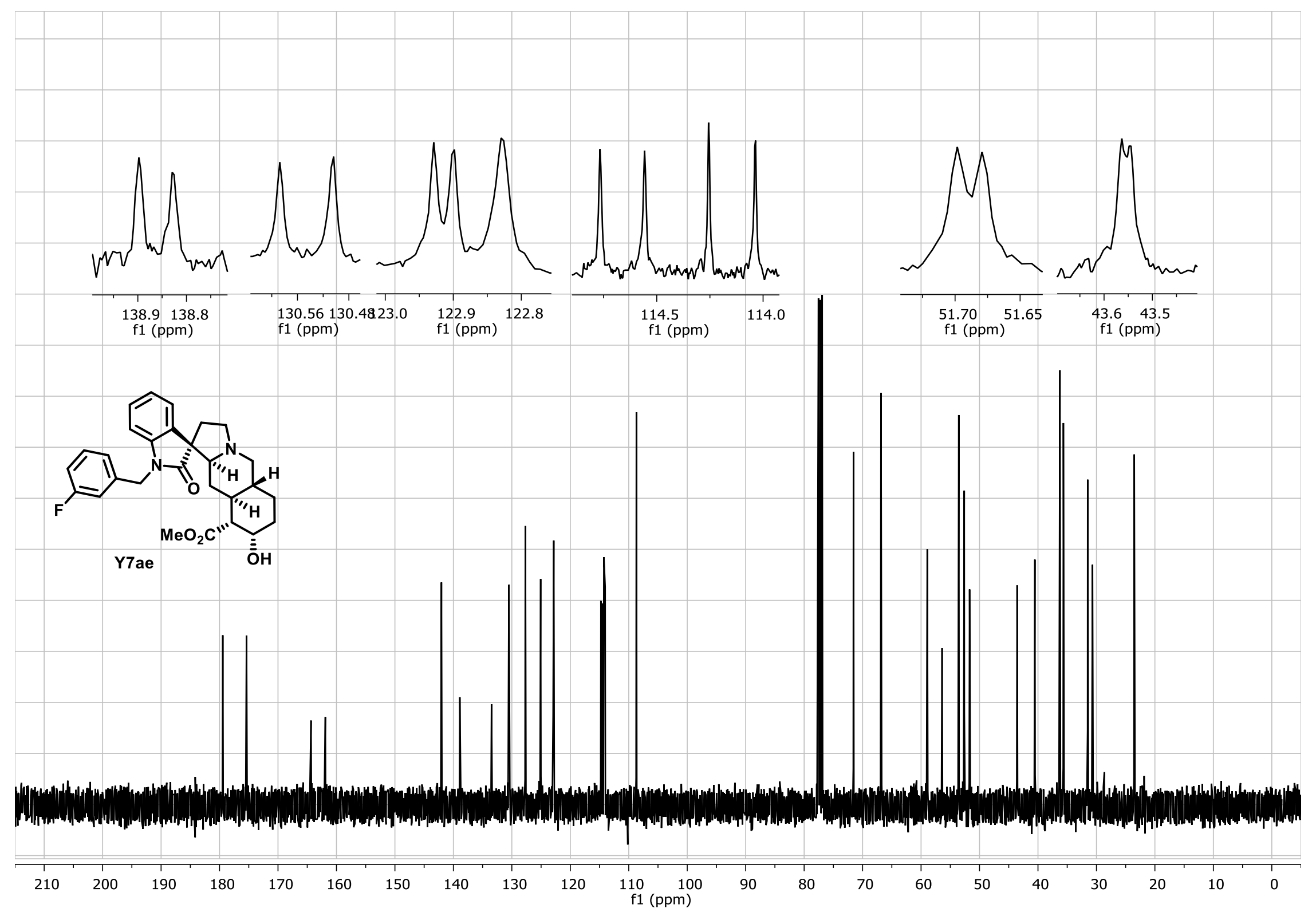




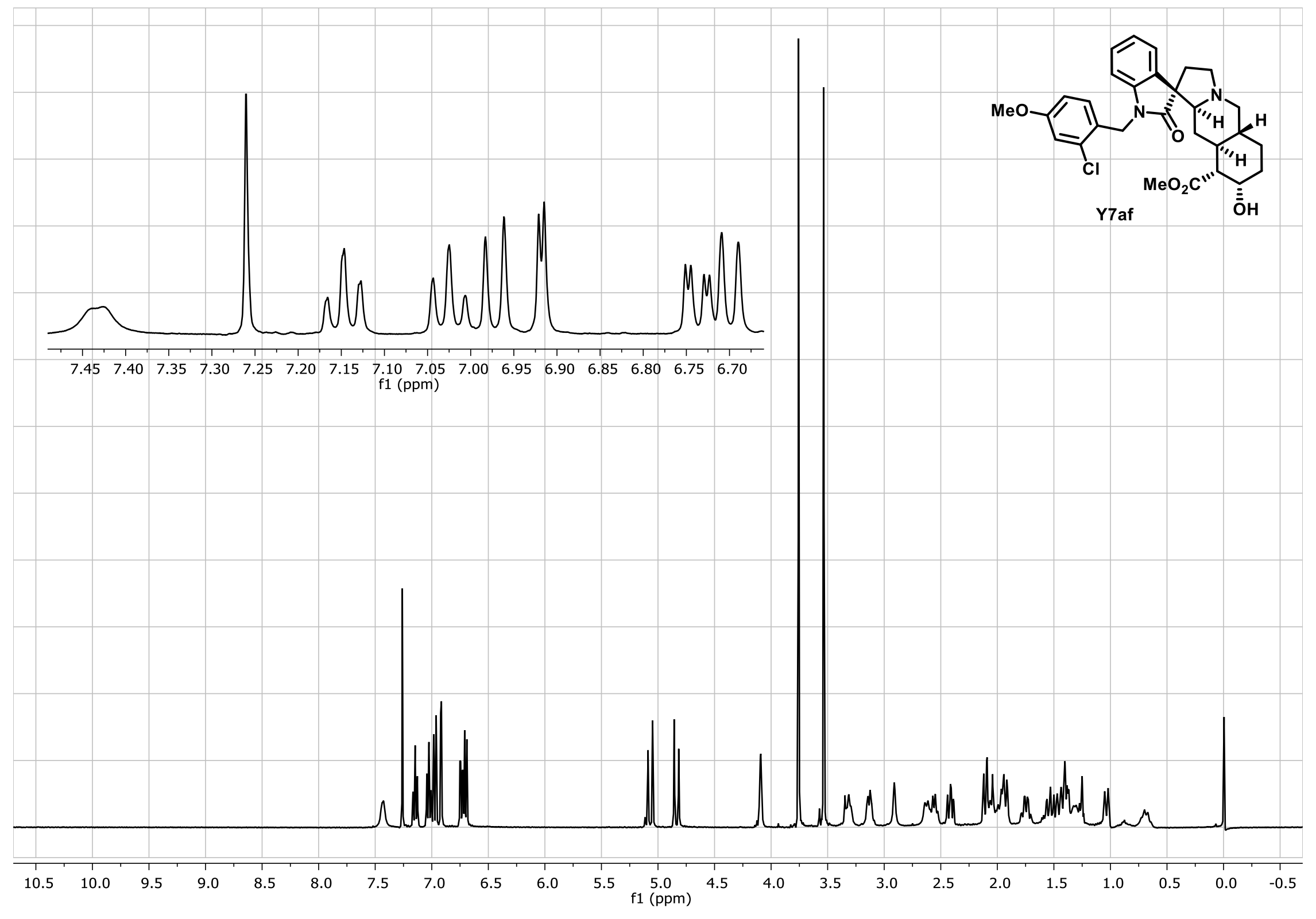




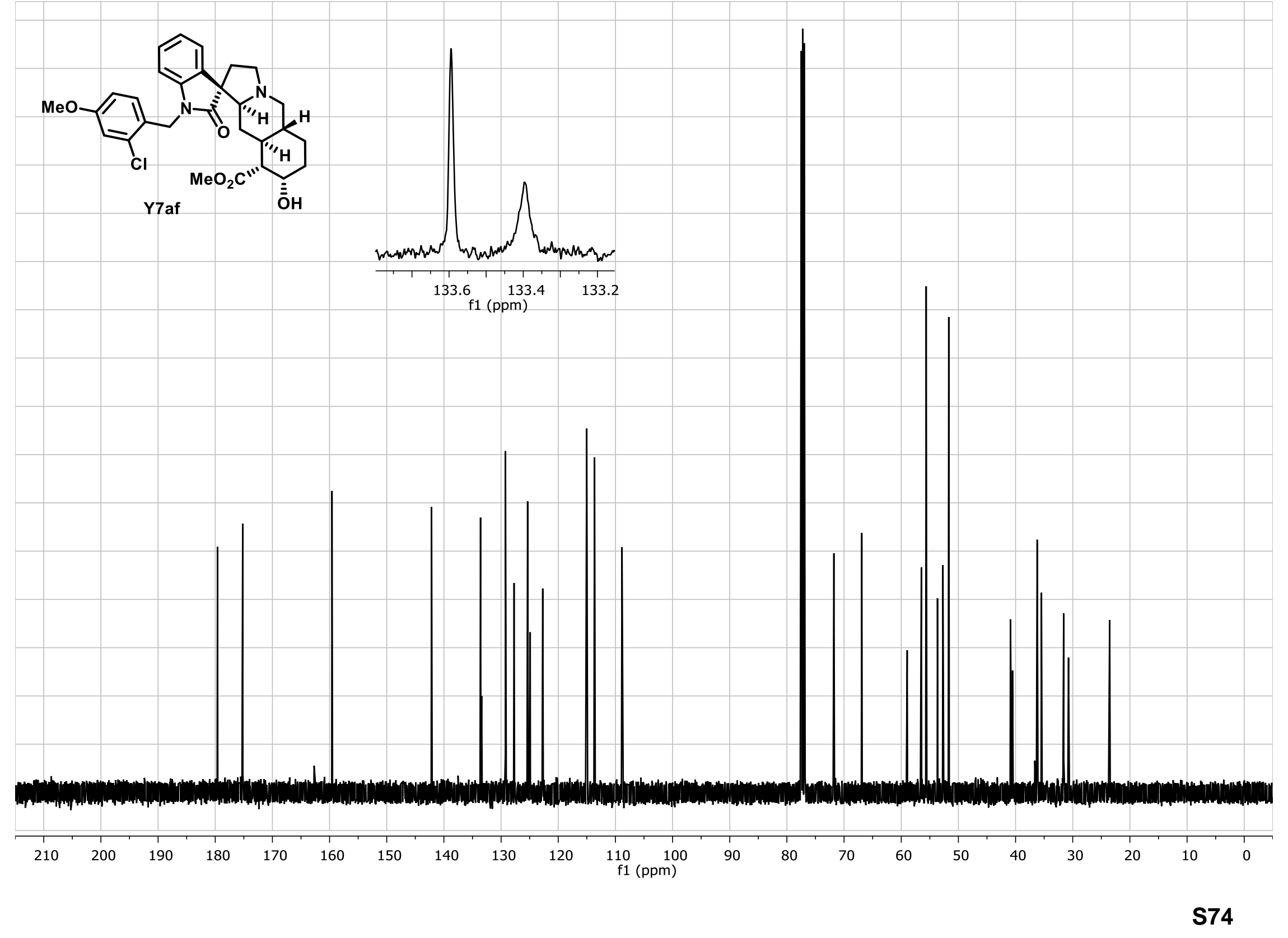




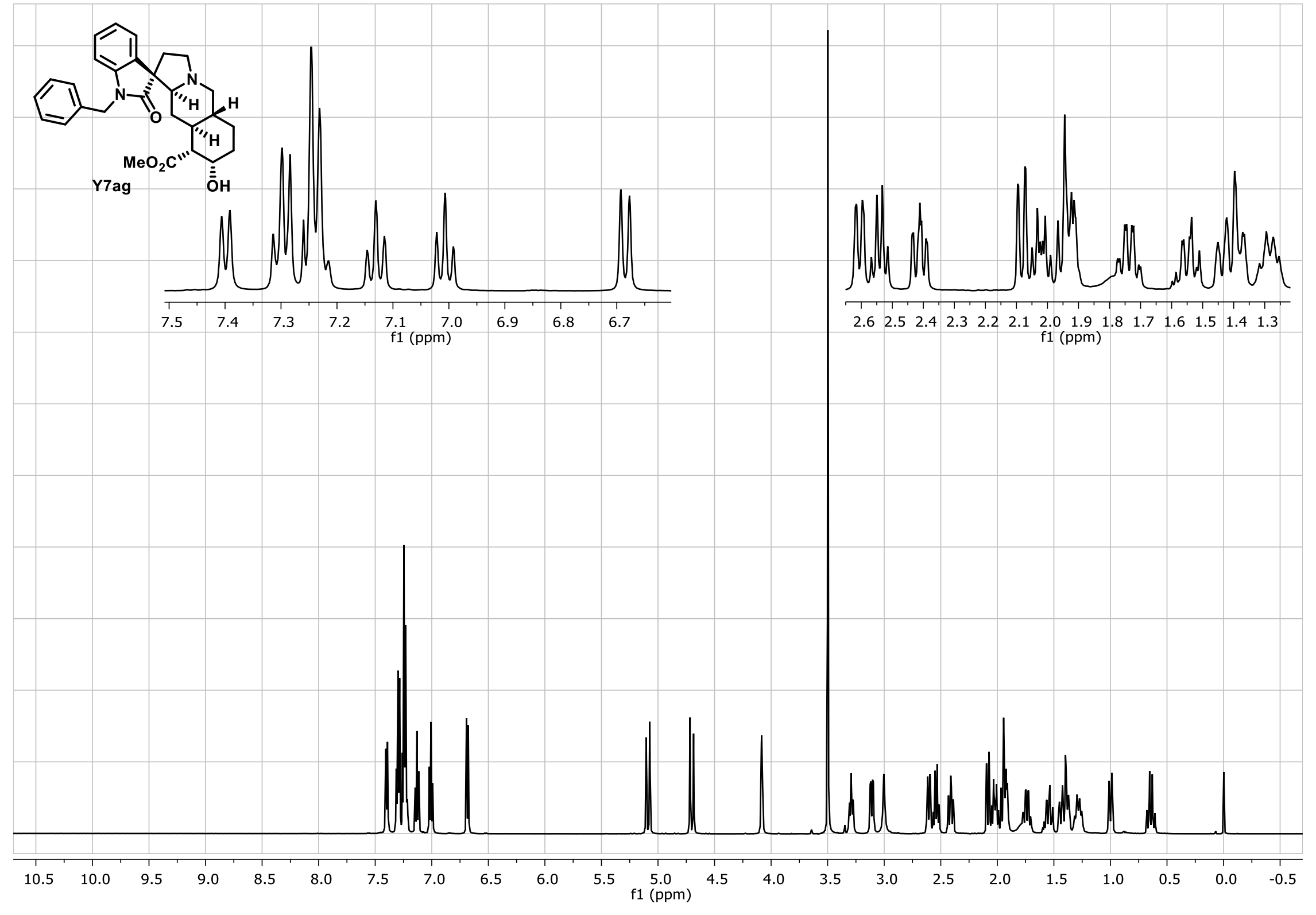




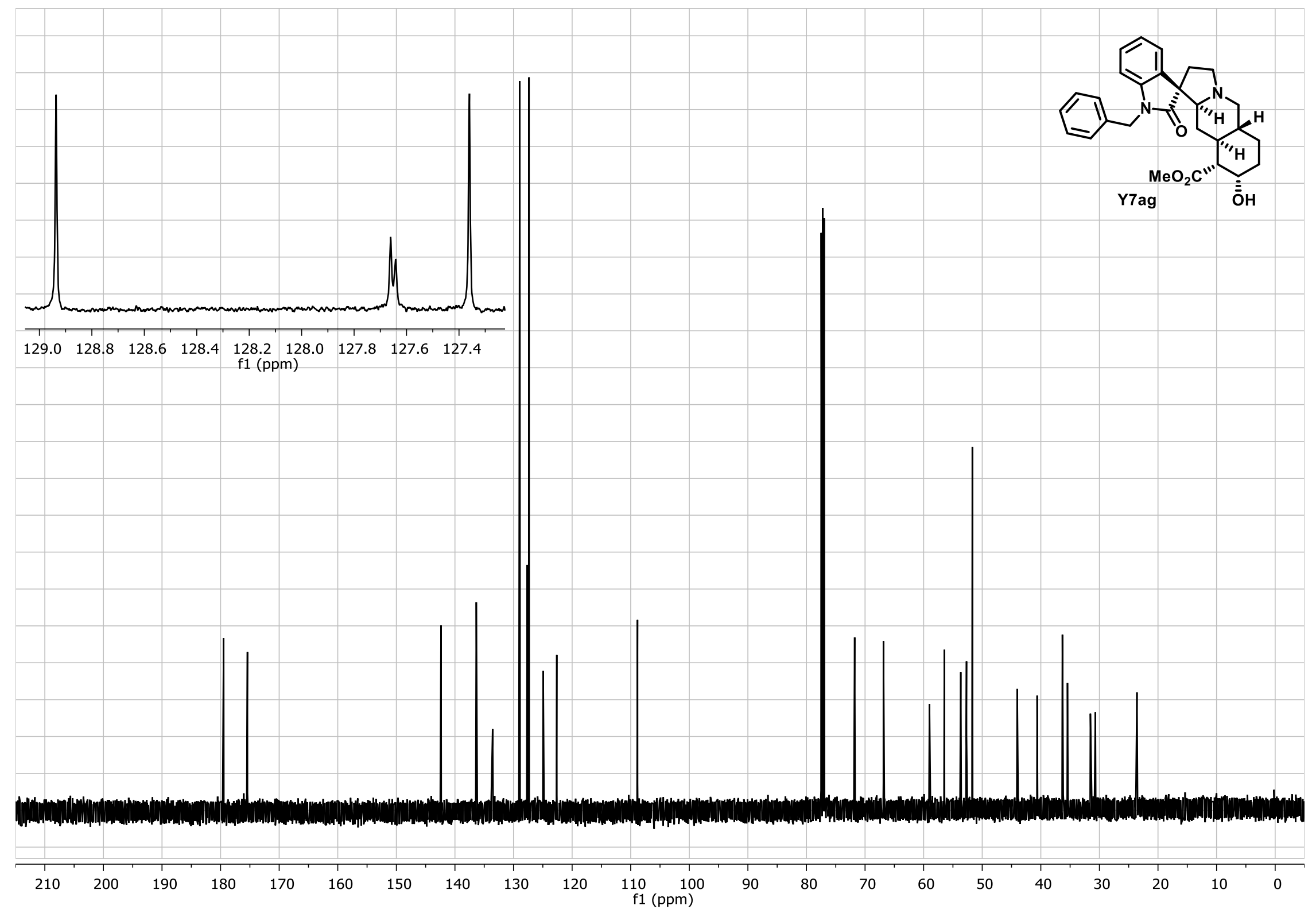



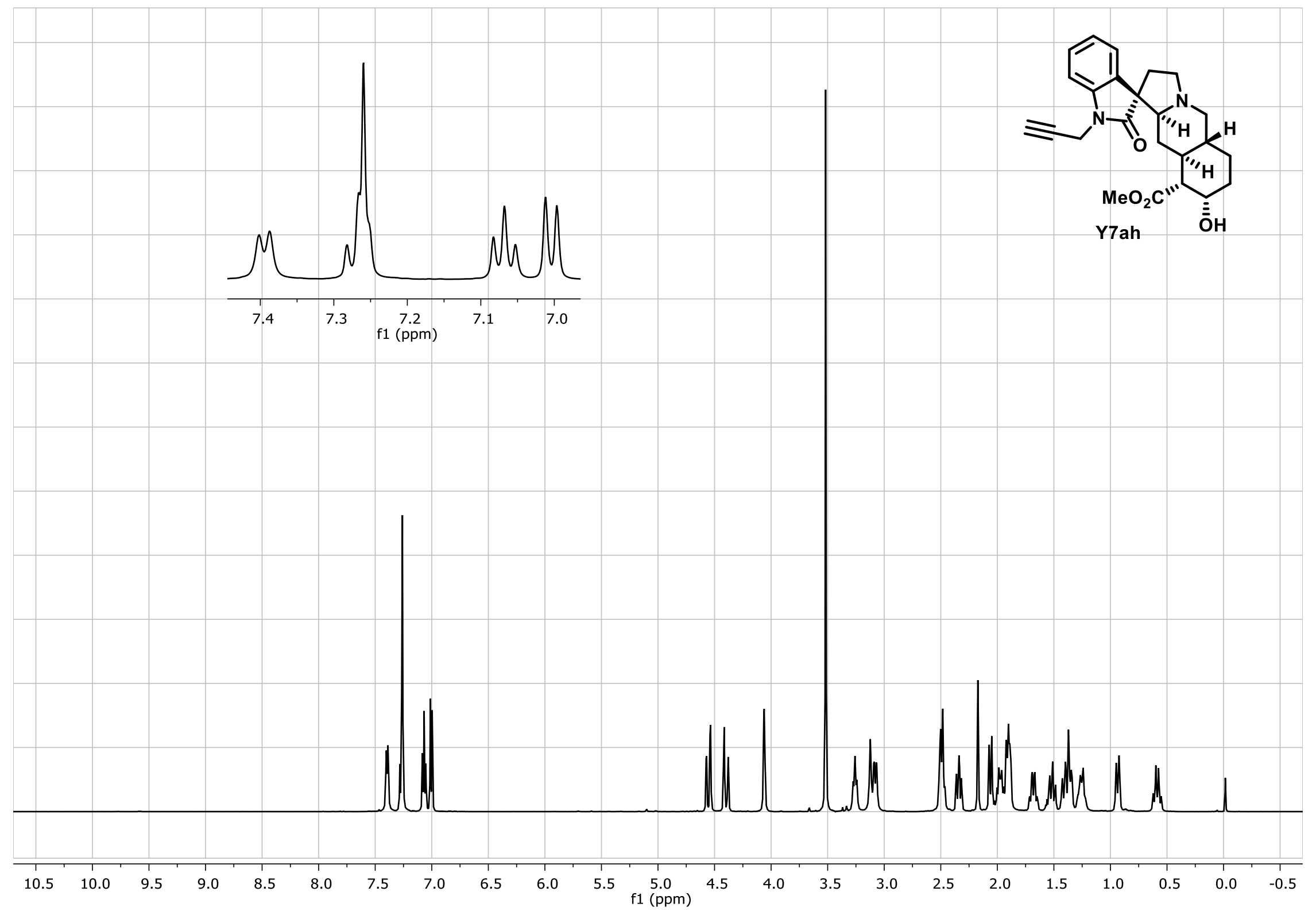


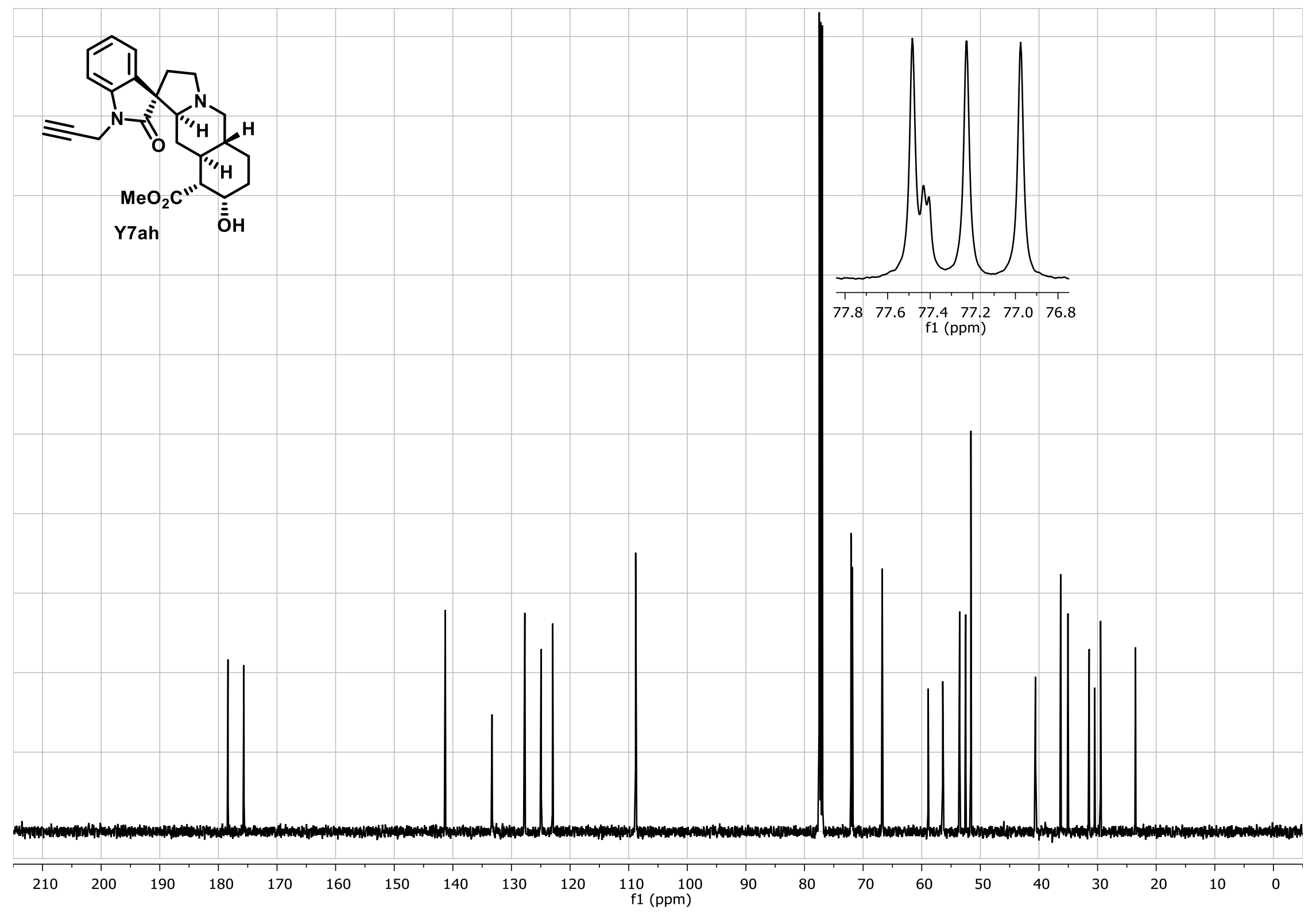

S78 


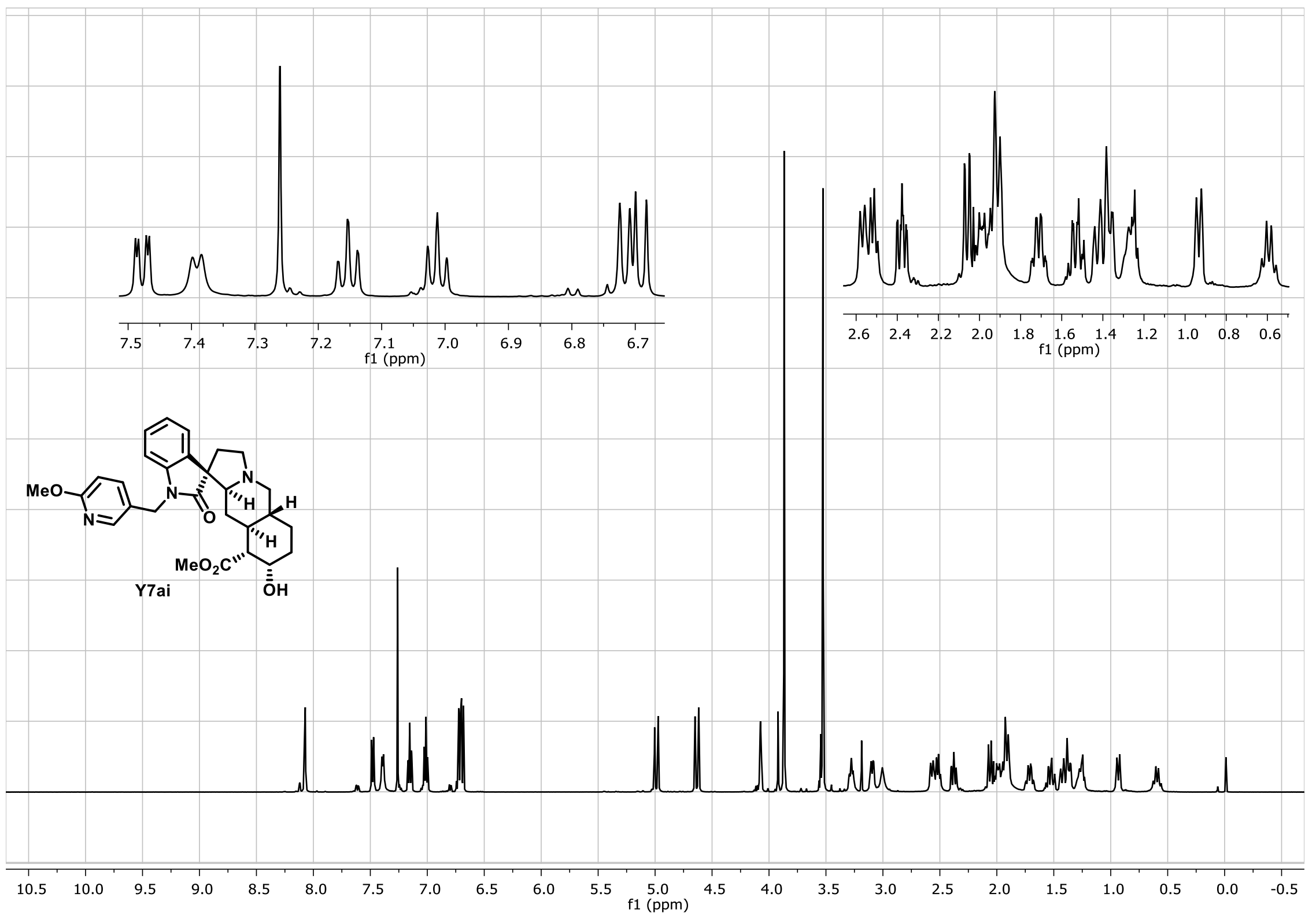

S79 


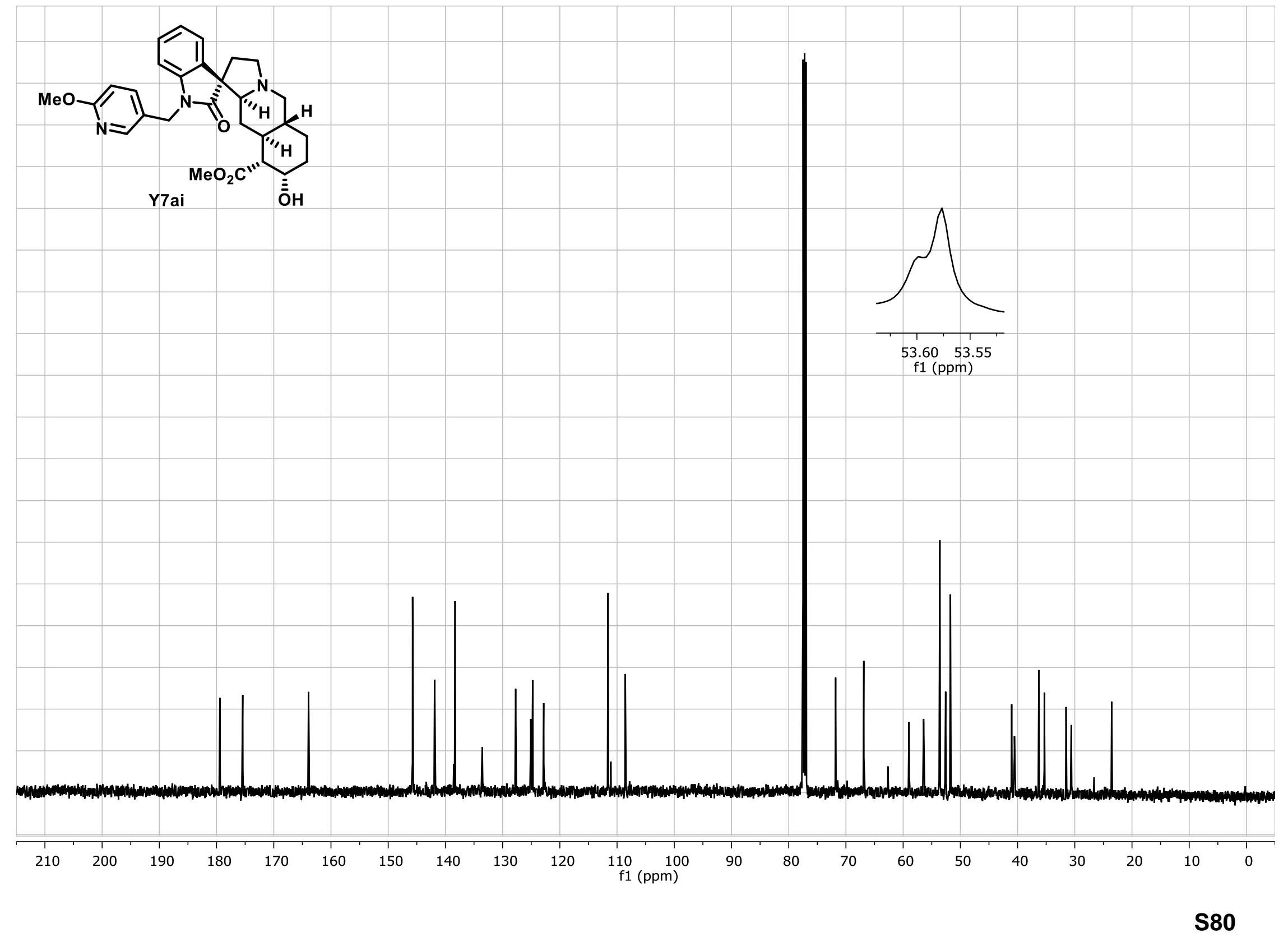



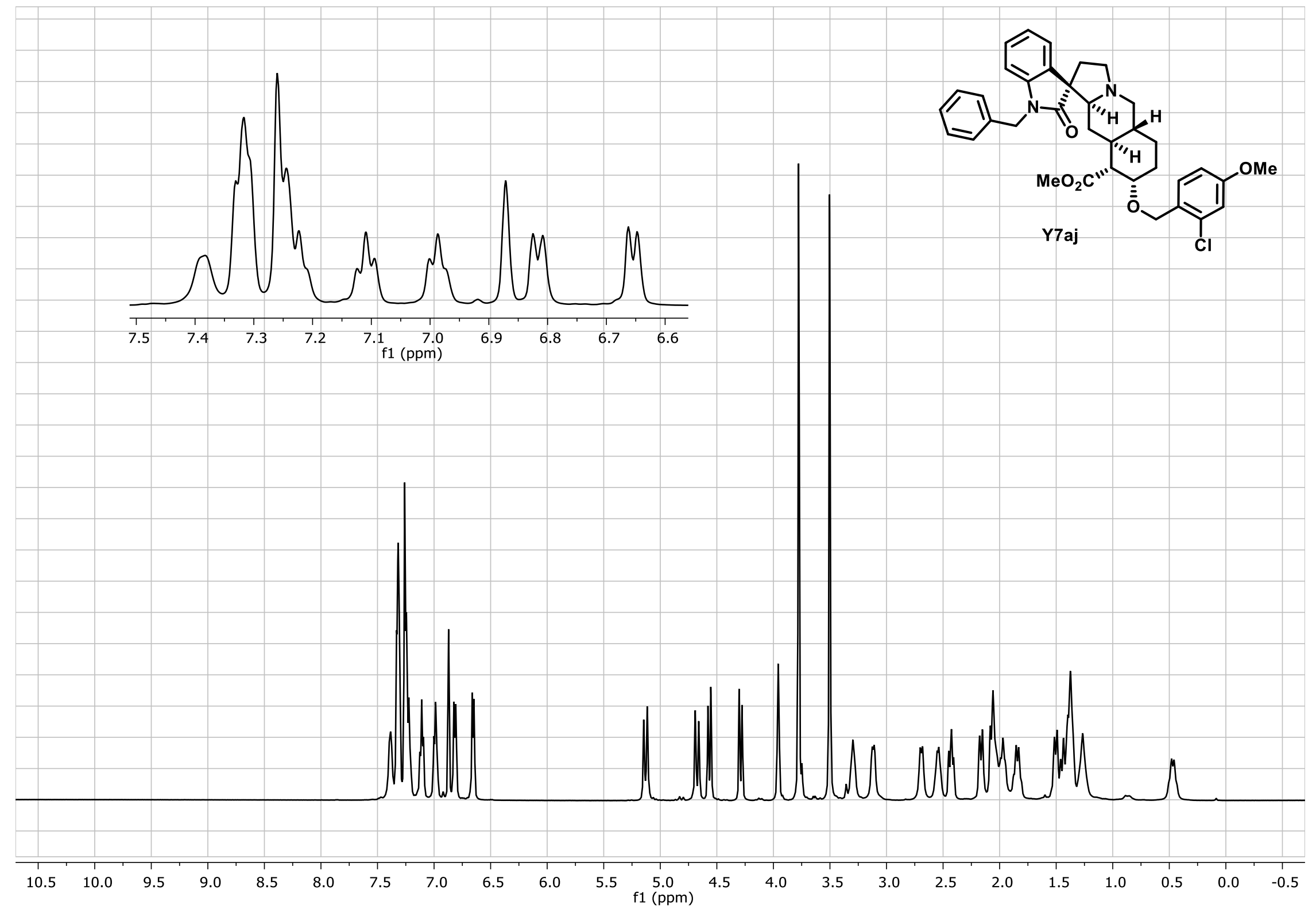

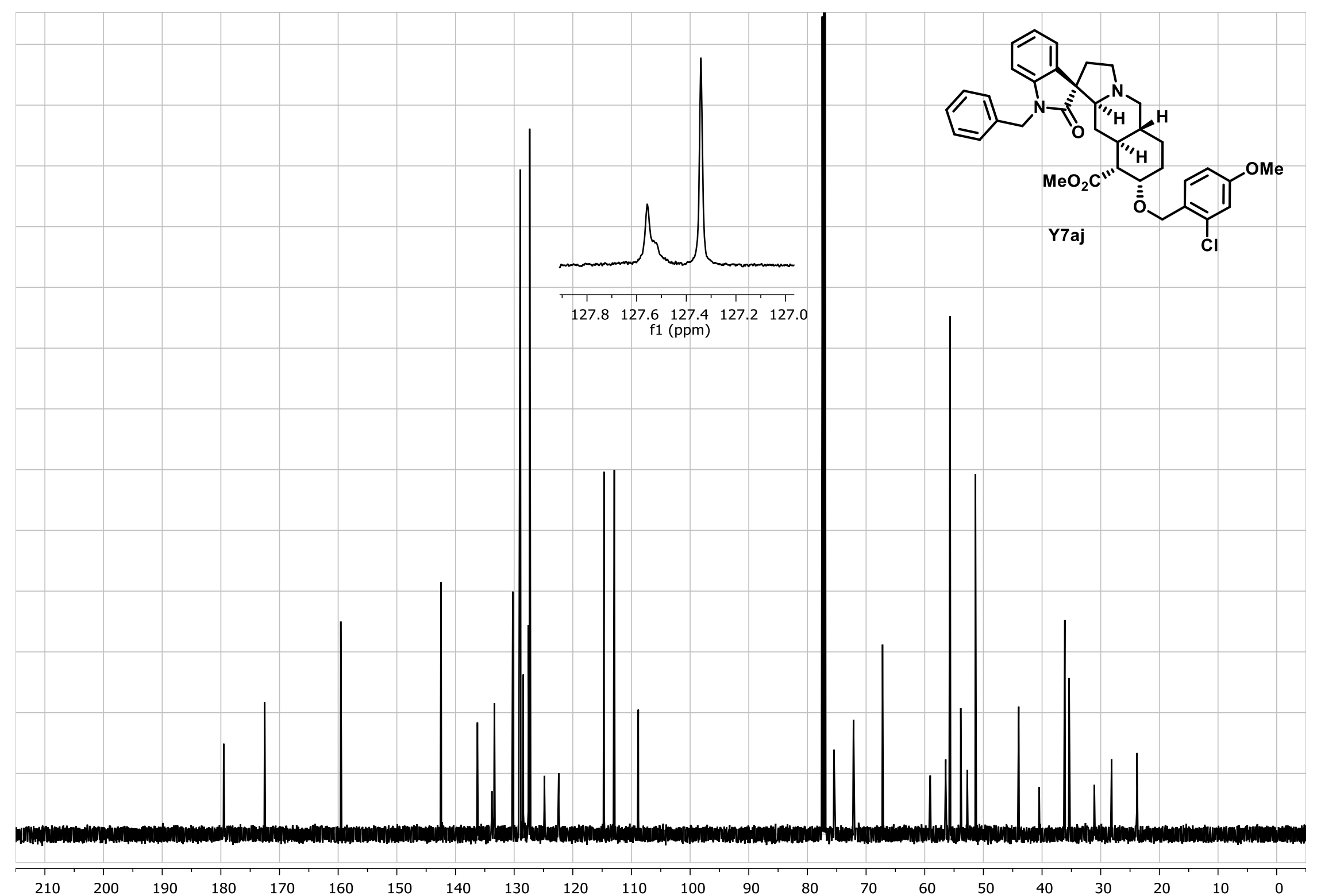

180
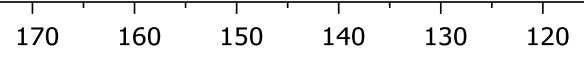

$110 \quad 100$

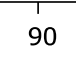

80

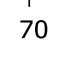

60

50

40

30

20

$10 \quad 0$ 

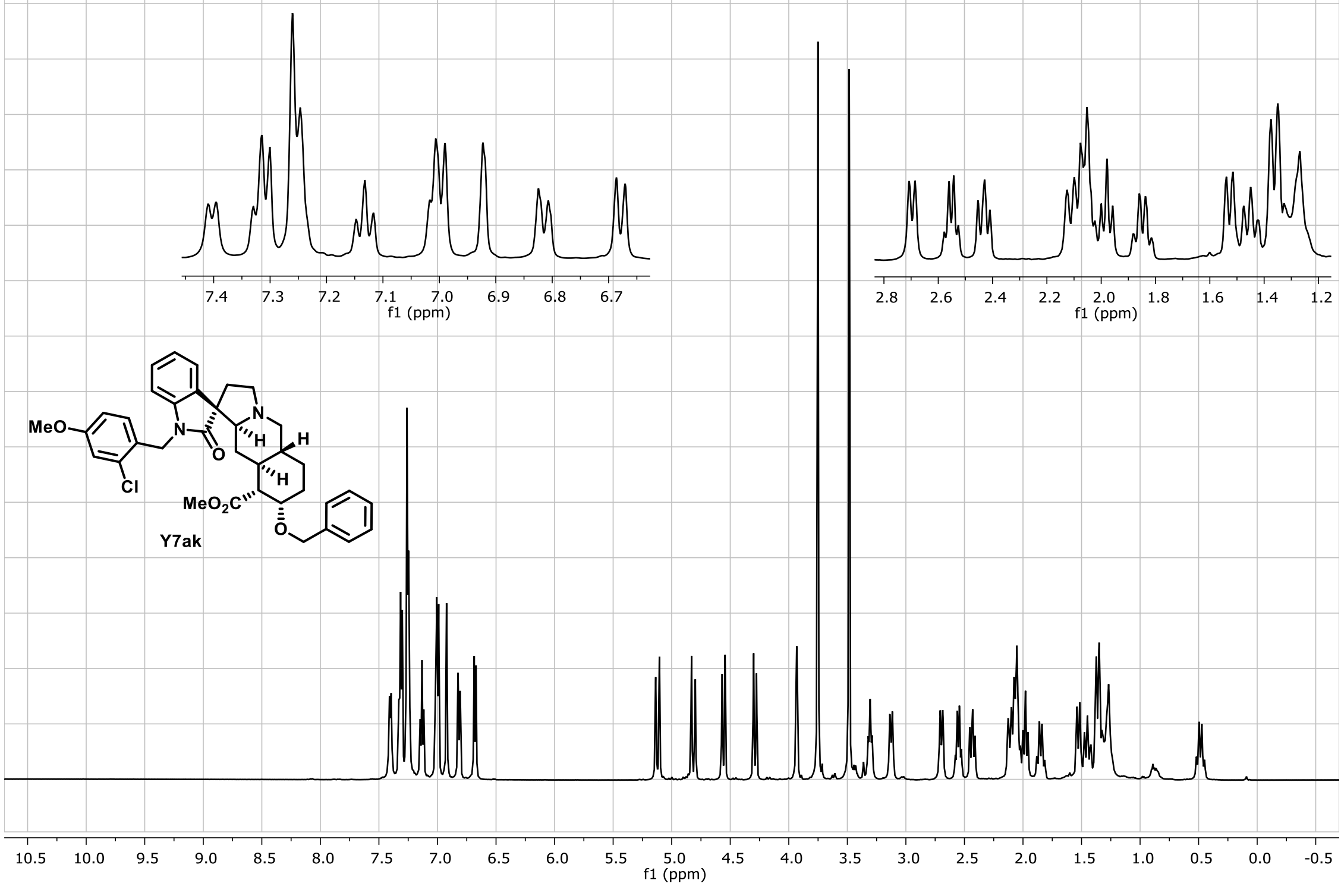


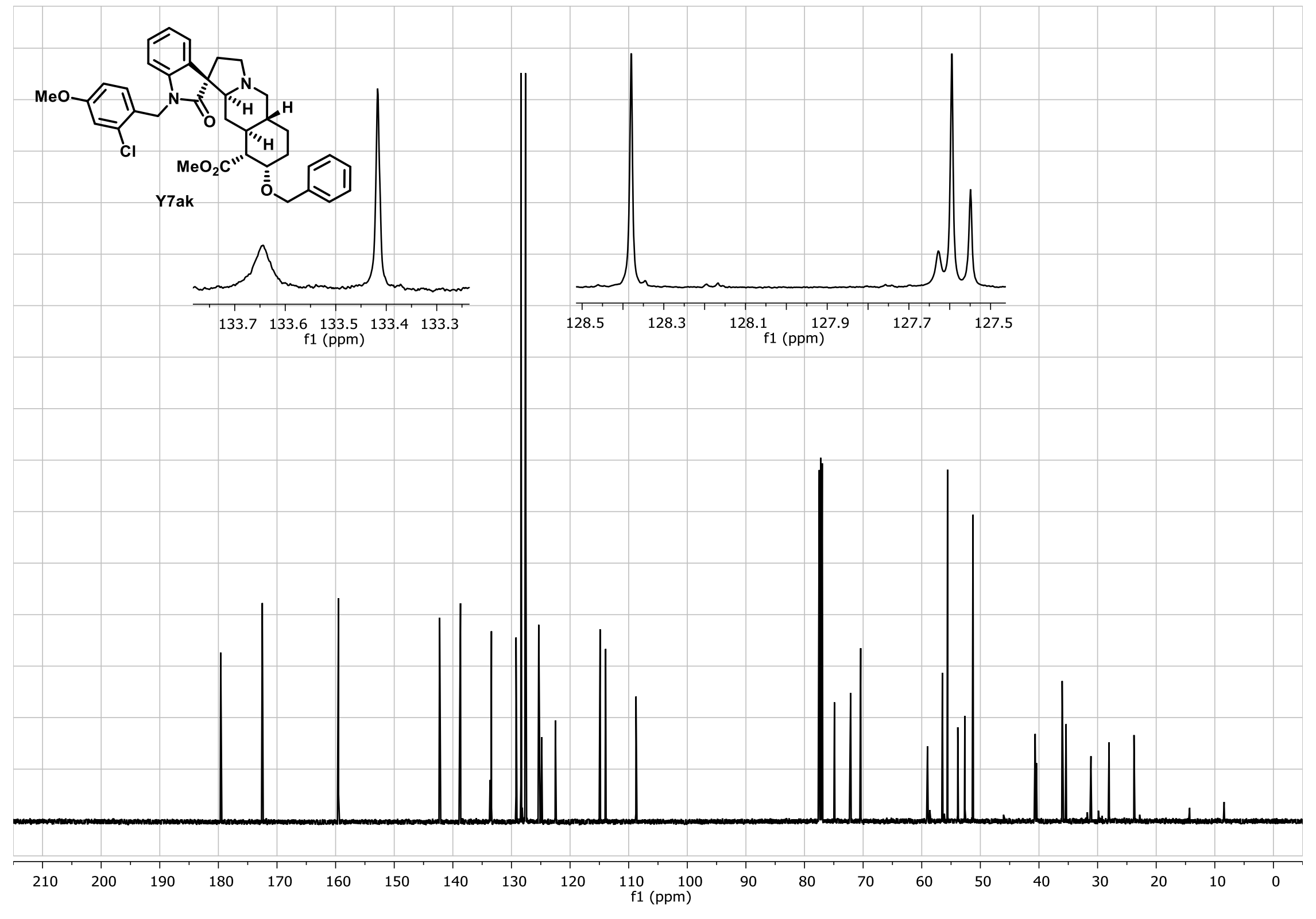




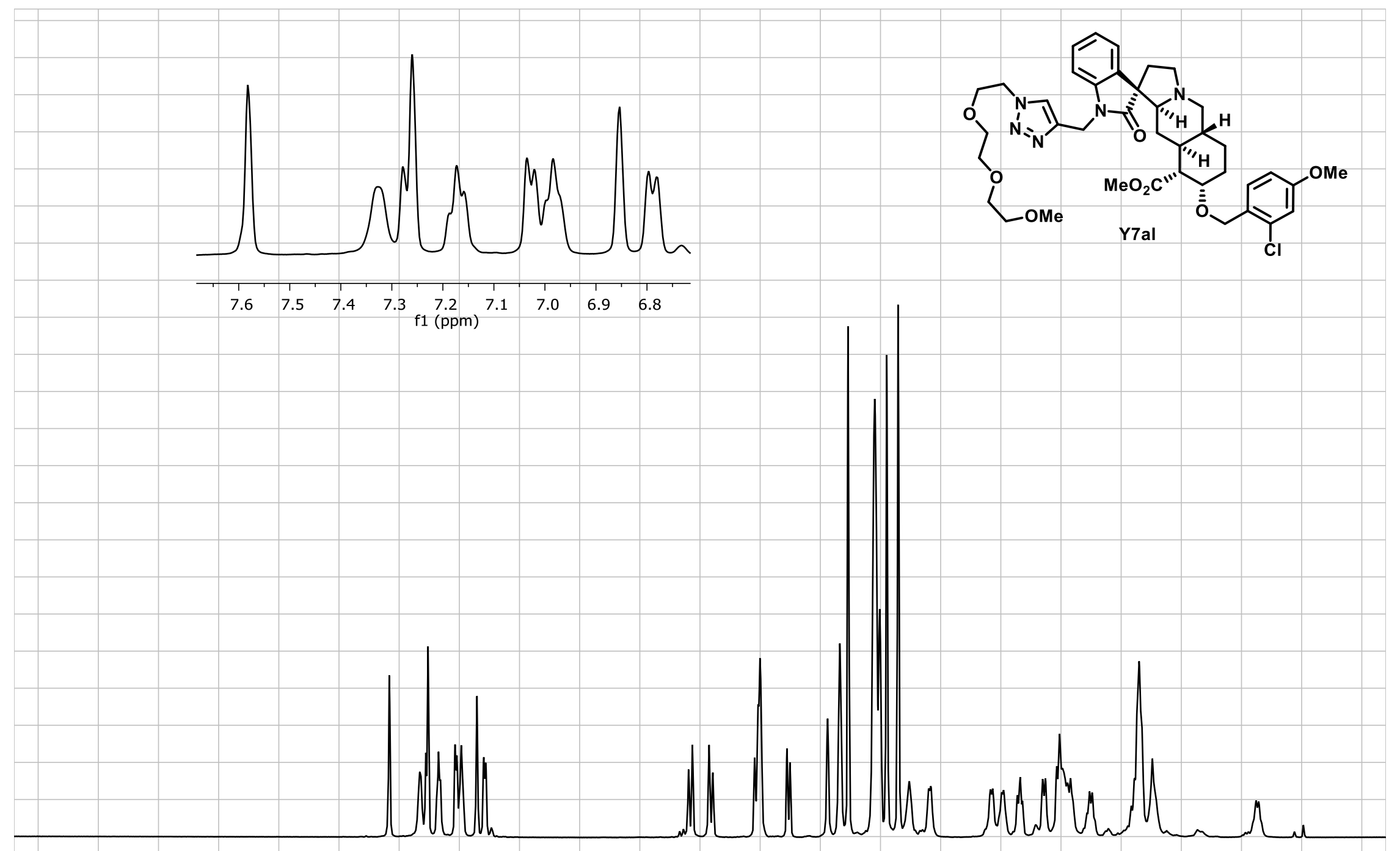

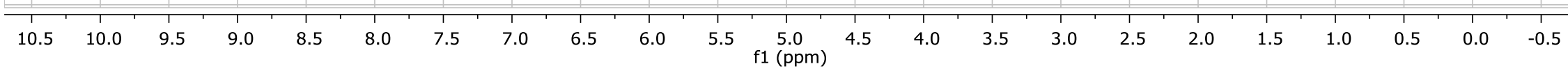



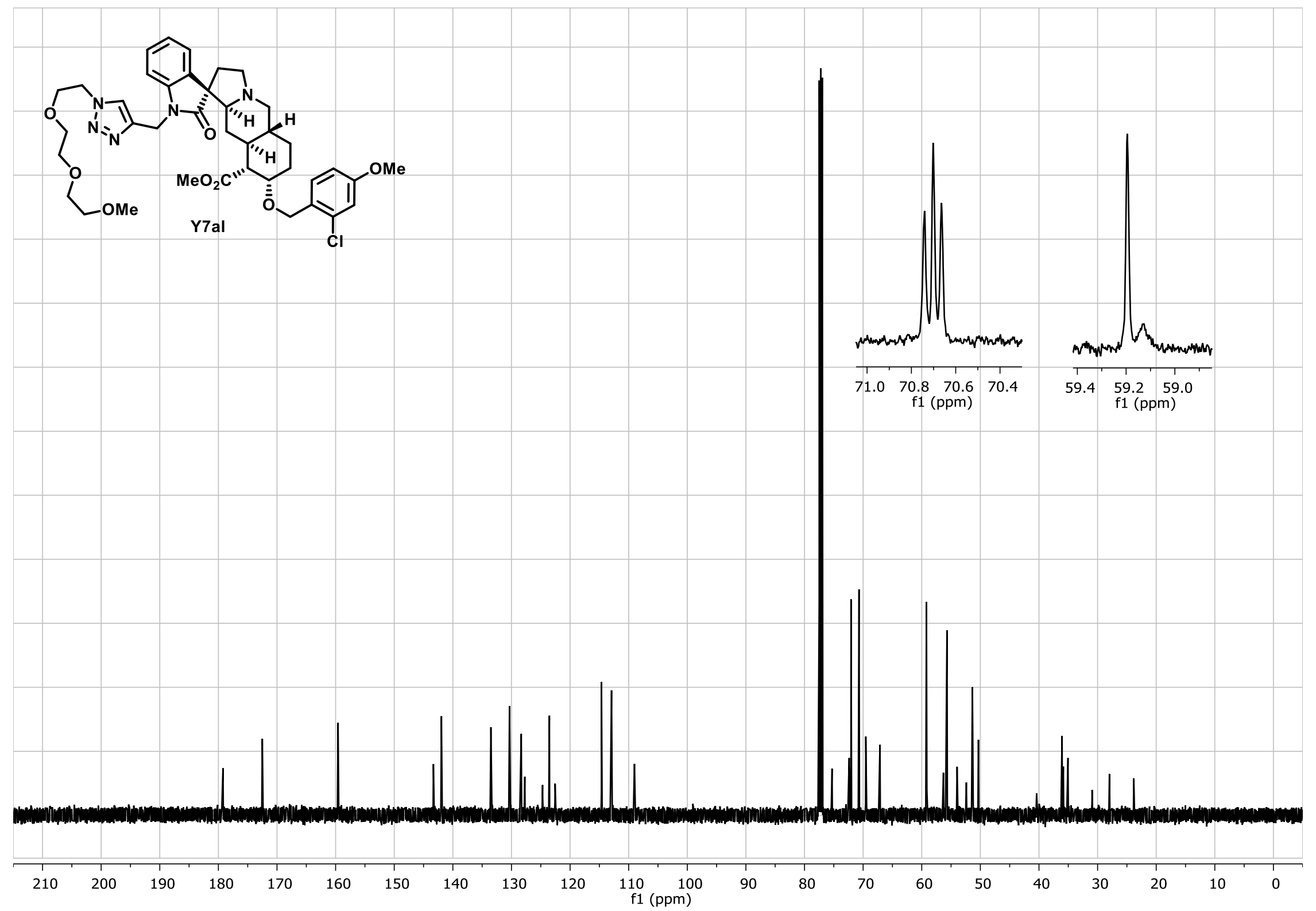

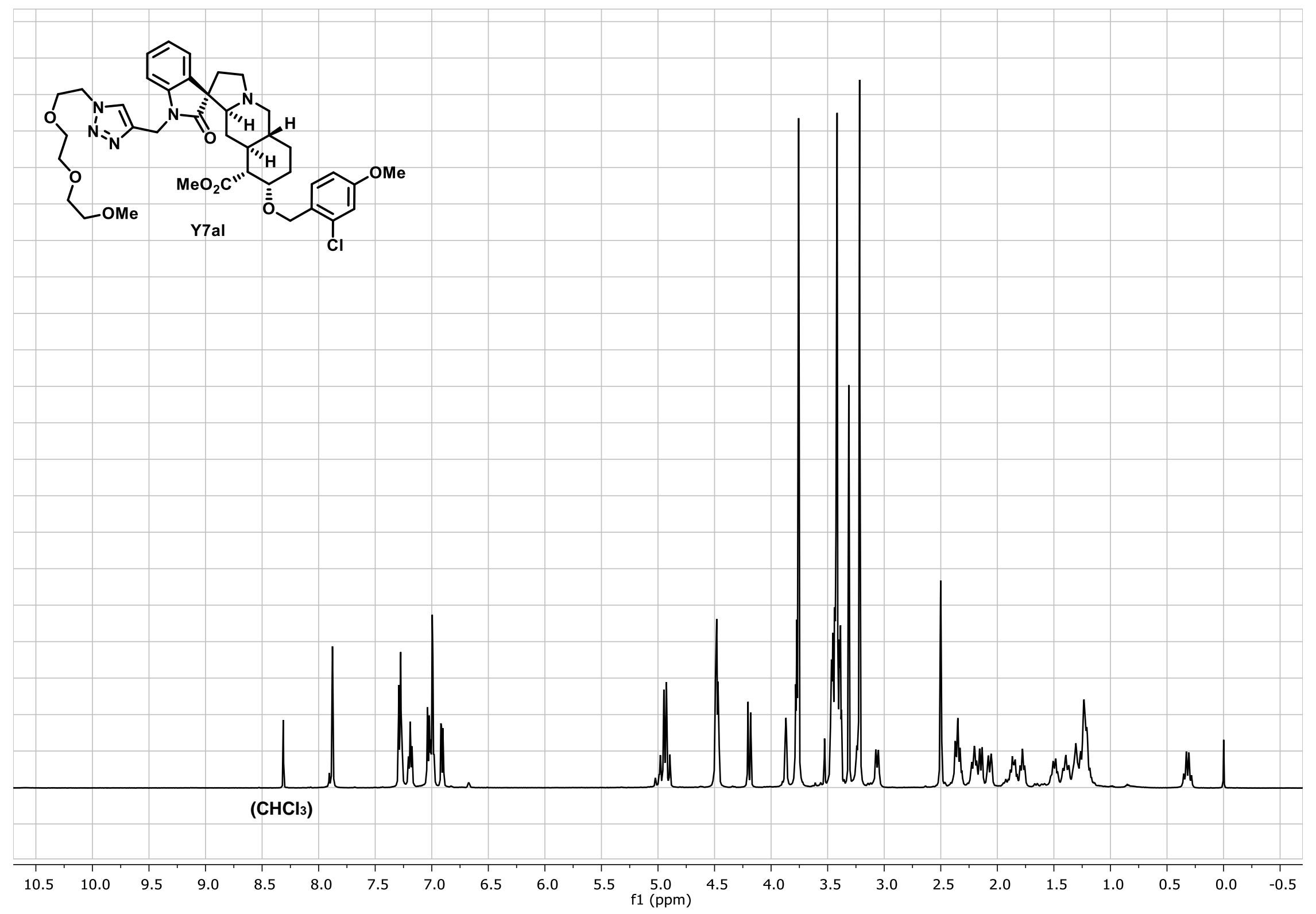


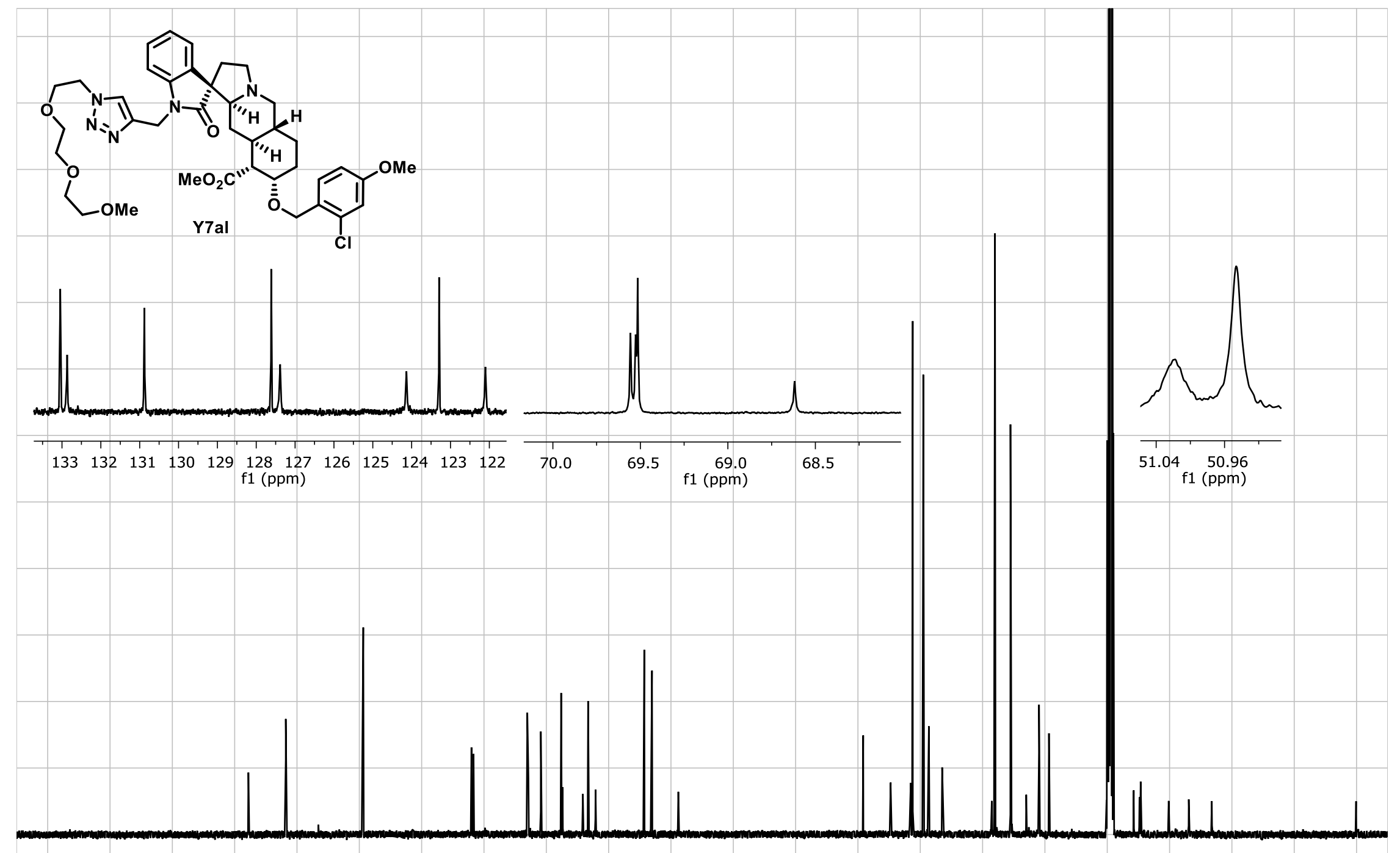

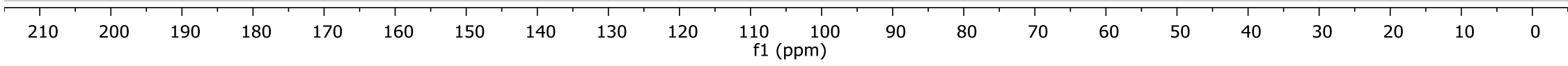




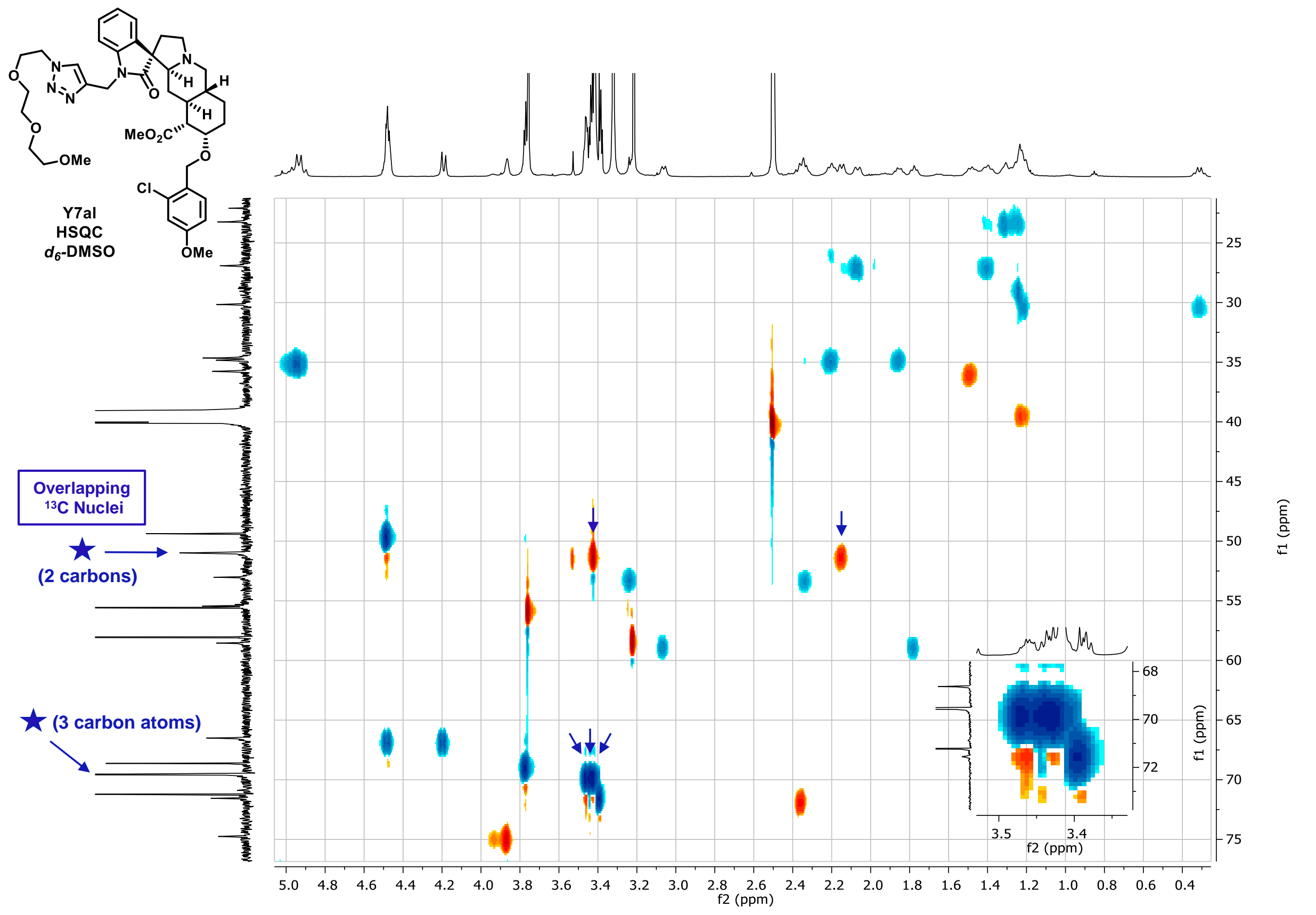



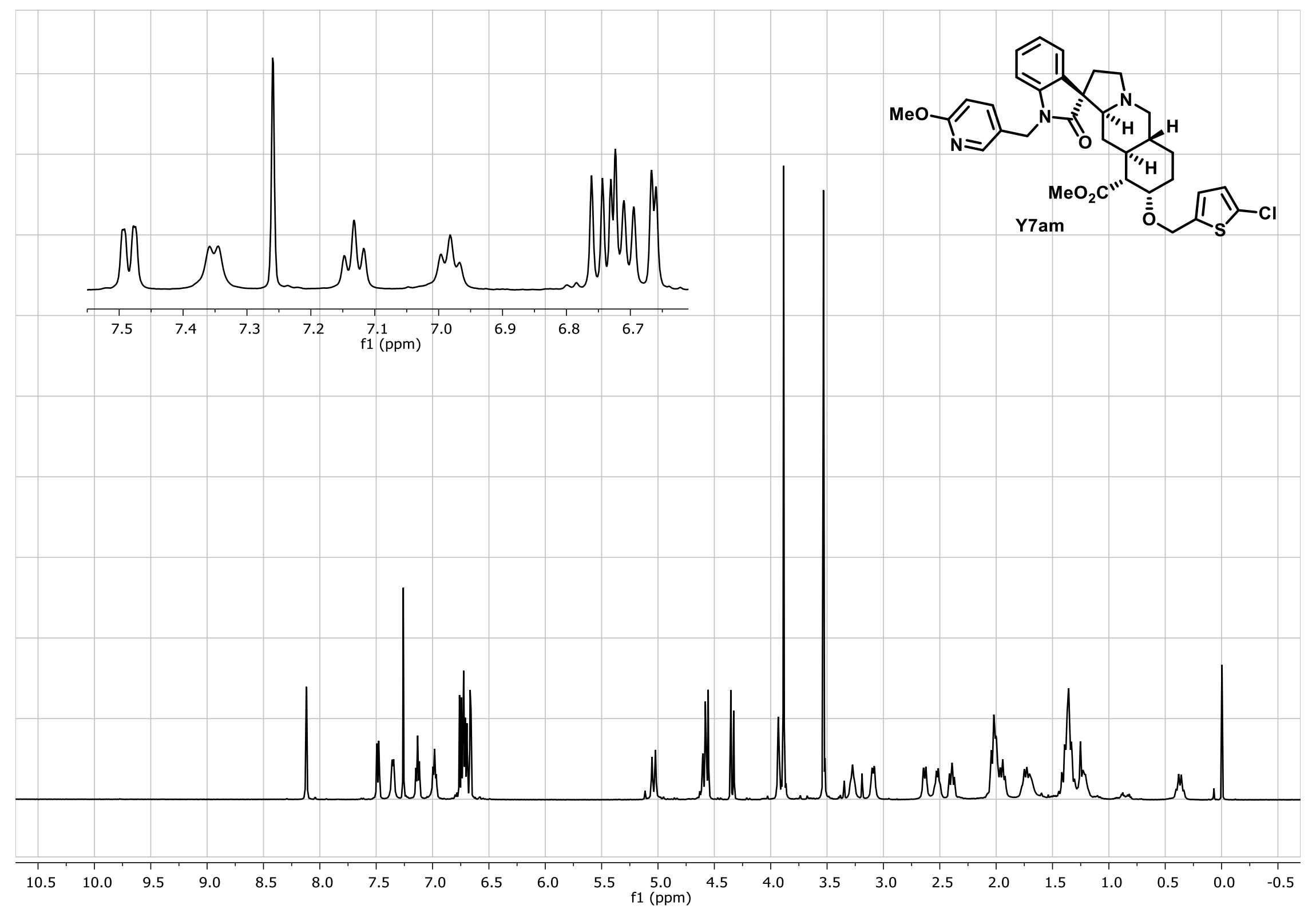


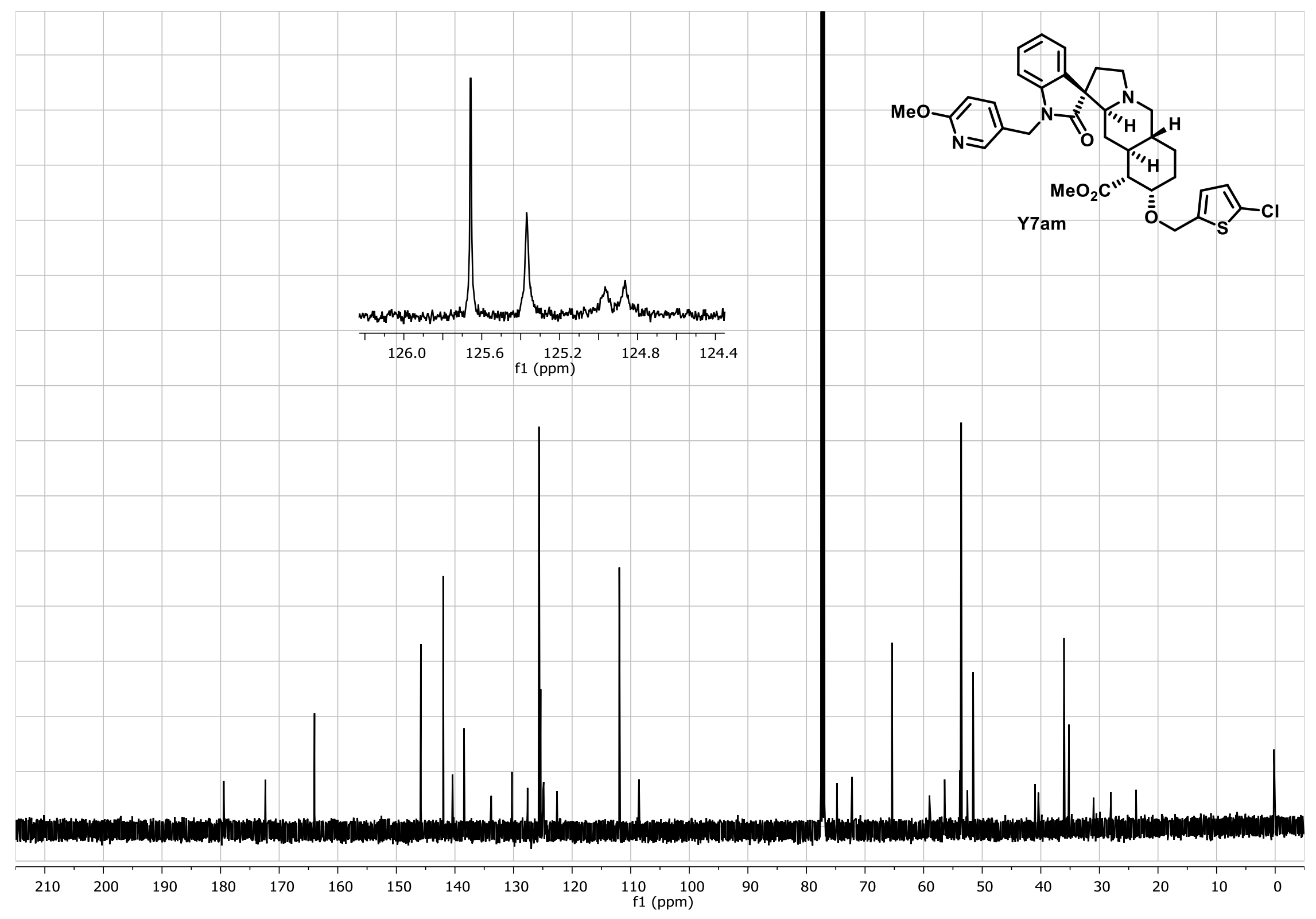



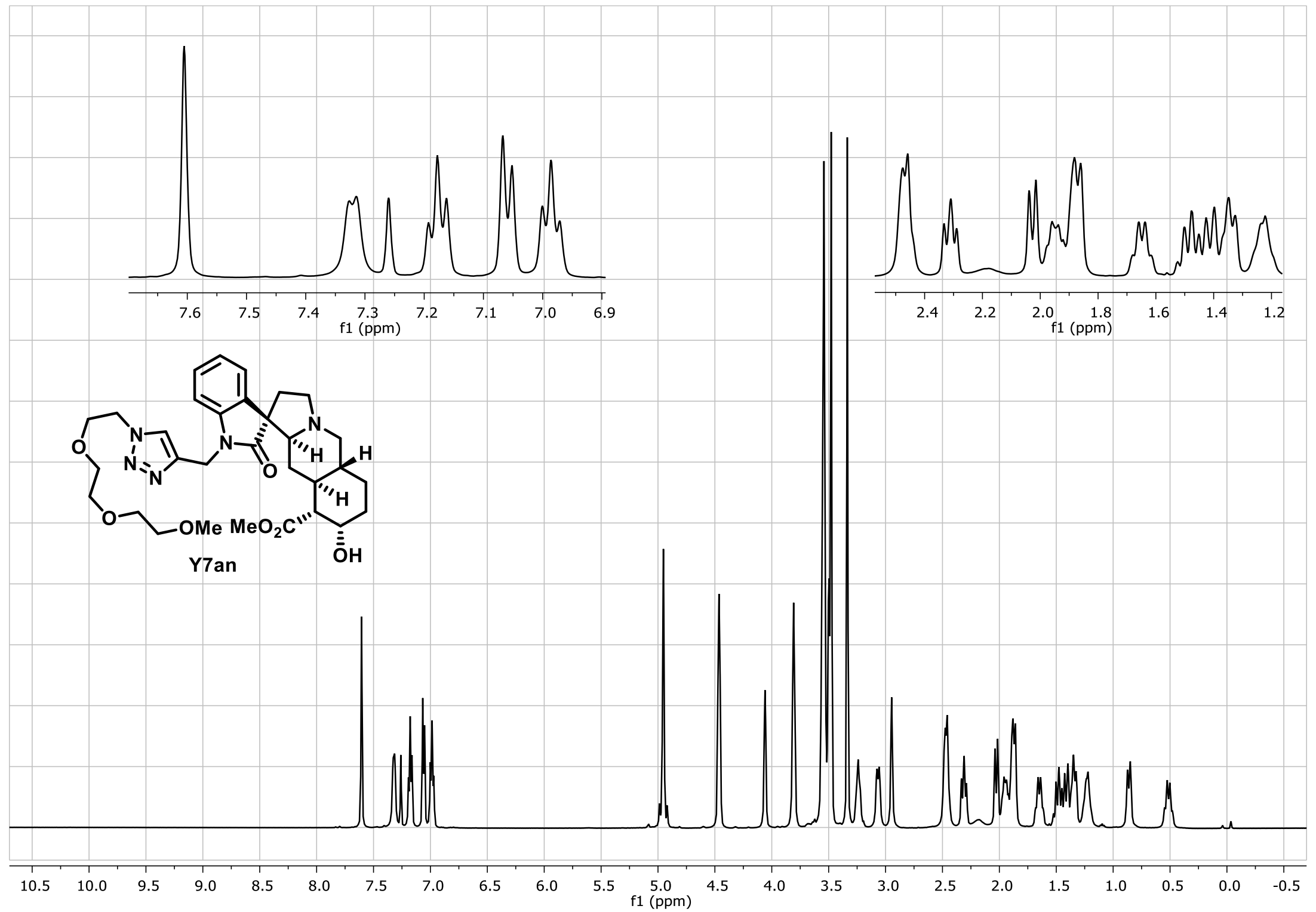


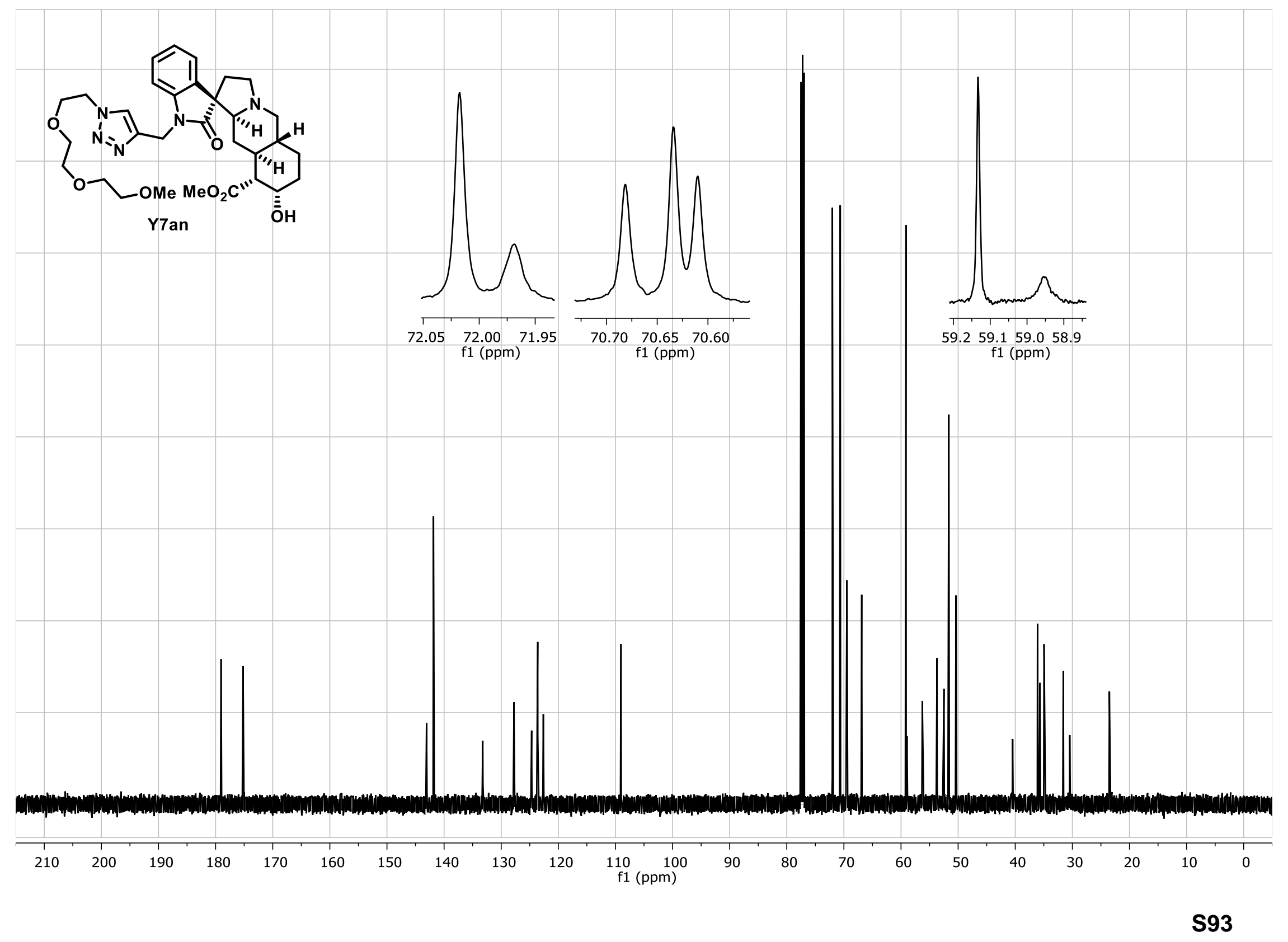

